\title{
THE IMPACT OF RESTORATIVE JUSTICE PRACTICES ON PARTICIPANTS
}

\author{
by
}

Tanya Rugge, M.A.

\author{
A dissertation submitted to \\ the Faculty of Graduate Studies and Research \\ in partial fulfillment of \\ the requirements for the degree of \\ Doctor of Philosophy \\ Department of Psychology \\ Carleton University \\ Ottawa, Ontario \\ July 2006 \\ (C) copyright \\ 2006, Tanya Rugge
}




$\begin{array}{ll}\begin{array}{l}\text { Library and } \\ \text { Archives Canada }\end{array} & \begin{array}{l}\text { Bibliothèque et } \\ \text { Archives Canada }\end{array} \\ \begin{array}{l}\text { Published Heritage } \\ \text { Branch }\end{array} & \begin{array}{l}\text { Direction du } \\ \text { Patrimoine de l'édition }\end{array} \\ \begin{array}{l}\text { 395 Wellington Street } \\ \text { Ottawa ON K1A 0N4 }\end{array} & \begin{array}{l}\text { 395, rue Wellington } \\ \text { Ottana ON K1A ON4 } \\ \text { Canada Oa }\end{array}\end{array}$

Your file Votre référence ISBN: 978-0-494-18235-2 Ourfile Notre référence ISBN: 978-0-494-18235-2

NOTICE:

The author has granted a nonexclusive license allowing Library and Archives Canada to reproduce, publish, archive, preserve, conserve, communicate to the public by telecommunication or on the Internet, loan, distribute and sell theses worldwide, for commercial or noncommercial purposes, in microform, paper, electronic and/or any other formats.

The author retains copyright ownership and moral rights in this thesis. Neither the thesis nor substantial extracts from it may be printed or otherwise reproduced without the author's permission.
AVIS:

L'auteur a accordé une licence non exclusive permettant à la Bibliothèque et Archives Canada de reproduire, publier, archiver, sauvegarder, conserver, transmettre au public par télécommunication ou par l'Internet, prêter, distribuer et vendre des thèses partout dans le monde, à des fins commerciales ou autres, sur support microforme, papier, électronique et/ou autres formats.

L'auteur conserve la propriété du droit d'auteur et des droits moraux qui protège cette thèse. $\mathrm{Ni}$ la thèse ni des extraits substantiels de celle-ci ne doivent être imprimés ou autrement reproduits sans son autorisation.
In compliance with the Canadian

Privacy Act some supporting forms may have been removed from this thesis.

While these forms may be included in the document page count, their removal does not represent any loss of content from the thesis.
Conformément à la loi canadienne sur la protection de la vie privée, quelques formulaires secondaires ont été enlevés de cette thèse.

Bien que ces formulaires aient inclus dans la pagination, il n'y aura aucun contenu manquant. 


\begin{abstract}
There is an abundance of research that suggests that restorative justice processes are satisfying to both victims and offenders. Restorative justice processes are also said to have positive impacts on participants' wellbeing. Despite references made to the positive impacts on participants' health, there are no studies that specifically examine the impact of restorative justice processes on participants' psychological health and physical health using specific health indicators. This study utilized a quasi-experimental repeatedmeasures design to assess changes in psychological health and physical health in 92 participants (50 victims and 42 offenders) who experienced a restorative justice process. Social support has also been cited in the literature as to its positive effects for individuals who experience traumatizing incidents (e.g., a criminal offence). Restorative justice aims to engage participants' support systems, partly to assist in the reintegration of both the victim and offender back into the community. Therefore, this study also examined social support and its relationships with psychological and physical health change. Results indicated that the majority of participants did experience positive changes in their psychological and physical health from preprogram to postprogram. No changes in social support were evident, nor was social support found to be related to psychological or physical health. Future research directions and limitations are discussed.
\end{abstract}


Acknowledgements

There are many people I would like to thank and acknowledge. First, this study would not have been possible without the support of the two restorative justice programs involved. Thank you to all the restorative justice program staff who made this study possible. Second, this study would also not have been possible if it were not for Dr. Bob Cormier and Dr. Jim Bonta of PSEPC, who granted permission for this small study to take place within a larger PSEPC evaluation. Without your continuous support, along with the support of Mary Campbell and Diane Thompson, my education leave may never have come to fruition. Third, special thanks to all my colleagues and fellow research staff who assisted in the data collection, provided feedback, proofed my report, and kept me sane throughout all the various pitfalls and mountains we climbed. Fourth, I am also extremely grateful to my friends and family who provided me with continuous and unwavering support, through all the bad times, especially the last year. Tremendous thanks to Wendy, Stephanie, Brian, Terri, Chantal, Richard, Brent, and the three Jennifers in my life, as well as my Mum and Dad. Words are just not enough. Lastly, thank you to my committee (Dr. Bob Hoge, Dr. Don Andrews, Dr. Tim Pychyl, Dr. John Zelenski, Dr. Don Clairmont, and Professor Ron Saunders), who advised and guided me through this process. It was a long road. I am especially grateful to Dr. Bob Hoge for continuing to advise me after his retirement! I cannot conclude without saying special thanks to Etelle Bourassa and Dr. Tim Pychyl for all the help and support they provided over the course of my degree. I dedicate this dissertation to my grandparents, who sadly are no longer with us, but I know they are looking down ... and are very pleased that I am finally finished! 
Table of Contents

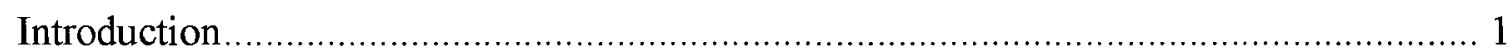

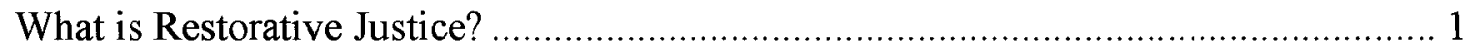

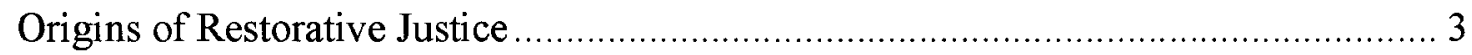

Models of Restorative Justice ......................................................................... 4

Restorative Justice in Canada .......................................................................... 7

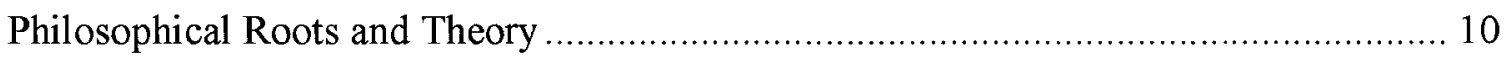

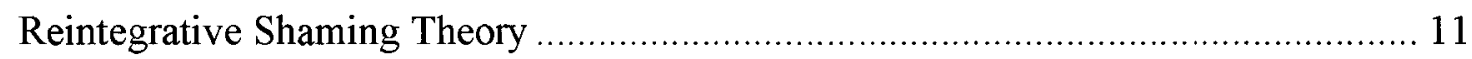

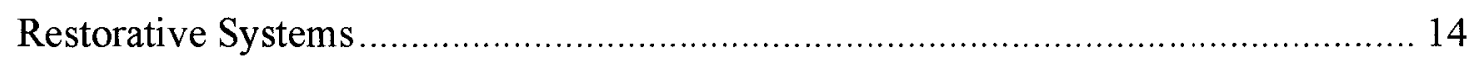

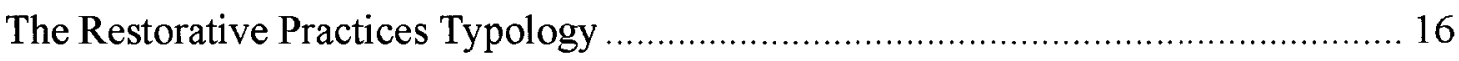

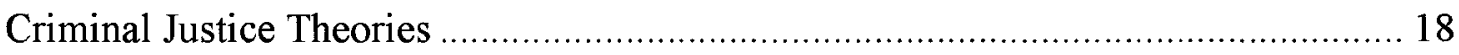

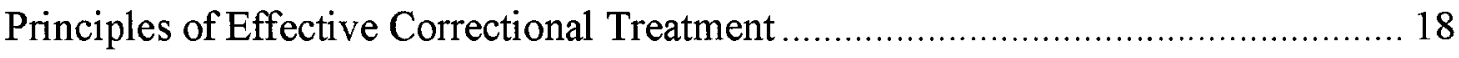

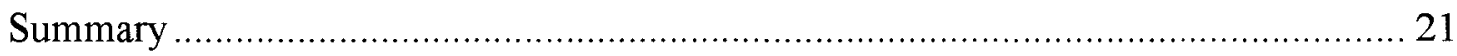

Why Explore the Restorative Justice Approach? .................................................. 23

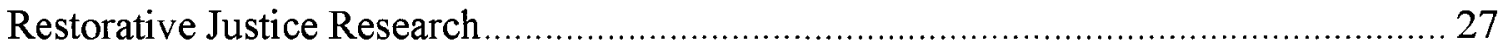

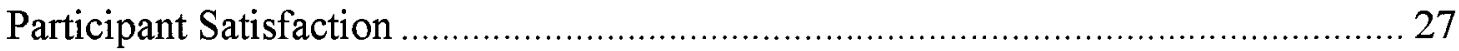

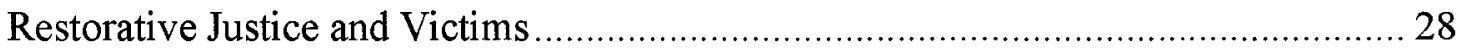

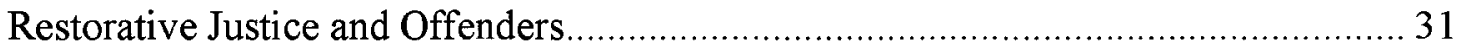

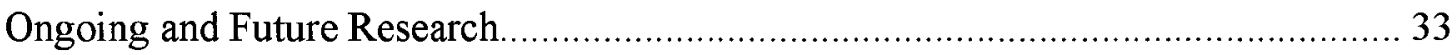

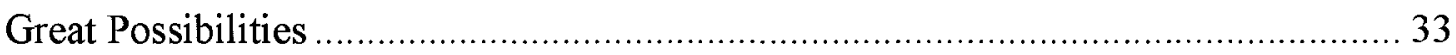

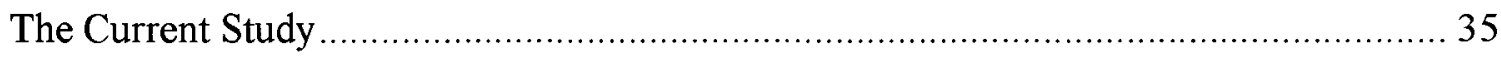

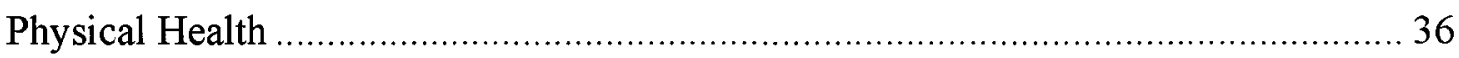

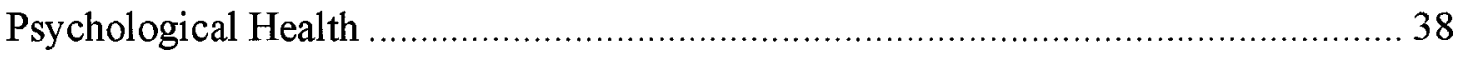

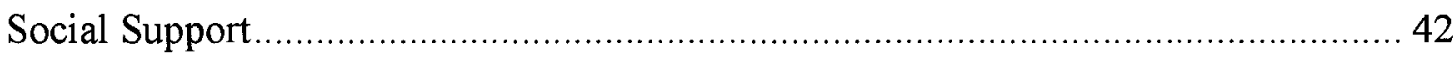

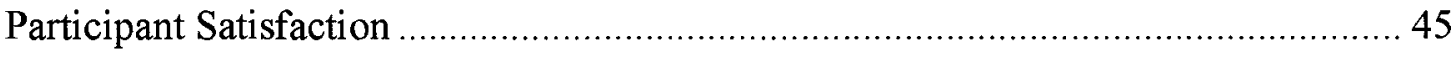

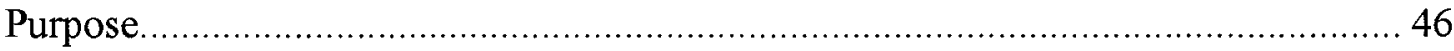

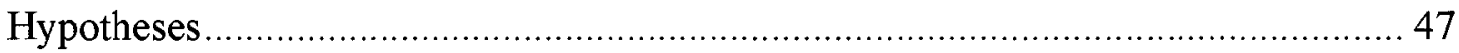

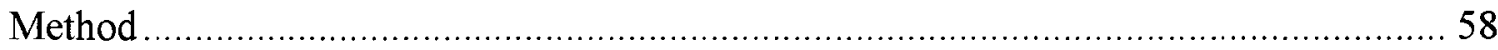

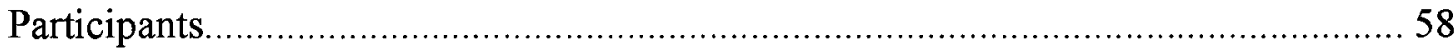




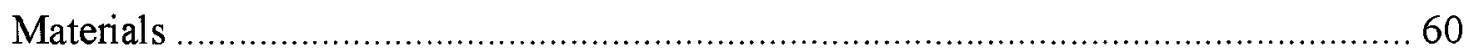

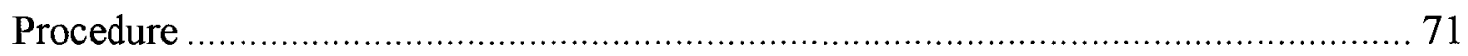

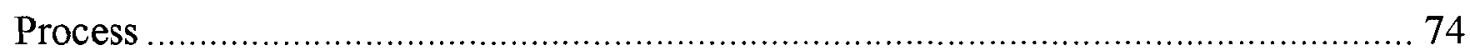

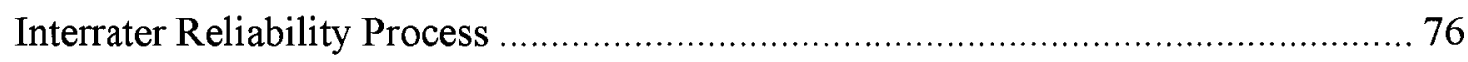

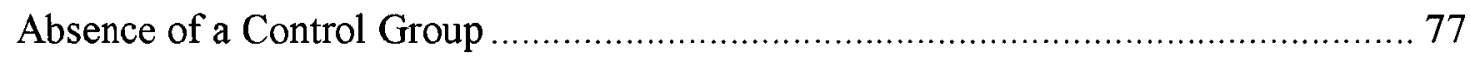

Drawing the Sample from Two Programs ......................................................... 78

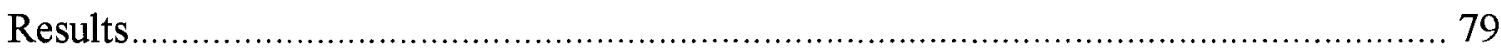

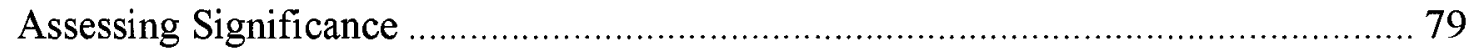

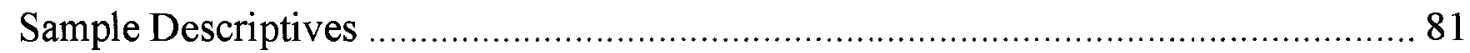

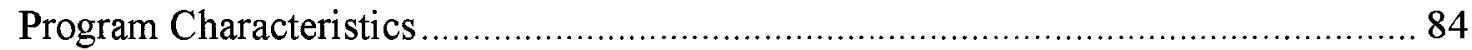

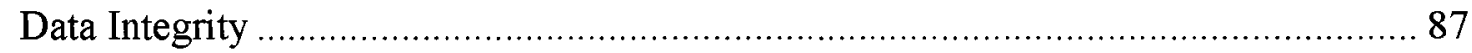

Physical Health, Psychological Health and Sense of Social Support ......................... 92

Offender Risk Level.................................................................................. 109

Victim-Offender Meeting ............................................................................... 110

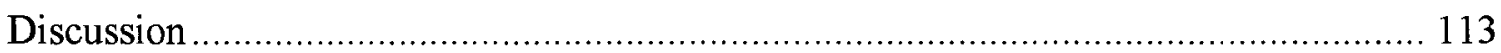

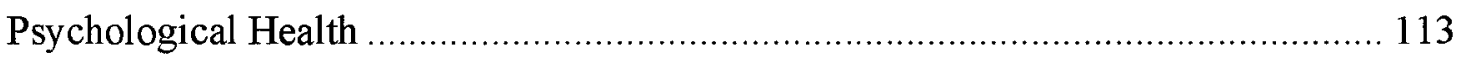

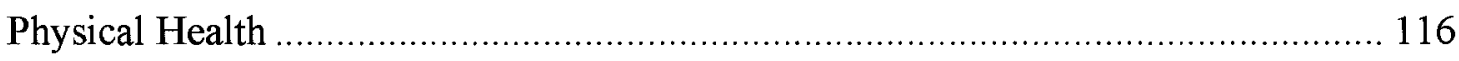

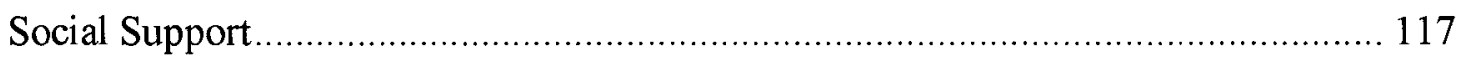

Impacts of Participant Satisfaction, Victim-Offender Meetings, Offence Type and

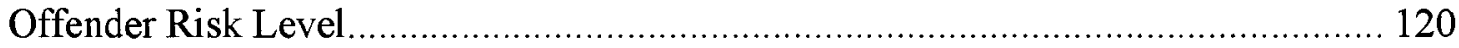

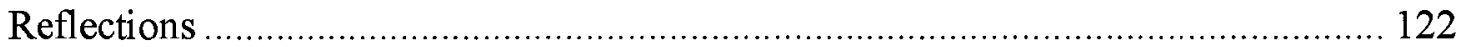

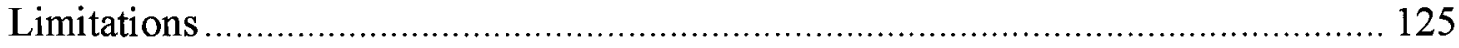

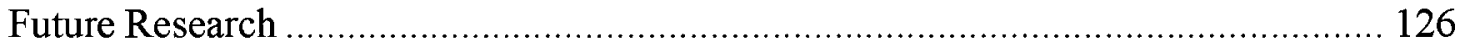

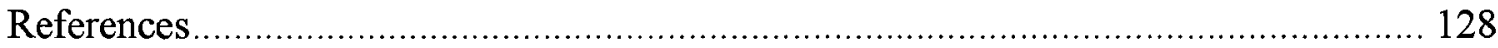


List of Tables

Table 1. Personal-Demographic Characteristics of Victims, Offenders and Total Sample 83

Table 2. Type of Index Offence, Disposition and Offender Risk Level Characteristics. 85

Table 3. Percentage of Cases "Probably Invalid" by Group and Time 88

Table 4. Correlations Between IM Scores, PsH Checklist Scores, and the SSS Scale Scores 90

Table 5. PhC, PsC, and SSS Scale Scores from Preprogram to Postprogram by Group. 93

Table 6. Examination of Other Variables Potentially Relating to PhC, PsC and SSS ... 98

Table 7. Presence of Physical Health Items by Group. 100

Table 8. Presence of Psychological Health Items by Group. 104

Table 9. Satisfaction Categories by Categories of Psychological Change 108

Table 10. Satisfaction Categories by Victim-Offender Meeting by Group 112 


\section{List of Figures}

Figure 1. Illustration of a Fully Restorative System ............................................ 15

Figure 2. A Restorative Practices Typology …................................................... 17

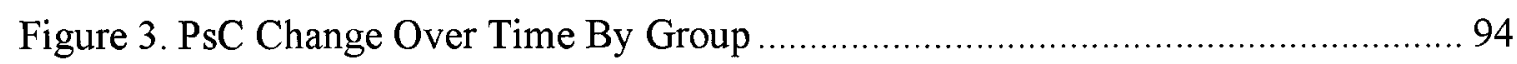

Figure 4. PhC Change Over Time By Group........................................................... 94

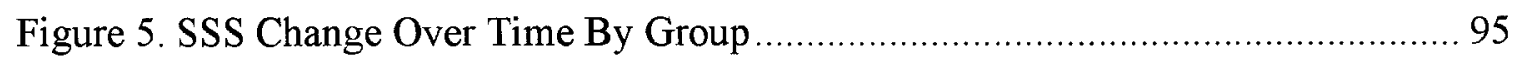


List of Appendices

Appendix A: PSEPC Information Sheet For Victims \& Offenders .............................. 145

Appendix B: PSEPC Consent Form For Victims and Offenders ……......................... 147

Appendix C: PSEPC Preprogram Interview Package For Victims ……….................... 149

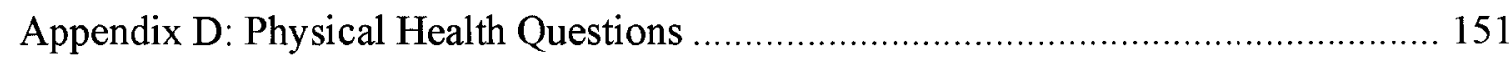

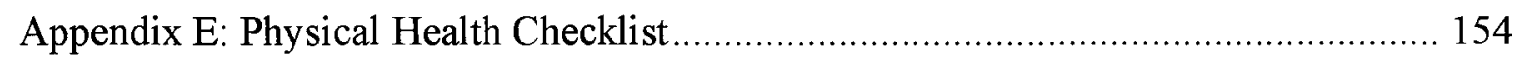

Appendix F: Psychological Health Questions ……………......................................... 156

Appendix G: Psychological Health Checklist .......................................................... 162

Appendix H: PSEPC Preprogram Interview Package For Offenders............................ 165

Appendix I: PSEPC Postprogram Interview Package For Victims .............................. 167

Appendix J: PSEPC Postprogram Interview Package For Offenders............................. 169

Appendix K: PSEPC Debriefing Form For Victims and Offenders ............................. 171

Appendix L: Repeated Measures Analyses Results

Using Impression Management Score as a Covariate 
Introduction

Victims and offenders, and the community as a whole, are affected by crime. Currently, the main venue to address the effects of crime is through the traditional criminal justice system, ${ }^{1}$ where the main goal is to punish, and perhaps rehabilitate the offender. In many cases, the traditional criminal justice system is unequipped to deal with the psychological and physical harms that crime can cause. Canada's current criminal justice system is not designed to offer a holistic approach to repairing the harm caused by crime.

The traditional criminal justice system is an evolving entity, one that requires regular reform. In an effort to improve our current system, address some of its imperfections, and view crime through a more humanizing lens, various groups are exploring restorative approaches to criminal justice. The goal of restorative justice is to repair the harm that the crime has caused, with a focus on restoration, in an attempt to facilitate healing for the victim, the offender and the community. Restorative justice attempts to address the various needs of all participants, by using a flexible, all-inclusive, and humanistic approach.

\section{What is Restorative Justice?}

Restorative justice is a philosophy that strives to address the harm that is caused by crime, by seeking reparation through re-establishing relationships, and involving the victim, the offender, and the community (Braithwaite, 1996; Cormier, 2002). Although no single, universally accepted definition of restorative justice currently exists, the

\footnotetext{
${ }^{1}$ The terminology "traditional criminal justice system" is defined as Canada's current criminal justice system, and will be hereinafter referred to as the traditional criminal justice system.
} 
majority of experts, researchers and practitioners agree that reparation of the harm caused by the crime is a central component (Cormier, 2002). Cormier (2002) defines restorative justice as:

an approach to justice that focuses on repairing the harm caused by crime while holding the offender responsible for his or her actions, by providing an opportunity for the parties directly affected by a crime - victim(s), offender and community - to identify and address their needs in the aftermath of a crime, and seek a resolution that affords healing, reparation and reintegration, and prevents future harm. (p.1)

The main objectives of restorative justice include: holding the offender accountable in a meaningful way; repairing the harm caused to the victim, the offender and the community by the offence or behaviour; achieving a sense of healing of the victim and the community; and reintegrating the offender into the community and restoring him or her to a law-abiding life. Restorative justice is a flexible process, and is typically designed to meet the needs of all involved, in a variety of different situations. Restoration, therefore, may involve almost anything, depending on the persons involved and the context of the situation. Restoration may occur in the areas of personal injury, property loss, reestablishing peaceful relationships, and returning a sense of security, dignity, justice and empowerment to victims and the community (Braithwaite, 1996).

Restorative principles may be presented by some as a "new idea", but restorativetype principles are, to some extent, cultural universals, evident throughout history, and are rooted in both Western and non-Western traditions (Bazemore \& Griffiths, 1997; Hudson \& Gallaway, 1996). A renewed interest in restorative justice developed in the 
1970s, largely in North America, developing from the victims' rights, social justice, and informal justice movements (Llewellyn \& Howse, 1998).

Origins of Restorative Justice

Many researchers posit that restorative justice in Canada is rooted in Aboriginal culture (Cormier, 2002; LaPrairie, 1992; Roach, 2000). It is certainly true that the foundation of restorative justice philosophy is consistent with the Aboriginal traditions of healing and community restoration, though it has been argued that not all Aboriginal models of justice would be considered restorative justice (Cormier, 2002).

Restorative justice, in a non-Aboriginal context, is most commonly cited as originating in Kitchener, Ontario in 1974, when a probation officer thought it might be useful to bring two teenage vandals to meet their victims (Peachey, 1989). Shortly after the success of this intervention, the Mennonite Central Committee began a victimoffender mediation program (Peachey, 1989). Since then, many other faith communities and other non-governmental organizations have developed programs that apply a restorative philosophy to criminal justice.

Although the exact number of restorative justice programs is not known, it is estimated that close to 2,000 restorative justice programs are currently in operation around the world (Hughes \& Mossman, 2001). Hughes and Mossman (2001) reported that there are more than 1,000 victim-offender mediation programs operating in the United States, more than 25 programs operating in Canada and over 700 programs in Europe. Other countries around the world that are embracing restorative justice processes include Australia, New Zealand, England, South Africa, and Russia, just to name a few. 
Restorative justice programs can compliment our current traditional system, either by running parallel to it, or by being incorporated directly into it. The types of programs currently in operation are diverse; however, the philosophy, premise and overall goals of the programs are similar.

\section{Models of Restorative Justice}

Restorative justice can take many forms. "Pure" restorative justice includes the offender, the victim, and members of the community, typically referred to as the "three legs of a stool" (Krug, n.d.). Krug articulated that the litmus test of any true restorative justice program is whether it possesses these three key components (involvement of the victim, the offender and the community) and more specifically whether the restorative justice process addresses the needs of all three parties affected by the crime. Although many programs describe themselves as restorative justice programs and do not involve all three "legs", it has been argued that as long as the program adheres to the basic restorative justice philosophy and principles, they are valid forms of restorative justice (Krug, n.d.). However, if a program does not adhere to the basic principles of restorative justice then it has been described as analogous to sitting on a three-legged stool with one or two of the legs missing (Krug, n.d.). Although "pure" or "true" restorative justice may be the ideal, it cannot and does not occur in all instances. However, that is not to say that alternative forms of restorative justice do not result in positive outcomes for the parties involved

There are many different "categories" or "models" of restorative justice described throughout the literature. The Department of Justice categorizes restorative justice programs into three core models: victim-offender mediation, family group conferencing 
and circles (Department of Justice Canada, 2000). These three models are the most frequently used. Victim-offender mediation was the first model that was established and used in Kitchener. This model brings together the victim(s) and the offender(s), with a trained mediator, to address issues related to the crime and to develop a plan to repair the harm caused (often referred to as a reparation plan or resolution agreement). Victimoffender mediation was originally conducted at the pre-sentence stage (Peachey, 1999), but in recent years, it has also been used post-sentence (Roberts, 1995).

It could be argued that victim-offender mediation, either with or without community representation, is the most common model used in criminal justice cases, where all affected parties convene to discuss the crime and develop a plan to repair the harm caused. These meetings typically involve the offender, the victim(s), one or two trained facilitators, and where appropriate, community members, and support persons for the offender and the victim. When multiple victims, community members and support persons attend, the meeting is usually referred to as a "circle" or "conference", rather than a victim-offender mediation meeting. It should be noted that terminology varies widely across programs and within the restorative justice field.

Family group conferencing is the second model outlined by the Department of Justice (2000), which is usually more applicable to youthful offenders, and engages the youth, as well as the family of the young offender, to resolve the conflict and repair the harm. Family group conferencing originated from the traditions of the Maori people in New Zealand (Braithwaite, 2002). This model was adapted and introduced into Canada by the Royal Canadian Mounted Police (RCMP) in 1995, in the form of Community Justice Forums, with a trained RCMP officer acting as facilitator (Chatterjee, 1999). 
The final model outlined by the Department of Justice (2000) is the circle. Two of the more common types of circles they highlight are the "sentencing circle" and the "healing circle". The Department of Justice (2000) describes circles as a coming together of the community to discuss and resolve issues that affect the community. The format of the circle allows for each member of the circle to have an opportunity to speak. The circles described are based on the traditions of the Aboriginal people.

Although the term "circle" refers to a type of model, it is also a format that is used in other restorative justice models. For example, the circle format is also often used in conferencing, and expanded forms of victim-offender mediation. This dual terminology often results in confusion as not all "circles" are sentencing circles or healing circles, but may in fact be expanded forms of victim-offender mediation using a circle format. Again, terminology is frequently used in different ways, depending on the program.

Some restorative justice programs use only one type of model, whereas other restorative justice programs may use various models, depending on the case particulars and the needs of the participants. For example, in cases of serious crime, where there is one offender and one victim, victim-offender mediation may be most appropriate, whereas in cases where it is appropriate to engage a larger group of people, a circle or conference engaging all affected parties may be arranged.

In recent years, practitioners have explored the various models of restorative justice around the world. Although victim-offender mediation, circles and conferences are most common, other adapted models exist. For example, there are programs that operate under a restorative justice model, but have chosen to use "surrogate" victims rather than the true victim. Involving the "community" has also taken many forms, such 
as having the community be represented by "support persons", community volunteers (one or more), or by involving the police or other criminal justice professionals. Another form of restorative justice, which is gaining in popularity among clients, is a different form of mediation, one of indirect or shuttle mediation, where all communication between the offender and the victim is passed through the facilitator or mediator (i.e., no face-to-face meeting occurs; Rugge, Bonta, \& Wallace-Capretta, 2005; Wemmers \& Cyr, 2005). Models continue to adapt, in an attempt to meet the needs of participants.

Research in the area of restorative justice is still in its infancy, so an exploration of what methods best meet the needs of the offenders, the victims, and the community, is essential.

Restorative Justice in Canada

As previously mentioned, the roots of restorative justice in Canada are found in the traditions of Aboriginal culture, where reparation, healing and community are core values. Stemming from this basis, non-Aboriginal Canadian restorative justice began with the faith communities, specifically the Mennonite Central Committee (Cormier, 2002; Peachey, 1999). The restorative justice approach was embraced by faith communities, as the key values of restorative justice were clearly compatible with the teachings of the Church (Church Council on Justice and Corrections, n. d.). For example, repairing harm, facilitating healing, encouraging community support and involvement are important considerations in both faith teachings and the restorative justice philosophy. 
The Church Council on Justice and Corrections has emphasized restorative justice in its work, since it was established in $1974 .^{2}$

Since 1974, Canada has seen the development of numerous restorative justice initiatives, and has played a role internationally in research and policy development (Cormier, 2002; Wemmers \& Cyr, 2005). Within the Canadian federal government, documents such as Taking Responsibility (1988) have been produced citing the needs of victims and the benefits of restorative justice. More recently, the Canadian government played a key role in the development of the United Nation's Declaration of Basic Principles on the Use of Restorative Justice Programmes in Criminal Matters (2002). Although these principles were not "officially adopted" by the Council, the United Nations encourages member states to consider these guidelines when addressing crime and in developing restorative justice programs within their respective home countries.

In terms of Canadian legislation, it could be argued that both the Criminal Code of Canada and the Youth Criminal Justice Act allow for the philosophy of restorative justice. For example, the Criminal Code cites the objective of reparation in section 718(e), regarding sentencing ${ }^{3}$. Also, the Youth Criminal Justice Act emphasizes the importance of exploring extra-judicial alternatives when dealing with young people and encourages reparation for crime victims. In fact, the majority of restorative justice programs, until very recently, focused on young offenders. Restorative justice is

\footnotetext{
${ }^{2}$ The Church Council on Justice and Correction is a national coalition of faith-based individuals and eleven founding churches. Its mission is to seek "a faith vision of healing justice", and encourages that criminal justice to be administered in a more humane means (Church Council on Justice and Corrections, n.d.). ${ }^{3}$ Section 718 of the Criminal Code of Canada states "The fundamental purpose of sentencing is to contribute, along with crime prevention initiatives, to respect for the law and the maintenance of a just, peaceful and safe society by imposing just sanctions that have one or more of the following objectives: ... (e) to provide reparations for harm done to victims or to the community". (p.1312).
} 
certainly not a standard option in our current criminal justice system, but it can be argued that the legislative groundwork exists. Continued program development and research will assist in Canada's decision as to whether a restorative justice approach should become a formal and accessible option to all those involved in criminal justice processes. In short, restorative justice has gained significant momentum in the past decade. On the surface, restorative justice certainly has the potential to address the needs arising from crime, perhaps more so than our current criminal justice system. However, despite its appearance and its appealing philosophy, research in this area is still in its infancy. Whether restorative justice can successfully address the effects of crime is a question that has not been fully answered. This study explored this question. 


\section{Philosophical Roots and Theory}

Most restorative justice programs incorporate an all-inclusive approach to helping the offender, the victim, and the community cope with the effects of the crime. Differing from many treatment programs where the offender is the sole focus of attention, the focus of restorative justice processes is on meeting the needs of the offender, the victims, and the community. Unlike the criminal justice system, most restorative justice programs adopt an open and flexible position towards all those affected by the crime, attempting to address a wide range of issues (such as social issues, health issues, financial realities), experienced by both the perpetrator and the victim. These diverse issues may have contributed to or arose from the original conflict or incident, and are addressed in variety of different ways, depending on the participants.

Restorative justice differs most clearly from the traditional retributive justice in that its view of crime and criminal behaviour is more focused on the injury to victims, communities, and offenders rather than focusing primarily on the offender (Bazemore \& Umbreit, 1994; Zehr, 1990). The restorative justice approach focuses on the "bigpicture" relationship between the offender, the victim, and the community, incorporating a more humanistic tone to the process. Restorative justice programs aim to repair relationships and social injury, where the emphasis is on accountability. Accountability is encouraged by assisting the offender to understand the consequences of his or her actions, and enabling him or her to make amends by repairing the harm caused by the crime. Restorative justice programs emphasize problem-solving techniques and cooperation, and use the community as both an indirect victim and a resource. In short, 
the restorative justice approach focuses on achieving justice through enablement, empowerment, and real accountability (Hahn, 1998).

A number of theories have been posited in the area of restorative justice, all integrating the importance of empowerment, reintegration and the repair of harm. The most prominent theory in the area of restorative justice is Braithwaite's (1989) reintegrative shaming theory. This theory is premised on the individual's shame over the wrongdoing, and the subsequent desire to take responsibility and make amends.

\section{Reintegrative Shaming Theory}

Reintegrative shaming theory was introduced by Braithwaite in 1989, when the theory development of restorative justice was in its infancy. In Crime, Shame and Reintegration, Braithwaite (1989) provided an account of why restorative justice processes ought to prevent crime more effectively than traditional retributive practices. Summarized by Braithwaite (2002), the core claims were:

(1) that tolerance of crime makes things worse; (2) that stigmatization, or disrespectful, outcasting shaming of crime, makes crime worse still; and (3) that reintegrative shaming, or disapproval of the act within a continuum of respect for the offender and terminated by rituals of forgiveness, prevents crime (Braithwaite, 2002, p. 74).

Reintegrative shaming theory emphasizes both constructive shame and reintegration. Within a restorative justice circle or conference, a discussion of the consequences of the crime and the harm that has resulted encourages feelings of shame; however, this shaming is accompanied by the support of those individuals who respect and care about the offender, which acts as the reintegration component. As Braithwaite 
(2002) argues, shame is most effective when it is felt in the presence of loved-ones and in "the eyes of those we respect and trust" (p. 74).

Since the original presentation of Braithwaite's integrative shaming theory in 1989, other theories have been presented (e.g., procedural justice, unacknowledged shame, defiance, and self-categorization), but the majority of them emerge from a sociological perspective and appear to possess strong relationships with one another (Braithwaite, 2002). Braithwaite argues that while theories of reintegrative shaming, procedural justice, unacknowledged shame, defiance, and self-categorization all offer an explanation of why restorative justice processes may be effective in accomplishing various forms of restoration and reducing crime, to date, one single validated restorative justice theory does not exist. Though, as stated, reintegrative shaming theory is the most prevalently cited.

Braithwaite's work stems from the traditions of the Maori people of New Zealand, where the Maori use "whanau" conferences (similar to a "Western" version of restorative justice conferencing) that emphasize "whakama" (shame) in a "healing" or "embracing" context (Braithwaite, 2002). In Maori cultures, and in many Asian cultures, the shame of letting one's family down is an important item of discussion after a crime or wrongdoing has occurred. Two main studies have been conducted to validate this theory.

First, Makkai and Braithwaite (1994) tested this theory in the domain of compliance with health care quality in an Australian nursing home. Using independent inspectors, test-retest reliabilities of the measure of compliance with the law were found to be between .93 and .96 . Inspectors used either a reintegrative shaming philosophy, a stigmatizing philosophy, or a philosophy of tolerance and understanding. Makkai and 
Braithwaite (1994) found that the use of a reintegrative shaming philosophy resulted in improved compliance within a two-year period. Results indicated that nursing homes that had an inspector who utilized a stigmatizing philosophy dropped in level of compliance, and nursing homes that experienced a tolerant and understanding inspector demonstrated an intermediate fall in compliance (Makkai \& Braithwaite, 1994).

Second, the reintegrative shaming theory was tested in the context of the Canberra Reintegrative Shaming Experiments (RISE), a project that is still ongoing in the capital city of Australia, where adult and juvenile cases are randomly assigned to either court or restorative justice conference. Preliminary data on the first 548 cases (Braithwaite, 2002; Sherman \& Strang, 1997) were based on offender-reported and researcher-observed findings. Sherman and Strang (1997) found that offenders who were conferenced (i.e., participated in the restorative justice process) encountered more reintegrative shaming than offenders who were processed through the traditional court process. Offenders also experienced more remorse and more forgiveness than court offenders, and reported learning (from the restorative justice process) that there were people in their lives who cared about them and their future (Sherman \& Strang, 1997).

The findings of these two studies combined suggest that there may be validity to the reintegrative shaming theory presented by Braithwaite (1989). It appears as though constructive shaming of an offender, by those who are still supportive of the offender, may provide for a more effective reintegration strategy than other philosophies (such as a stigmatizing or tolerance philosophy). 


\section{Restorative Systems}

Weitekamp and Kerner (2002) discussed various theoretical foundations of restorative justice, all of which hinge on the key elements of a restorative justice encounter. The importance of communication is stressed and occurs in the encounter through the narrative aspect, the emotional aspect and the understanding and agreement aspect (Van Ness, 2002). Van Ness (2002) cites the importance of three basic principles, which are based on four key features: the victim-offender encounter, making amends, reintegration of the offender and the victim(s), and inclusion of all parties. The first principle is that "justice requires that we work to restore victims, offenders and communities who have been injured by crime" (Van Ness, 2002, p. 2). The second is that "victims, offenders and communities should have opportunities for active involvement in the restorative justice process as early and as fully as possible" (Van Ness, 2002, p. 2.). The third principle is that "in promoting justice, the government is responsible for preserving order and the community for establishing peace" (Van Ness, 2002, p. 2). Van Ness (2002) depicts a fully restorative system (the dark grey shaded area of Figure 2 below) where all elements of each of the four features are included and available to participants. The top row of the figure depicts a fully restorative system, whereas the lower the row in the figure, the less restorative the activity. Various combinations of differing restorative level activities are possible. For example, in some cases a system could be moderately restorative, which would be depicted by combining the dark grey shaded area and the lighter grey shaded area of Figure 1. Van Ness (2002) acknowledges that not all parties will want to explore these features but the significance is that they are offered. 
Figure 1

Illustration of a Fully Restorative System (Van Ness, 2002)

\begin{tabular}{|c|c|c|c|}
\hline Encounter & Reparative Activities & Support & Openness \\
\hline $\begin{array}{l}\text { Meeting, } \\
\text { communication and } \\
\text { agreement }\end{array}$ & $\begin{array}{l}\text { Apology restituition and } \\
\text { change }\end{array}$ & $\begin{array}{l}\text { Respectand } \\
\text { assistance }\end{array}$ & $\begin{array}{l}\text { Invitation, acknowledgement of } \\
\text { interests and acceplance of } \\
\text { alternative approaches }\end{array}$ \\
\hline $\begin{array}{l}\text { Meeting and } \\
\text { communication }\end{array}$ & Apology and restitution & Respect & $\begin{array}{l}\text { Invitation and } \\
\text { acknowledgement of interests }\end{array}$ \\
\hline $\begin{array}{l}\text { Meeting and } \\
\text { agreement }\end{array}$ & Apology and change & Assistance & Invitation \\
\hline $\begin{array}{l}\text { Communication and } \\
\text { agreement }\end{array}$ & Restitution and change & $\begin{array}{l}\text { Indifference to either } \\
\text { victim or offender }\end{array}$ & $\begin{array}{l}\text { Permission to participate in } \\
\text { traditional ways }\end{array}$ \\
\hline Communication & Apology & $\begin{array}{l}\text { Indifference to both } \\
\text { victim or offender }\end{array}$ & $\begin{array}{l}\text { No interest in participation of } \\
\text { parties }\end{array}$ \\
\hline Agreement & Restitution & $\begin{array}{l}\text { Stigmatization or } \\
\text { isolation of either } \\
\text { victim or offender }\end{array}$ & $\begin{array}{l}\text { Prevention of parties who wish } \\
\text { to do so from participating }\end{array}$ \\
\hline $\begin{array}{l}\text { No encounter } \\
\text { elements }\end{array}$ & Change & $\begin{array}{l}\text { Stigmatization or } \\
\text { isolation of both } \\
\text { victim or offender }\end{array}$ & $\begin{array}{l}\text { Prevention of parties who wish } \\
\text { to do so from observing }\end{array}$ \\
\hline Separation of parties & No amends/new harm & $\begin{array}{l}\text { Safety obtained } \\
\text { through separation of } \\
\text { offender from victim } \\
\text { and/or community }\end{array}$ & $\begin{array}{l}\text { Coercion of unwilling parties to } \\
\text { serve state or defence } \\
\text { interests }\end{array}$ \\
\hline
\end{tabular}

Adapted from "The shape of things to come: a framework for thinking about a restorative justice system", by D. W. Van Ness (2002). In E. G. M. Weitekamp and H. J. Kerner (Eds.), Restorative Justice Theoretical Foundations, p. 11. Copyright 2002 by Willan Publishing. Reprinted with permission of the author. 
The Restorative Practices Typology

McCold and Wachtel (2002) have also proposed a theory of restorative justice, suggesting that there are three distinct but connected causal structures: the social discipline window, stakeholder needs and restorative practices typology (see Figure 2). McCold and Wachtel (2002) recently attempted to validate the restorative practices typology. They concluded that there was empirical evidence to argue that it passes the initial test of theory validation (McCold \& Wachtel, 2002).

Using three measures of "restorativeness" (participant satisfaction, perceptions of fairness, and a balance of ratings between victims and offenders), program evaluations were examined using forced choice responses of "satisfied or not satisfied" and "fair or not fair". Results indicated that both victims and offenders rated "fully restorative" programs as more satisfying and fair than "mostly restorative" programs and "nonrestorative" programs. Based on the results of this study, the authors concluded that there was evidence to support their hypothesis that participants would rate "fully restorative" programs as more satisfying and fair than "mostly restorative" programs and "nonrestorative" processes (e.g., the criminal justice system). Their results indicated that victim satisfaction, offender sense of fairness, and the parity of outcomes between victim satisfaction and offender sense of fairness were better, on average, for conferencing and victim-offender mediation than for the non-restorative justice processes (McCold \& Wachtel, 2002). 
Figure 2

A Restorative Practices Typology (McCold \& Wachtel, 2002)

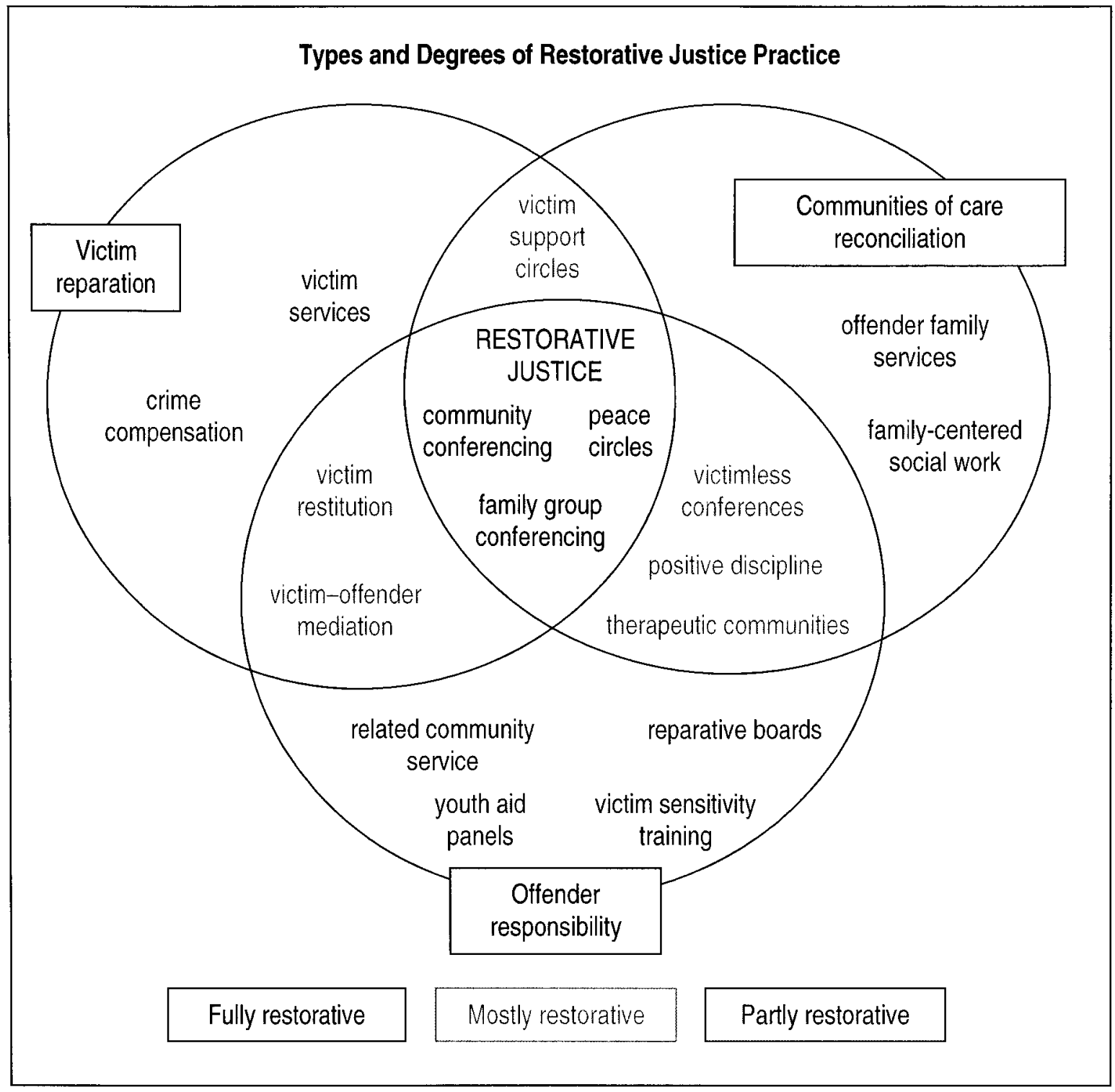

Adapted from "Restorative justice theory validation", by P. McCold and T. Wachtel (2002). In E. G. M. Weitekamp and H. J. Kerner (Eds.), Restorative Justice Theoretical Foundations, p. 116. Copyright 2002 by Willan Publishing. Reprinted with permission of the author. 


\section{Criminal Justice Theories}

Fattah (2001) argues that a theory of justice may not be attainable given that there is no agreed upon definition of justice; justice means different things to different people. Fattah (2001) purports that the field of restorative justice also "suffers from some misguided, though well-intentioned, attempts to develop a theory" (p. 313). Although a well-grounded, concrete theoretical model of how restorative actions lead to restorative outcomes, or an explanation that clearly outlines the inner workings of a restorative process, may not exist, there are some basic principles that can be applied to restorative justice.

\section{Principles of Effective Correctional Treatment}

Andrews and Bonta (2003) outlined the four principles required for effective correctional treatment: risk, need, responsivity and professional discretion. The risk principle requires that the level of intervention be matched to an offender's risk level. For example, a low-risk offender should receive a low level of treatment intervention whereas a high-risk offender should receive a higher, more intensive level of intervention (Andrews \& Bonta, 2003). Research has found detrimental effects of mismatched risk levels and level of intervention (e.g., intensive intervention with a low-risk offender could actually increase the potential of recidivism; Andrews \& Bonta 2003). The need principle requires that the treatment strategy be targeted at addressing the offender's criminogenic needs ${ }^{4}$ rather than an offender's non-criminogenic needs ${ }^{5}$ (Andrews \& Bonta, 2003). The third principle developed by Andrews and Bonta (2003) is the

\footnotetext{
${ }^{4} \mathrm{~A}$ criminogenic need is a need that is directly related to risk of re-offending; a need, that once addressed, will decrease the offender's likelihood of recidivism.

${ }^{5}$ A non-criminogenic need may still be problematic, but a non-criminogenic need is one that is not related to an offender's criminal behaviour, and even if targeted will not decrease the likelihood of recidivism.
} 
responsivity principle, which requires that treatment be delivered in a means that acknowledges and is appropriate to the offender's learning style. For example, if an offender is illiterate, the treatment cannot be in a format where the offender must read certain elements. The last principle is that of professional discretion, which acknowledges that circumstances and situations may exist where professional discretion should be incorporated into risk and need assessments and into effective correctional treatment strategies (Andrews \& Bonta, 2003).

Restorative justice is a means of addressing the harm caused by crime. To be useful in a correctional context, the principles of effective correctional treatment should be incorporated. Incorporating these principles does not only mean that the offender's needs will be effectively addressed, it all also addresses the needs of all participants. Although at first glance these principles may not appear applicable to the practice of restorative justice, they do in fact emphasize the same underlying goal - to address the needs of participants. In restorative justice, the goal is to meet the needs of the parties involved.

Elements of the risk principle currently exist in restorative justice practice, but a stronger adherence to the principle would be beneficial. For example, if restorative justice programs assessed offender risk, the likelihood of future risk could be obtained, and this information could result in protection for the offender, the victim and the community. Addressing risk from a psychological perspective could be equated to the restorative justice program ensuring the safety of the participants, as well as addressing the offender's risk to re-offend. In terms of matching the level of intervention to an offender's level of risk, current restorative justice programs accomplish this to a certain 
degree, but it is an area where more attention should be directed. Typically, more serious crimes, with more damaging consequences, take a longer period of time to go through a restorative process (suggesting a higher level of intervention). The seriousness of the crime is usually an indication of a lengthy restorative justice process, but not always. It is also important to note that research suggests that seriousness of index offence is not, on its own, related to future violent re-offending (Webster, Harris, Rice, Cormier, \& Quinsey, 1994).

The need principle is also important and should be incorporated, for many of the same reasons listed for the risk principle. Addressing an offender's criminogenic needs can ensure that the offender is more equipped to return to the community, again reducing the likelihood of recidivism, which is a "need" of most restorative justice participants, and society at large. However, many restorative justice programs are not equipped or trained to assess an offender's criminogenic needs. If the need is evident, for example, a substance abuse problem, than it is likely that the offender would be referred to treatment, but a full assessment is rarely conducted.

Responsivity, delivering the intervention in a style that is consistent with an offender's learning style, capabilities and limitations, is currently considered in a restorative justice context, although practitioners would not recognize this strategy as the incorporation of the responsivity principle. In a restorative justice process, a facilitator or caseworker accompanies each participant through the process, working directly with them in a variety of ways that will meet the client's needs. The flexible approach of restorative justice allows for the responsivity principle to be met. However, no formal 
"treatment" is being offered in the majority of restorative justice programs, though what is offered is usually designed for the client, recognizing their strengths and limitations.

The last principle of effective correctional treatment is that of professional discretion. Using professional discretion in a restorative justice program allows for cases to be screened out if they are not appropriate. Currently, although the majority of restorative justice practitioners are not trained in "clinical" judgement, most restorative justice programs do rely, to a certain degree, on "gut instincts". It is often the role of the facilitator(s) to judge a participant's "state of mind" and determine whether participation is appropriate, as well as whether a victim-offender meeting or encounter is likely to be beneficial to the parties involved. Recognizing that "gut instinct" and the option of professional discretion is important in certain circumstances, it is also argued that restorative justice programs could benefit from the incorporation of specialized standardized assessment instruments to assist in the area (Rugge et al., 2005).

The use of the effective correctional treatment principles would benefit restorative justice programs. Even though these principles have not been directly applied and tested in the restorative justice field, it is argued that their application would be an asset as they help not only the offender, but are beneficial to all parties - ultimately, everyone benefits.

\section{Summary}

While various theories and models have been put forth, which suggest that a restorative justice process may facilitate healing (Braithwaite, 2002) and that certain elements lead to participant satisfaction and perceptions of fairness, research has yet to examine the specific changes that occur as a result of the restorative justice process (McCold \& Wachtel, 2002). Although there is much research still to be done, advocates 
argue the many strengths of the restorative justice approach. The strengths and weakness of the approach are examined next. 
Why Explore the Restorative Justice Approach?

Research on the current traditional criminal justice system suggests that the needs of victims are not being met (Beven, Hall, Froyland, Steels, \& Goulding, 2005; Sherman, 2003; Sullivan, 2005; Viano, 1978; Wemmers \& Cyr, 2005; Wexler \& Winick, 1996). The criminal justice system has been described as inhumane and impersonal, alienating or ignoring the rights of victims, and being focused more on the punishment of offenders than on rehabilitation and reintegration. Although in 2003, there were over 600 victim services agencies in operation in Canada, providing services to almost 300,000 clients (Kong, 2004), victims' advocates emphasize that the criminal justice system does not recognize the needs of victims. Research suggests that victims want to have the opportunity to be involved in the justice process and that their primary need is one of seeking information (Rugge et al., 2005; Sherman, 2003; Wemmers \& Cyr, 2005). Restorative justice is a plausible means of addressing these needs.

When examining restorative justice as a viable justice resolution option, the strengths and weaknesses of its approach must be examined. First and foremost, restorative justice involves the victims, giving them an active voice in the process, and empowering them by engaging them in the decision-making process. Although victims' groups have voiced concerns that restorative justice may not be an appropriate process for all crimes (e.g., sexual abuse cases and domestic violence) unless special attention is paid to potential power imbalances or re-victimization, many victims and victims advocates have praised the restorative justice process for addressing many of the currently unmet needs of victims. In restorative justice processes, the victim is central to the process of defining the harm and how it might be repaired. Restorative justice 
provides victims with the opportunity to express their experience, feelings and concerns as well as ask questions of the offender.

Second, restorative justice focuses on how the harm caused by the offender can be repaired and gives the offender a voice in the development of a restorative plan. This approach requires that the offender accept responsibility for his or her crimes, whereas the traditional criminal justice system emphasizes that the offender remain quiet where the focus is not on the discovery of truth but whether there is enough evidence to convict. Restorative justice requires that the offender admit guilt and is prepared to accept responsibility for his or her actions, and is willing to take the necessary steps to attempt to repair the harm. In many cases, the offender may not truly comprehend or may minimize the extent of the harm that they caused (e.g.. "I didn't hurt anyone", "they have insurance", etc.). The majority of restorative justice programs explore the consequences of the offender's actions (i.e., the harm) to ensure that there is an understanding of the true consequences.

In addition to focusing on the truth, many restorative justice processes also develop a plan, one which includes elements to repair the harm, and in several cases, one that also includes elements of rehabilitation, to ensure that the offender does not commit another crime. Often, offenders must take steps to "prove" that they are remorseful, such as by enrolling in a treatment program, or offering financial compensation, before the victims will even agree to participate in the restorative justice program.

When compared to the current criminal justice system, restorative justice processes appear to be more effective at ensuring the offender does not re-offend (Bonta, Jesseman, Rugge, \& Cormier, 2006; Latimer, Dowden, \& Muise, 2001; Rugge et al., 
2005). Restorative justice provides a forum for offenders to: accept responsibility for their actions and acknowledge the harm caused; hear first-hand how their behaviour has affected others; participate in determining how to repair the harm caused and take action to repair damage and seek help with problems related to the offence (Department of Justice, 1998).

Lastly, restorative justice processes involve a party that the current criminal justice system does not, the community. It has been said that it takes a community to raise a child, and that we are all responsible for our community, but the current criminal justice system is not equipped or designed to involve active community participation (with the exception of public outcry due to media coverage, and jury membership). Restorative justice involves the community and empowers them to address the societal problem of crime. Restorative justice provides community members with the opportunity to express thoughts and concerns, show disapproval without labeling the offender as an outcast, and actively participate in the achievement of justice. Community needs such as safety, re-establishing relationships, and prevention of recidivism can be addressed.

Although there are many reasons why restorative justice is a viable option, the three mentioned above are more than compelling. It can be argued that the benefits of restorative justice, when compared to the current criminal justice system, are strong (Beven et al., 2005; Bonta et al., 2006; Braithwaite, 2002; Latimer et al., 2001). However, the questions now focus on whether restorative justice can operate within the current criminal justice system. Unfortunately as important a question as this is, it is beyond the scope of this study. 
Victims' advocates and restorative justice critics voice concerns about restorative justice approaches, primarily regarding power imbalances, potential re-victimization of victims, and restorative justice being inappropriate for certain types of crimes.

Discussions around these issues continue, and critics and proponents continue to work together to develop approaches that address the valid concerns that exist. Research continues to explore when restorative justice works and for whom, and in what circumstances. The development of the United Nation's Basic Principles (2002) and the other guiding principles which have been developed by practitioners have addressed many concerns that have been voiced. Unique innovative approaches continue to be developed regarding crimes that were originally deemed inappropriate, such as sexual assault and domestic violence; however, practitioners continue to tread cautiously.

Despite arguments suggesting that restorative justice is a viable option, the main limitation of restorative justice is that the body of research that currently exists is still in its infancy. Furthermore, much of the research that does exist is weakened by the methodologies used and the inherent selection bias that comes with the essential voluntary nature of restorative justice. Although more evaluations are utilizing comparison groups, few are able to incorporate random assignment. Hence the quality and quantity of the research continues to be a limitation. Researchers continue to strive to conduct solid research studies in order to inform the restorative justice field and to determine the effects of restorative justice processes. 
Restorative Justice Research

Given that we recognize the strengths of restorative justice and its benefits to participants, what does research in this area say about this approach? Although restorative justice initiatives are gaining in popularity, there is relatively little research evaluating the effectiveness of such programs. Evaluations to date mainly focus on satisfaction of the clients (offender and victim) but research has yet to explore other successful outcome indicators (e.g., positive changes in physical or psychological health).

\section{Participant Satisfaction}

Umbreit (1994) reviewed over 3,000 cases of victim-offender mediation across the United States and found very high levels of satisfaction, $79 \%$ for victims and $87 \%$ for offenders. High satisfaction rates for both victims and offenders are consistent across studies (Beven et al., 2005; Bonta et al., 2006; Bonta, Wallace-Capretta, Rooney, \& McAnoy, 2002; Clairmont, 2005; Latimer et al., 2001; Rugge et al., 2005; Strang, 2002; Umbreit, 1994). Umbreit (1994) also found that restorative justice processes have a strong effect for both victims and juvenile offenders in humanizing the system. As important as participant satisfaction is, it is important to note that some researchers have scrutinized the sole use of satisfaction rates in determining the success of restorative justice programs, as high levels of satisfaction do not necessarily indicate program effectiveness (Zehr, 1990). For example, in order to evaluate program effectiveness, all program goals should be examined (e.g., reducing offender recidivism, increasing overall participant well-being), not only participant satisfaction. As a result, research has moved beyond examining only client satisfaction. 
In Canada, meta-analytic reviews (Bonta et al., 2006; Bonta et al., 2002; Latimer et al., 2001) suggest that participation in restorative justice programs has moderate positive effects on victim satisfaction, offender satisfaction, reduced recidivism, as well as restitution and community service compliance.

\section{Restorative Justice and Victims}

One of the goals of restorative justice is to attempt to heal the suffering of victims that has been caused by a criminal event (Zehr, 2002). Restorative justice, when compared to the traditional system of criminal justice, has been described as a model of "therapeutic jurisprudence" (Wexler \& Winick, 1996). The philosophy of restorative justice focuses on reducing the harm and making right the wrong that was perpetrated (Zehr, 2002). As such, restorative justice offers victims more than the traditional criminal justice system currently does (Fattah, 2001; Scheff, 1998; Wemmers \& Cyr, 2005).

Restorative justice empowers victims by providing them with the opportunity to actively participate in the crime resolution process. Victims control the type and degree of their involvement. Research suggests that victims are certainly more satisfied with the restorative justice approach when compared to the traditional criminal justice system (Beven et al., 2005; Bonta et al., 2002; Latimer et al., 2001; Rugge et al., 2005; Umbreit, 1994; Wemmers \& Cyr, 2005); however, this is not surprising given that the current

\footnotetext{
${ }^{6}$ Therapeutic jurisprudence, as posited by Wexler and Winick (1996), is an interdisciplinary approach to law, one that views the legal system as a social force that can produce therapeutic or anti-therapeutic effects on the people who are involved. Using the example of victims, this view purports that victims can be negatively or positively affected by the criminal justice system. Therapeutic jurisprudence argues for the examination of the consequences of the legal process to determine whether the law's anti-therapeutic effects can be reduced, without affecting the core values of due process and other core justice principles (Wexler \& Winick, 1996).
} 
system does not empower victims to the slightest degree (apart from being given the opportunity to prepare a victim impact statement; Sullivan, 2005).

The research on restorative justice's effect on victims does not extend much past the elements of satisfaction and perceived fairness. Umbreit (1994) reported on the healing effects of victim-offender mediation on victims and found that $90 \%$ of victims who participated in the restorative justice process were satisfied. Umbreit compared post-meeting results to pre-meeting results and found that victims were less upset about the crime and less fearful of the offender after the victim-offender meeting than before the meeting. Unfortunately no comparison group was utilized in this study, so no comparisons were possible to determine whether the traditional criminal justice process has a similar effect.

Strang (2002) utilized a quasi-experimental design and compared victims who experienced a restorative justice process with victims who experienced the traditional court system. Strang (2002) found that victims who participated in the restorative justice process (i.e., conferencing) were more satisfied than victims who experienced the traditional court process. This study also examined emotional restoration and results indicated that victims who experienced the restorative approach were less angry and less fearful post-process than pre-process (Strang, 2002). The offender accepting responsibility was a key component of the restorative justice process, and in cases where this did not occur, the victims were not satisfied but instead felt re-victimized. These findings again stress the importance of offender screening and voluntary participation (Strang, 2002). This study also adds evidence to the argument that the principles of effective correctional treatment would be beneficial in the restorative justice context in 
order to better enable facilitators to assess offender readiness and appropriateness for a victim-offender meeting.

Research has also been conducted to determine whether or not the degree of victimization plays a role. In cases where the offender does not accept responsibility and where victims are re-victimized, it is clear that the restorative justice process is not helpful to victims. Thus, the question becomes: when is restorative justice more beneficial to victims - in less serious crime cases or in more serious cases where the degree of victimization is greater? Currently, there is no consensus on this question. Daly (2004) found that victims who experienced high levels of victimization (e.g., were victims of a violent crime) and evidenced higher levels of distress were less likely to find conferencing helpful. On the other hand, Strang (2002) reported that victims who experienced a violent incident and evidenced considerable harm as a result of their victimization found the restorative justice process most helpful. This is an area that requires additional exploration.

Wemmers and Cyr (2005) also examined the relationship between restorative justice and recovery from victimization. Their design was a post-victim-offender meeting one, and as a result, no causal inferences were drawn. Victim's well-being was assessed by questioning victims as to whether program participation helped them to put the incident "behind them". Results indicated that the majority of victims felt the program did help them to put the incident behind them and that they "felt better" regarding their victimization after the victim-offender meeting. Victims were questioned as to their perceived benefits of the restorative justice process, and the majority reported psychological benefits, and in some cases monetary benefits, in addition to the 
informational benefits. Unfortunately "psychological" benefits were not expanded upon and it is unclear as to the types of psychological benefits that may have resulted (e.g., reduction in fear levels, anxiety levels etc.).

Lastly, Wemmers and Cyr (2005) also examined the link between therapeutic procedural justice and victim well-being. Results indicated that fair procedures appear to be therapeutic for victims, although no comparison group was utilized. However, other research suggests that satisfaction and perceptions of fairness are closely related (Latimer et al, 2001; Rugge et al., 2005; Strang, 2002; Umbreit, 1994).

In sum, further research is required to examine the psychological benefits that victims receive from a restorative justice process. This study seeks to further explore this area.

Restorative Justice and Offenders

Although consumer satisfaction is less palatable when it comes to offenders (when compared to victims), research has found that offenders who experience the restorative justice approach are more satisfied than offenders who are processed through the traditional criminal justice system (Bonta et al., 2002; Latimer et al., 2001; Rugge et al., 2005; Umbreit, 1994). It has been argued by victim advocates (and the general public to a certain degree) that if an offender receives a less severe criminal sanction by going through a restorative justice process than he or she would have if processed through the traditional criminal justice system, it is no wonder that the offender is more satisfied. Although it is true that offenders who participate in a restorative justice process may receive a reduced sanction (Rugge et al., 2005), participating in a restorative justice 
process is by no means the "easier" process. Facing victims and attempting to repair the harm caused may in fact be more difficult than serving a period of incarceration.

In addition to participant satisfaction, Latimer and colleagues (2001) found that participating in a restorative justice process resulted in a small reduction in offender recidivism (7\%). More recently, Bonta et al.'s (2006) meta-analysis on restorative justice and recidivism concluded the restorative justice interventions had a statistically significant impact on recidivism (7\%), consistent with Latimer et al.'s meta-analysis. Furthermore, Bonta and colleagues (2006) found the more recent studies (post-1995), studies with a high adherence to restorative justice principles and studies that incorporated a highly structured model, resulted in higher effects sizes $(12 \%)$ related to recidivism. This meta-analysis also found the restorative justice interventions appear to be more effective with low-risk offenders (Bonta et al., 2006).

Little research has been conducted on the effects of restorative justice on offenders, beyond the outcomes of offender satisfaction, perceptions of fairness and reoffending. No studies currently exist on the potential psychological benefits of restorative justice or its role in facilitating offender healing. Given the importance of offender reintegration, restorative justice should be explored as a viable option for assisting in this goal as it engages the community, the victim and the offender in collectively developing a reparation plan, with an eye to preventing future criminal activity and having the offender return to being a productive member of a pro-social and law-abiding community. 


\section{Ongoing and Future Research}

There are currently several comprehensive evaluations being conducted on restorative justice programs in Canada and around the world; however, results are not yet available. Most of the research to date, with perhaps the exception of research conducted in the last five years or so, has been methodologically weak, as few utilized a comparison group and many were susceptible to selection bias. Despite the lack of research supporting the long-term effectiveness of restorative justice programs, results to date are promising. Generally, restorative justice interventions are hailed for their flexible and all-encompassing approach and the satisfaction they appear to bring to program participants. However, researchers have yet to explore the inner workings of restorative justice processes and need to continue to explore the effects and impacts of restorative justice on participants.

\section{Great Possibilities}

Practitioners argue that restorative justice processes can be "magical", and that researchers may not be able to quantify or articulate the magical elements that can occur when all aspects of the encounter are perfectly aligned. Although not evident in every restorative meeting, participants and facilitators describe some cases as "nirvana stories", stories of victims and offenders meeting and experiencing a "coming together" that changes their lives forever. A nirvana story could occur when participants are ready and able to resolve disputes, to repair harms, to feel contrite, and perhaps to forgive others (Daly, 2002). Of course, in many cases, participants are not ready and not able to do these things. In some cases, the victim-offender meeting can involve forgiveness, and perhaps closure and healing. 
To date, there has been little research into the "magic" that occurs during the victim-offender meeting, or as a result of this meeting. Changes occur, but these changes have only been highlighted through questions of satisfaction. There is a need for research to go further, and to document what changes occur, as a result of this meaningful, perhaps life-altering victim-offender meeting. Participant satisfaction is an important goal in any program, but other outcomes should be examined as well. 


\section{The Current Study}

Restorative justice practices may affect many areas of an individual's life. Three of these areas were explored in this study. The three identified areas were developed through a review of the literature, and numerous interviews that were conducted with program practitioners and facilitators as well as victims and offenders who had participated in restorative justice programs. The three most prominent areas identified were: (1) physical health, (2) psychological health, and (3) the concept of social support. Each of these content areas will be examined in detail below.

Research has examined the effects on physical and psychological health that result from stress (Brown \& Harris, 1978; Dohrenwend \& Dohrenwend, 1974; Lazarus \& Folkman, 1984; Segerstrom \& Miller, 2005); therefore, the concept of stress will be briefly examined before reviewing the research findings from a review of the literature. Stress has been described by Holmes and Rahe (1967) as any environmental, social or internal demand that requires an individual to re-adjust behavioural patterns. Researchers argue that as stressors accumulate, an individual's ability to re-adjust can be over-taxed, thereby depleting their physical or psychological resources, which then results in an increased probability of illness, injury, and disease occurring (Brown \& Harris, 1978; Dohrenwend \& Dohrenwend, 1974; Lazarus \& Folkman, 1984; Segerstrom \& Miller, 2005). Lazarus and Folkman (1984) redefined stress by incorporating the element of individual appraisal to a potentially stressful situation.

Research suggests that many factors can contribute to the determination of whether an event is stressful (Gal, 2003). For example, an individual's appraisal of the situation, an individual's perceived ability to cope with the environment, and an 
individual's level of access to various beneficial resources (such as social support) could all contribute to whether an event is described by an individual as being stressful (Folkman \& Moskowitz, 2004; Gal, 2003). Research distinguishes between effects of chronic stress and a specific stressful event. For the purpose of this study only research pertaining to stressful events (e.g., victimization), rather than prolonged chronic stress, was reviewed. It was the premise of this study that victimization (i.e., being a victim) and involvement in a criminal incident (i.e., being an offender) may result in individuals (both victims and offenders) experiencing stress. In other words, the criminal incident (applying to both victims and offenders) was used as an example of a stressful event, and was characterized as such for the purposes of this study.

\section{Physical Health}

There is plenty of empirical literature to suggest that stressful events can affect an individual's physical health as well as their psychological health (American Psychological Association, 2005; Fava \& Sonino, 2000; Gal, 2003; Greer, 2005; Koss, Koss, \& Woodruff, 1991; Leahy, Pretty, \& Tenenbaum, 2003; Segerstrom \& Miller, 2005). The American Psychological Association (2005) speaks to the findings of almost 300 studies that confirm that stress affects the immune system. Most recently, Segerstrom and Miller (2005) conducted a meta-analysis and concluded that long-term stress or chronic stress causes the immune system to weaken and potentially break down. Furthermore, the American Psychological Association (2005) found 293 independent peer-reviewed studies, which sums to approximately 18,000 participants, that found supportive evidence that stress alters immunity and the causal connection becomes a strong, almost irrefutable conclusion. Examining stressful events specifically (as 
opposed to chronic stress), Segerstrom and Miller (2005) concluded that there was a weak association to different immune consequences, depending on the type of stressful event. The findings suggest that different patterns exist for the different types of stressful events (e.g., the pattern or link between bereavement and health consequences were different from the pattern for trauma and health consequences; Segerstrom \& Miller, 2005).

Fava and Sonino (2000) documented the frequent clinical observation that when an individual experiences life events and situations that are meaningful (hence, stressful), there is an increased occurrence of ill health. For example, research in this area (e.g., Gal, 2003, Sonino \& Fava, 1998; Sonino, Fava, \& Boscaro, 1993) has established a link between stressful life events and endocrine conditions and cardiovascular disease (Rozanski, Blumenthal, \& Kaplan, 1999) and asthma (Wright, Rodriguez, \& Cohen, 1998).

Victimization, as a specific stressful event, has also been examined by researchers. Koss, Koss and Woodruff (1991) examined the long-term consequences of criminal victimization on physical health. In a sample of 316 victims and 74 non-victims, they found that severely victimized women reported higher levels of distress and lower levels of well-being than non-victimized women (Koss et al., 1991). Furthermore, victimized women made twice as many visits to their physician in a year and had outpatient costs that were two and a half times greater than women who did not experience criminal victimization (Koss et al., 1991). The level or degree of victimization was found to be a significant predictor of physician visits and outpatient 
costs (Koss et al., 1991). Other physical reactions to victimization include nausea, sleep problems and increased muscle tension (Leahy et al., 2003).

As indicated, victimization can be characterized as a stressful event where the stress of victimization could have effects on a victim's physical health as well as their psychological well-being. Alternatively, committing a criminal act, being apprehended, charged and facing criminal sanctions as well as other consequences resulting from the criminal act could also create stress for the offender. Thus, offenders too may experience physical effects as a result of their behaviour and the ensuing stress of the criminal incident. Offender effects has been less of a focus in this area, but it is logical to suggest that offenders may also experience stress, and consequently, the same link between stress and physical effects could apply.

When placing the stressful effects of victimization or perpetration into a restorative justice context, it is plausible that the restorative justice process may have a positive effect on a participant's physical health. Participants in the restorative justice process are provided with a mechanism that could assist them in dealing with the negative effects of the crime, by gaining information, exploring options to meet their needs, and by being actively involved in the development of a reparation plan. This study examined this plausibility - that the restorative justice process could have positive effects on participants' health problems that have resulted from the criminal incident.

\section{Psychological Health}

Linked closely to the relationship between stress and lowered immunity is the impact of stressful events on psychological health. Although stress itself can be described as an indicator of psychological health, there may be a causal relationship 
between stress and other psychological health indicators. Research has shown that individuals who experienced criminal victimization may experience the following cognitive changes: anxiety (Boney-McCoy \& Finkelhor, 1996; Mezy, 1988; Norris, Kaniasty, \& Thompson, 1997), anger and hostility (Casarez-Levison, 1992; Greenberg \& Ruback, 1992; Leahy et al., 2003; Norris et al., 1997; Wemmers \& Cyr, 2005), fear or phobias (Boney-McCoy \& Finkelhor, 1996; Casarez-Levison, 1992; Greenberg \& Ruback, 1992; Leahy et al., 2003; Mezy, 1998; Wemmers \& Cyr, 2005), embarrassment (Casarez-Levison, 1992), depression (Mezy, 1988), grief (Casarez-Levison, 1992; Leahy et al., 2003), guilt and shame (Leahy et al., 2003; Mezy, 1988), and lowered self-esteem (Norris et al., 1997). Furthermore, victims also experience alienation (Mezy, 1998), flashbacks (Mezy, 1988) confusion (Leahy et al., 2003; Mezy, 1988) and dissociation (Birmes, Carreras, Ducassé, Charlet, Warner, Lauque, \& Schmitt, 2001; Leahy et al., 2003).

The study conducted by Birmes and his colleagues (2001) examined the relationship between the stressful event of victimization and posttraumatic stress disorder, and the role of immediate dissociation at the time of the traumatic event (versus non-immediate or no dissociation). Forty-eight violent assault victims were interviewed within 24 hours of victimization and assessed for the presence of immediate dissociation using a standardized assessment instrument and re-interviewed at two- and five-week intervals (Birmes et al., 2001). Results indicated that high levels of immediate dissociation and acute stress following a violent assault were indeed both risk factors for early post-traumatic stress disorder (Birmes et al., 2001). 
Psychological reactions to stressful life events, such as victimization, can range from mild reactions to more severe reactions (Markesteyn, 1992). For example, according to Markesteyn (1992), mild reactions could include symptoms such as irritability, worry, attention lapses, minor sleep disturbances, interpersonal strain, and exacerbation of prior health problems. More severe symptoms are similar to those that may result in a posttraumatic stress disorder diagnosis, such as persistent heightened arousal, psychic numbing and recurring thoughts of the incident that impair life functioning (Markesteyn, 1992).

In an effort to examine whether degree of reaction was related to severity of victimization, Markesteyn (1992) examined the psychological impacts of non-sexual criminal victimization and found that although the psychological symptoms may vary in intensity among victims who experienced different crimes (e.g., robbery, burglary, kidnapping), the nature of their distress was still similar. He concluded by arguing that more research is required to examine the psychological effects of victimization and to develop effective strategies to minimize the long-term effects of victimization (Markesteyn, 1992).

In 1997, Norris and colleagues also examined victimization severity and found that violence during a crime increased response severity (i.e., victims exhibit more severe-type symptoms such as posttraumatic stress disorder symptoms), recognizing that victims who experience a non-violent victimization can still exhibit increased fear and psychological symptoms. Markestyen (1992) examined possible patterns regarding victim response severity, and was not able to distinguish patterns as all victims evidenced distress. Overall, both Norris et al.'s findings (1997) and Markestyen's findings (1992), 
concluded that the more violent the crime, the more severe the reaction which will be experienced by the victim.

Placing the psychological effects of victimization into the criminal justice context, victims' advocates argue that the criminal justice or court experience adds to or exacerbates an already stressful situation for victims as they have no control in the process (Beven et al., 2005; Campbell \& Raja, 1999; Sullivan, 2005; Wemmers \& Cyr, 2005; Viano, 1978). This possible re-victimization by the system is also often referred to as secondary victimization, which has been defined as the worsening of an already difficult situation (Hill, 2004). Research has found that when victims find their contact with the system (e.g., contact with police) "helpful", they feel more connected to others (Norris et al., 1997), whereas when victims have a negative experience, there is an increase in posttraumatic stress symptoms (Campbell, Sefl, Barnes, Adrens, Wasco, \& Zaragoza-Diesfeld, 1999).

Hill (2004) argues that an understanding of the psychological changes that are directly related to being victimized is essential when attempting to understand a "victim's internal world". There exists preliminary research to suggest that participating in a restorative justice process may decrease victims' fear levels (Strang, 2002; Umbreit, 1994; Wemmers \& Cyr, 2005). Levine (2000) argues that victim-offender mediation may be therapeutic for victims as it provides victims with a sense of participation and control over their lives and process - in short, it is argued that restorative justice empowers victims. Furthermore, victims have cited that both receiving information about the case and meeting the offender is beneficial (Rugge et al., 2005; Strang, 2002; Umbreit, 1994; Wemmers \& Cyr, 2005). Research examining the effects of restorative 
justice on psychological health requires further exploration, a task which this study attempted to address.

As stated earlier, the majority of research on the psychological effects of a criminal incident focuses on victims; however, offenders may also exhibit psychological effects. Research in the restorative justice field has examined satisfaction, on the part of both victims and offenders, but the majority of the psychological effects examined pertain to victim "fear", with the exception of "feeling better" and the receiving fair treatment (which pertain to both victims and offenders). As a result, this study sought to examine the possible psychological health benefits that restorative justice processes had on offenders, as well as victims.

\section{Social Support}

Researchers have also explored the concept of social support and its relationship to stressful events (Gal, 2003; Greenberg \& Ruback, 1992; Nolen-Hoesksema \& Davis, 1999; Norris et al., 1997). Social support typically refers to the functions that are performed by the "significant others" (e.g., spouses, family members, close friends) or other individuals one has in their life, who play a supportive role (Gal, 2003). Supportive individuals can provide various types of support: instrumental, informational and emotional, or a combination of the three (House \& Kahn, 1985). Research has shown that victims who receive positive social support experience better adjustment than victims who do not (Nolen-Hoesksema \& Davis, 1999). Again, research in the area of victimization focuses on the effects of social support for victims, not offenders (which is not surprising). 
Norris and colleagues (1997) found that support from both natural supports (e.g., family and friends, etc.) and professional supports (e.g., police, lawyer, clergy, and mental health professionals) can be helpful to victims; however, it should be noted that victims who are supported by natural supports are more likely to also seek professional assistance. Furthermore, Gal (2003), along with other researchers (McFarlane \& Yehuda, 1996) found that social support acted as a buffer to the negative effects of stress, particularly under conditions of high stress. McFarlane and Yehuda (1996) found that individuals who were able to access and use their social support network immediately after a traumatic event were more resilient and evidenced fewer posttraumatic stress disorder symptoms.

After a review of the social support literature, Thoits (1995) concluded the following. First, social support and feelings of social integration are directly and positively related to psychological and physical health; however, they do not buffer the physical or emotional effects of major life events or chronic life difficulties. Second, he concluded that perceived social support usually buffers the damaging physical and psychological effects of major life events and chronic strains and is associated directly with better physical and psychological health. Lastly, Thoits (1995) concluded that the most powerful measure of social support appeared to be whether or not an individual has an intimate and supportive relationship.

Research specifically examining the importance of a relationship is consistent. Cohen and Wills (1985) found that if an individual has an intimate and supportive relationship, they are more likely to experience stress-induced growth and ultimately thrive after a stressful life circumstance. Their results indicated that having a confidant 
significantly reduced the possible negative psychological and physical health effects of a stressful experience (Cohen \& Wills, 1985). Furthermore, it has been found that an individual's satisfaction with their social support was moderately positively related to stress-related growth from a negative event (Park, Cohen, \& Murch, 1996).

The presence of social support may enable individuals to interpret stressful events in a less threatening manner as a result of the positive background (Norris \& Kaniasty, 1996; Park, 1998) or may provide individuals with opportunities to discuss and process the negative event, resulting in the possible identification of positive aspects (Lepore, Silver, Wortman, \& Wayment, 1996). The presence of social support has also been linked to positive psychological health outcomes, such as increased psychological wellbeing (Lambert, Lambert, Klipple, and Mewshaw, 1990) as well as positive physical health outcomes, such as decreased susceptibility to disease, lower mortality rates (Blazer, 1982), lower cardiovascular reactivity (Kamarck, Manuck, \& Jennings, 1990) and enhanced immune functioning (Jemmot \& Magliore, 1988).

Research has found that the perception of social support is as important as the presence of actual support (Dolbier \& Steinhardt, 2000; Gal, 2003; Hill, 2004; Norris et al., 1997). Examples of actual support include talking to a friend, participating in a support group, and meeting with a counsellor, whereas perceived social support is the knowledge that these resources are available if and when needed (e.g., knowing you have a friend you could talk to or knowing you could attend the weekly survivor meeting). Perceived social support (knowing support is there when needed) has been found to reduce fear, depression and posttraumatic stress symptoms (Norris et al., 1997). As Hill (2004) suggests, a victim may be helped by the mere fact of just knowing that their local 
community has a victim services agency, regardless of whether they choose to use the service. In fact, research has found that the perceived social support is actually a much stronger influence on psychological health than receiving actual support (Norris \& Kaniasty, 1996; Wetherington \& Kessler, 1986). Furthermore, comparisons of the two types of support suggest that perceived support is a better predictor of positive health outcomes (Cohen \& Wills, 1985; Wetherington \& Kessler, 1986).

Restorative justice actively seeks to involve a participant's support system, as well as the community; hence, the restorative justice process may also have a positive impact by increasing an individual's perceived social support, especially in cases where victims and offenders enter the process lacking a social support network. Given the role that social support plays in buffering the effects of stressful situations (e.g., victimization, consequences of criminal activity), exploring perceived social support in the restorative justice context warrants examination - therefore, it was also included in this study.

\section{Participant Satisfaction}

In addition to these three content areas, a fourth area was included for further examination: participant satisfaction. This study examined participant satisfaction and how it was related to the other content areas (physical health and psychological health). Because the restorative justice approach is flexible, victims may identify different needs, offenders may make various offers of reparation, and ultimately, every case results in a unique resolution plan. Victims may request different reparation activities, such as in a case of drunk driving, the victim may request that the offender speak to high school students about the possible consequences of drunk driving; other victims may request only a letter of apology, or that the offender update them on his or her rehabilitation 
progress for several years. Alternatively, offenders are in different positions, allowing them to only offer what is possible given their life circumstances and their abilities.

It is possible that participant satisfaction may relate to other outcomes; for example, if a participant is not satisfied, then other beneficial outcomes (such as improved psychological health) may not be seen. Past research suggests that there is a positive association of consumer satisfaction with services and outcomes (Carlson \& Gabriel, 2001; Lebow, 1982; Pandiani, Banks, \& Schacht, 2001).

Also, research has suggested that a victim-offender meeting or an "encounter" needs to occur for the process to be "true" restorative justice (Braithwaite, 2002; Krug, n.d.; Rugge et al., 2005); however, research to date has only just begun to examine participant satisfaction levels and how they vary depending on the restorative justice process that they choose. Therefore, this study will examine whether satisfaction levels differ in participants who experience a victim-offender meeting compared to those who utilize a form of indirect mediation.

\section{Purpose}

The main purpose of this research study was to expand the knowledge base in the area of restorative justice and explore the impacts of restorative justice processes on participants. Many programs praise the positive effects of restorative justice and the intrinsic value of bringing the offender and victim together, arguing that something almost "magical" occurs during this encounter. Research indicates that the majority of victims and offenders are "satisfied" with the restorative justice process, but satisfaction is not an indication of the effects (psychological and physical) that the restorative justice process has on participants. The goal of this study was to examine two areas of well- 
being that contribute to an individual's overall "wellness". Undoubtedly, victims and offenders of crime are affected by the experience (i.e., the incident), and the restorative justice process purports to restore an individual's sense of security and wellness. Specifically, this study examined the effects of the restorative justice process on an individual's physical health and psychological health. In addition, social support was examined to determine if it influenced the outcomes of physical health and psychological health.

\section{Hypotheses}

There were a number of hypotheses tested.

\section{Hypotheses Related to Physical Health}

Hypothesis 1: Physical health change. It was expected that participation in restorative justice processes would produce positive changes in the participants; specifically, victims and offenders who participated in restorative justice processes would have demonstrated positive changes in their physical health (as measured by their scores on the Physical Health Checklist (PhC), which is described in the Materials Section). Participants' scores on the $\mathrm{PhC}$ were measured at preprogram (Time 1) and again at postprogram (Time 2). It was hypothesized that participants' scores would decrease from Time 1 to Time 2, evidencing fewer health problems postprogram. This hypothesis was put forth based on a review of the literature, which suggested that restorative justice processes have been found to positively affect individuals, perhaps reducing the effects of a criminal incident on both victims and offenders (Beven et al., 2005; Boney-McCoy \& Finkelhor, 1996; Bonta et al., 2002; Bonta et al., 2006; Latimer et al., 2001; Rugge et al., 2005; Strang, 2002; Umbreit, 1994; Wemmers \& Cyr, 2005). This hypothesis was 
expected because restorative justice participants were provided with a mechanism that could assist them in dealing with the negative effects of the crime, by gaining information and allowing them to be actively involved in collectively working towards a reparative plan. As a result, positive benefits to participants' physical health may result from the restorative justice process. No differences between victims and offenders were expected.

Hypothesis 2: Physical health change and satisfaction. It was hypothesized that participants who were more satisfied with the restorative justice process would have a higher degree of positive change on the $\mathrm{PhC}$ from preprogram to postprogram (as measured at postprogram) than participants who were not satisfied. Participant satisfaction were be rated on a 4-point scale $(0=$ not satisfied, $1=$ somewhat satisfied, $2=$ satisfied, $3=$ very satisfied). This satisfaction variable was also collapsed into a dichotomous variable, for the purpose of some analyses, where the participant was either "satisfied" (scores of "2" and "3") or "less satisfied" (at least about certain aspects, encompassing scores of "0" and " 1 "). Change scores from preprogram to postprogram were calculated for each participant by summing the individual items in the $\mathrm{PhC}$ to create a total score. Total scores were calculated for the $\mathrm{PhC}$ at Time 1 and Time 2. The total score at Time 2 was subtracted from the total score at Time 1 to create a change score. Positive change was indicated by a decrease in score on the PhC from Time 1 to Time 2. It was hypothesized that an individual needed to be pleased or satisfied with a service in order to derive benefits from the service. For example, if a participant was not satisfied with the restorative justice process, then it was less likely that they would receive the full benefits (i.e., improved physical health). 
Hypothesis 3a: Physical health and type of crime. It was expected that participants who experienced a "more-serious" crime (defined as a crime against the person) would have higher PhC scores at preprogram (Time 1) than participants who experienced a "less-serious" crime (defined as a non-person based crime, such as a property crime). This hypothesis stemmed from the literature that suggested that the more serious the crime, the more severe the reaction of victimization effects (Koss et al., 1991; Markesteyn, 1992; Norris et al., 1997), which, in this study, may have been evidenced by more physical health symptoms being exhibited. It was expected that these findings would also be applicable to offenders (i.e., the more serious the stressful incident (the crime), the more severe the possible physical health reactions).

Hypothesis 3b: Physical health change and type of crime. It was expected that participants who experienced a more-serious crime (i.e., person-based crime) would exhibit a greater degree of positive change in their $\mathrm{PhC}$ scores (from preprogram to postprogram) than participants who experienced less-serious crimes. The rationale for this hypothesis was that individuals who experienced a less-serious crime would likely evidence fewer problematic physical health symptoms at the preprogram stage and hence, had less opportunity for a large degree of change to occur from Time 1 to Time $2{ }^{7}$ Also, in cases of serious crime, there may have been a higher number of participant needs to address and more issues to resolve during the restorative justice process, and hence, these participants may have been in the program for a longer period of time, resulting in them

\footnotetext{
${ }^{7}$ For example, if a victim of attempted murder scores an " 8 " on the $\mathrm{PhC}$ and a victim of fraud scores a " 3 ", the first victim could improve by as much as " 8 " points, where as the second victim could only improve by a possible " 3 " points (remembering that a score of " 0 " means no physical health problems indicated).
} 
receiving more "intervention" than participants who experienced a less serious crime. Again, no differences were expected between victims and offenders.

Hypothesis 4: Physical health and social support. It was expected that participants who felt they had strong social support (as measured by the Sense of Social Support (SSS) scale; Dolbier \& Steinhardt, 2000; see Materials section) would have had lower scores on the $\mathrm{PhC}$ (indicating fewer physical health symptoms) at Time 1 (program commencement). Specifically, it was hypothesized that high scores on the SSS scale at Time 1 would be associated with low scores on the $\mathrm{PhC}$ at Time 1 . This hypothesis was based on the literature that suggested that social support acts as a buffer against the potential negative effects of stressful or traumatic events on individuals (Cohen \& Wills, 1985; Gal, 2003; McFarlane \& Yehuda, 1996; Nolen-Hoesksema \& Davis, 1999; Norris \& Kaniasty, 1996; Norris et al., 1997; Park, Cohen, \& Murch 1996; Thoits, 1995).

\section{Hypotheses Related to Psychological Health}

The next four hypotheses are almost identical to the first four hypotheses; however, these hypotheses relate to psychological health rather than physical health.

Hypothesis 5: Psychological health change. Consistent with Hypothesis 1, it was expected that participation in restorative justice processes would produce positive changes in a participant's psychological health, measured by scores on the Psychological Health Checklist (PsC; expanded upon in the Materials Section). Participants' scores on the $\mathrm{PsC}$ were measured at preprogram (Time 1) and again at postprogram (Time 2). It was hypothesized that participants' scores would decrease from Time 1 to Time 2, evidencing fewer psychological health problems at the postprogram stage. This hypothesis was based on the research that found that restorative justice processes 
produced positive psychological health benefits for many individuals (e.g., decreased fear, "feeling better", etc.; Beven et al., 2005; Boney-McCoy \& Finkelhor, 1996; Bonta et al., 2002; Latimer et al., 2001; Rugge et al., 2005; Strang, 2002; Umbreit, 1994; Wemmers \& Cyr, 2005). Therefore, consistent with past research, it was expected that the restorative justice process would result in positive benefits to participants' psychological health. The same results were expected for both victims and offenders.

Hypothesis 6: Psychological health change and satisfaction. It was hypothesized that participants who were more satisfied with the restorative justice process would have a higher degree of positive change on the $\mathrm{PsC}$ from preprogram to postprogram than participants who were less satisfied. As indicated, participant satisfaction were rated on a 4 -point scale $(0=$ not satisfied, $1=$ somewhat satisfied, $2=$ satisfied, 3 = very satisfied), but the variable was also collapsed into a 2-category dichotomous variable ( 2 and $3=$ satisfied, 0 and $1=$ less-satisfied $)$. Change scores from preprogram to postprogram were calculated for each participant by summing individual items on the $\mathrm{PsC}$, to create a total score, and then the total score at Time 2 was subtracted from the total score at Time 1 to create the change score. Again, a positive change was indicated by a decrease in score on the PsC from Time 1 to Time 2 . The premise of this hypothesis was that, again as in Hypothesis 2, the participant needed to be satisfied with the restorative justice process in order to derive benefits from the program. The same results were expected for both victims and offenders.

Hypothesis 7a: Psychological health and type of crime. Consistent with Hypothesis 3, it was expected that the type of crime would affect the number of psychological health problems that participants' indicated. Specifically, it was expected 
that participants who experienced a "more-serious" crime (i.e., crime against the person) would demonstrate higher scores on the PsC at Time 1 (Preprogram) than participants who experienced a "less-serious" crime (i.e., non-person based crime). Research (Koss et al., 1991; Markesteyn, 1992; Norris et al., 1997) supported this hypothesis, finding that, in terms of victims, victimization severity was related to degree of victimization symptoms exhibited. No differences between victims and offenders were expected.

Hypothesis 7b: Psychological health change and type of crime. It was hypothesized that participants who experienced a more-serious crime (i.e., person-based crime) would exhibit a greater degree of positive change, from preprogram to postprogram, in their PsC scores than participants who experienced less-serious crimes. The basis for this hypothesis was the same as it was for hypothesis 3 , consistent with the research (Koss et al., 1991; Markesteyn, 1992; Norris et al., 1997) that has found that individuals who experienced a less-serious crime will exhibit a less severe reaction (i.e., fewer problematic psychological health symptoms). Participants who experienced a lessserious crime (therefore, less severe reactions) were expected to have lower scores on the PsC at the preprogram stage and hence, there was less opportunity for a large degree of change to occur from preprogram to postprogram, when compared to participants who experienced a more-serious crime. The same results were expected for both victims and offenders.

Hypothesis 8: Psychological health and social support. It was hypothesized that participants who had higher levels of perceived social support would have lower scores on the $\mathrm{PsC}$ at Time 1 (preprogram). Specifically, it was hypothesized that high scores on the SSS scale at Time 1 would be associated with low scores on the PsC at Time 1. 
Again, this hypothesis was based on the literature, which suggested that individuals with strong perceived social support were less affected by traumatic or stressful events (Cohen \& Wills, 1985; Gal, 2003; McFarlane \& Yehuda, 1996; Nolen-Hoesksema \& Davis, 1999; Norris \& Kaniasty, 1996; Norris et al., 1997; Park, Cohen \& Murch 1996; Thoits, 1995). No differences were expected between victims and offenders.

\section{Additional Hypotheses Related to Social Support}

Hypothesis 9: Change in perceived social support. It was expected that participants' sense of social support would increase over time. Specifically, it was hypothesized that participants with low scores on the SSS scale would have an increase in score at postprogram. A low-SSS group and a high-SSS group was created taking the top ten and bottom SSS scores. This hypothesis was expected because the restorative justice process aims to meet the needs of clients, engage the community and assist both victims and offenders in re-integrating into the community. Hence, if a participant lacks social support, the restorative justice practitioner will attempt to engage possible support persons, or if none are available, community resources will be identified and explored. In cases where a participant does not have social support outside the restorative justice process, research has shown that they utilize the restorative justice caseworker or referred community resources (e.g., counselor, AA sponsor etc.; Rugge et al., 2005). It was expected that participants who entered the program with a strong social support network (high scores on the SSS scale) would maintain this network throughout the process and it would not likely increase or decrease substantially; therefore, no change or only slight change was expected. 
Hypothesis 10: Social support and overall health change. It was hypothesized that at program commencement, participants who had high levels of perceived social support would exhibit less change (i.e., smaller change scores) than participants who had low levels of perceived social support. Specifically, it was expected that participants who had higher scores on the SSS scale at Time 1 would have lower change scores than participants who had lower scores on the Sense of Social Support scale at Time 1. For the purposes of this hypothesis, total change scores were calculated for the $\mathrm{PhC}$ and the PsC. These two scores were then added together to make the overall health change score. This overall health change score was compared to the SSS scores, at Time 1 and Time 2. This hypothesis was based on the expectation that individuals who perceived higher levels of social support evidenced fewer problematic symptoms, and hence, there was less room for change. No differences were expected between victims and offenders.

\section{Hypotheses Related to Offender Risk Level}

Hypothesis 11: Offender risk level and satisfaction. It was expected that the risk level of the offender, as measured by the LSI-SV (Andrews \& Bonta, 1998; see Material section for further information) score for adult offenders and by the YLS/CMI:SV (Hoge \& Andrews, 2004; see Materials section for further information) score for young offenders, would be associated with the outcome of satisfaction - higher offender risk levels would be associated with lower satisfaction levels. For offenders, research has found that restorative justice processes are more effective with low-risk offenders (Bonta et al., 2006; Latimer et al., 2001; Rugge et al., 2005). Therefore, it was hypothesized that low-risk offenders would be more satisfied with the restorative justice process than medium- or high-risk offenders. 
Although the number of high-risk offenders who participate in restorative justice processes is much lower than the number of low-risk offenders, there was still the possibility that high-risk offenders may have been included in this study. It is important to note the program limitations regarding high-risk offenders and relate these limitations to this hypothesis. Higher risk offenders possess a higher number of criminogenic need areas that require intervention. Unfortunately, neither of the restorative justice programs in this study were equipped to effectively deal with all of the needs of high-risk offenders. In cases where high-risk offenders are accepted into such programs, it is possible that they are participating for less than admirable reasons (e.g., to obtain an less severe sentence) and may be skilled at deception (e.g., appearing remorseful at program intake, but the remorse is not genuine). As a result, in this study, victim satisfaction was expected to be lower in cases where the offender was high-risk, as victims may not have felt that the reparative elements had been adequately met, and that offender recidivism was still a possibility. Hence, it was expected that higher scores on the LSI-SV or the YLS/CMI:SV would be associated with lower levels of participant satisfaction (for both victims and offenders)

\section{Hypotheses Related to Restorative Justice}

Hypothesis 12: Victim-offender meeting and overall health change. It was expected that participants who experienced a victim-offender meeting (as opposed to indirect shuttle mediation) would evidence higher degrees of change, in terms of physical and psychological health, from preprogram to postprogram. Again, using a combined change score from both the $\mathrm{PhC}$ and the $\mathrm{PsC}$ (the overall health change score), it was hypothesized that participants who met each other face-to-face (i.e., the victim and 
offender from the same case) would exhibit higher overall health change scores. This hypothesis was premised on the idea that something "special" could occur within the meeting (Daly, 2002); therefore, participants who exchanged information through an indirect means would not be exposed to the "magical possibilities" (e.g., positive effects on physical and psychological health).

Hypothesis 13: Victim-offender meeting and satisfaction. It was expected that there would be no difference in satisfaction ratings between participants who experienced a victim-offender meeting and those who do not. It has been argued that a "true" restorative justice process should incorporate a face-to-face encounter and the "richness" of the process is enhanced with a meeting (Braithwaite, 2002). However, other research examining the effects of a victim-offender meeting has found no differences in satisfaction levels of participants (Rugge et al., 2005). It is likely that there is merit to Braithwaite's argument; however, research to date has not been designed to examine this. So far, participants who experience an indirect process have expressed satisfaction with the restorative justice process; however, it is possible that they do not know how much more satisfied or enriched their experience could have been with a face-to-face encounter. ${ }^{8}$ Within the programs included in this study, participants did not get to experience both options (i.e., a restorative justice process with a meeting and a process without a meeting) so they could not compare the two experiences to determine which was more satisfying. Participants could only comment on their satisfaction with the process they did experience. Past research suggests that participants express satisfaction with restorative justice processes overall, satisfaction that is not dependent on whether or

\footnotetext{
${ }^{8}$ Using a completely different analogy, a person may think they have a good relationship until they are in a new relationship, and it is only then that they realize how much better something could be.
} 
not a meeting took place. Therefore, this hypothesis stated that no difference between the two groups (meeting versus no-meeting) was expected. 


\section{Method}

\section{Participants}

The sample consisted of both adults and youths who participated in a restorative justice process. To be included in the study, adults and youth must have voluntarily agreed to participate in a restorative justice process, as well as consented to participate in the additional evaluative component. All participants within the sample participated in a restorative process between April 2004 and April 2006, and were over the age of 12 . Expectations were to have at least 50 cases, each with at least one offender and at least one victim, participate in the study during the two-year period.

Due to the small number of cases that are referred to restorative justice processes, cases were drawn from two different restorative justice programs. The first program, the Collaborative Justice Project (CJP), is a program that has been in operation in the Ottawa Courthouse since 1998. This program addresses incidents of serious crime (e.g., robbery, assault causing bodily harm, impaired driving causing death, murder, etc.). The main focus of the program is to address the harm caused and bring the affected parties together post guilty plea but before sentencing. Cases can be referred to the CJP by the Crown, defence counsel, the judge, the victim or the offender; however, the majority of cases are referred at Judicial Pre-Trials (JPTs ${ }^{9}$ ). Once a case has been referred to the CJP, three criteria must be met in order for a case to be accepted: (1) the crime must be serious in nature, (2) at least one victim must be interested in receiving assistance from the CJP, and (3) the offender must be willing to accept responsibility (i.e., usually indicated by the

\footnotetext{
${ }^{9}$ A Judicial Pre-Trial is an informal session where the Crown, defence counsel, the judge and the investigating police officer collectively discuss the case, as well as the evidence, possible resolution options, and potential trial issues.
} 
offender entering a guilty plea) and to attempt to repair the harm caused by his or her criminal behaviour. Once a case is referred to the CJP, the case is adjourned by the court and a caseworker meets with the offender to ascertain his or her appropriateness, remorsefulness, and willingness to attempt to repair the harm caused. If the offender is deemed appropriate, then the caseworker will attempt to contact the victim(s). Provided at least one victim is willing to participate in the CJP, the case will proceed. Each case has at least one victim and one offender, but in some cases there are multiple victims or multiple offenders. Caseworkers work with the participating victim(s) and the offender(s) to determine their needs and to develop a plan based on these needs. Not all cases result in a victim-offender meeting within this program, as the goal is to meet the needs of the victim(s) and the offender(s) in whatever way they dictate. Since the offender is assessed first, their willingness is usually ascertained early, but many victims prefer to have their needs met through indirect or shuttle mediation. In cases where the parties develop a resolution agreement, this agreement is submitted to the court, indicating the preferences of the parties. In the majority of cases, the judge accepts the agreement. In cases where no resolution agreement is reached, the CJP indicates their process is complete and the court process resumes.

The second restorative justice project is the Lanark County Community Justice Project (LCCJP). This project has been operating in Lanark County since July 2002. This restorative justice program deals mainly with less serious crimes and has a large number of young offenders. Cases are usually referred to the LCCJP pre-charge from the local police detachments. Once a case has been referred, program staff review the case particulars and attempt to contact all parties involved (e.g., offender(s), victim(s), 
witnesses, school officials, investigating officer, etc.). The criteria for the LCCJP are not as formal as the CJP criteria, as they will accept almost all cases that are referred to them. ${ }^{10}$ The usual LCCJP process involves a forum, or large circle, being conducted, with all members affected by the incident being present. In this program, efforts are made to involve the police and community members as well. In the case that the offender or the victim did not want to participate in a face-to-face forum, it is likely that the case would not proceed as their process revolves around the forum. Given that this program is a relatively newly developed program, it is possible that they may explore other options (e.g., victim-offender meeting as opposed to a forum), such as the CJP, in the future. If the forum is successful (i.e., a resolution plan is developed by forum participants), no charges are laid against the youth. If the case was a post-charge case, charges are usually dropped once the offender fulfills the requirements of the resolution plan.

\section{Materials}

Information Sheet and Consent Form. All research participants were provided with an Information Sheet (see Appendix A), which outlined the purpose of the project, task requirements, duration and locale of the study, potential risk and discomfort, anonymity and confidentiality safeguards, right to withdraw as well as researcher contact information. Once the study was explained to potential participants, consent was sought. If an individual agreed to participate, the Consent Form (see Appendix B) was reviewed and signed by the participant. This research study was a small component of larger governmental program evaluation. Hence, the Information Form and the Consent Form

\footnotetext{
${ }^{10}$ Formal criteria have not been necessary to date as the police tend to refer only less serious crime, using the program more as a diversion program. Program staff have been attempting to seek cases that involve more serious types of crime.
} 
were those of the larger study. This arrangement is explained in greater detail in the Procedure Section.

Preprogram Interview for victims. The Preprogram Interview for victims (see Appendix C) consisted of two main categories: the general interview and the standardized questionnaires. The general interview was a collection of questions gathering information on the following categories: (1) demographic information, (2) incident (victimization) information, (3) physical health, (4) psychological health (including fear and safety), (5) social support and relationships, and (6) restorative justice elements. Two standardized instruments were also included: (1) the Sense of Social Support scale (SSS; Dolbier \& Steinhardt, 2000) and (2) the Paulhus Deception Scale (PDS: Paulhus, 1998).

General interview. The general interview was a 87 -item questionnaire, administered by the researcher in a telephone interview. Questions in this interview were derived from a number of sources, or developed by the researcher, in consultation with restorative justice practitioners. Many of the demographic, victimization, fear and safety questions were extrapolated from the General Social Survey: Victimization (Statistics Canada, 1996). Question format included openended, Likert scale, and forced-option responses. Certain sections began with an open-ended question and were then followed up with a specific list-type question. This format ensured that the responses that first came to mind were recorded separately from direct questions that may have triggered responses. For example, regarding the effects of the incident, the respondent was asked, "how has the 
incident affected you", which was followed up with "did you experience any of the following....".

Physical health questions. A total of 18 questions were asked pertaining to physical health in the general interview. The physical health questions have been separated from the entire general interview and are included in Appendix D so that they are more easily identified. A combination of open-ended, Likert scale and forced choice questions were used. Interview questions pertained to a participant's eating habits, sleeping habits, exercise, and substance use; areas that may have been affected by the criminal incident. Once the interview concluded, an 8-item Physical Health Checklist (PhC) was completed, which provided a total score, based on the number of physical health problem areas (see Appendix E). Six of the $\mathrm{PhC}$ items were scored on a 3 -point scale $(0=$ no problem, $1=$ some problem, $2=$ major problem $)$ and two items were scored on a 2-point scale $(0=$ no problem, 1 = some problem, which was coded more as a "yes/no" item). Higher scores indicate a higher number of physical health problems. Although standardized physical health measures exist, they were too lengthy to include in the interview package, as most included numerous specific and comprehensive questions.

Psychological health questions. Thirty-three questions in the general interview pertained to psychological health. The psychological health questions have also been separated from the entire general interview and are presented in Appendix F. Again, a combination of open-ended, Likert scale and forced choice questions were used. Interview questions pertained to feelings of safety, fear, and 
various other psychological health areas that may have been affected by the criminal incident. As with physical health, the number of psychological health indicators was compiled and summed in a Psychological Health Checklist (PsC), which consisted of 17 items (see Appendix G). Higher scores indicate more psychological health problems. Nine of PsC items were scored on a 3-point scale $(0=$ no problem, $1=$ some problem, $2=$ major problem $)$ and eight items were scored on a 2 -point scale $(0=$ no problem, $1=$ some problem, again similar to a "yes/no" item). For example, there were several questions on feelings of safety, so all responses were reviewed and the researcher determined whether feelings of safety (or not feeling safe) were not a problem, somewhat of a problem, or a major problem. Again, although there exist standardized assessment instruments to measure psychological health (such as the Psychological Well Being Scale with 84 items; Ryff, 1989), all the scales located consisted of numerous questions, too lengthy to include in this research.

Two standardized scales followed the general interview: the Sense of Social Support scale (Dolbier \& Steinhardt, 2000) and the Paulhus Deception Scales (Paulhus, 1998).

Sense of Social Support (SSS) scale. The SSS scale followed the general interview component in the Preprogram Interview (Dolbier \& Steinhardt, 2000). This scale was designed to measure the quality and quantity of social support in the respondent's life. The scale consists of 21 items, where the respondent indicates how true each statement is in their life, using a 4-point Likert scale ranging from 0 (not at all true) to 3 (completely true). Six of the 21 items are 
worded negatively to control for the tendency to agree or disagree consistently with items, regardless of the item's content. Higher scores indicate higher levels of perceived social support. The psychometric properties for this scale are acceptable, with convergent validity, divergent validity and concurrent validity as well as internal consistency reliability and test-retest reliability all being evidenced (Dolbier \& Steinhardt, 2000). The SSS scale can be found in PreInterview Package presented in Appendix C.

Paulhus Deception Scales (PDS). The next standardized instrument in the Preprogram Interview is the PDS (Paulhus, 1998). This scale was included to ensure quality control, validity and integrity of the data collected from participants. This instrument assisted the researcher in determining how confident to be with the results of this research. The 40-item PDS measures an individual's tendency to give socially desirable responses, and is scored using a 5point Likert scale $($ from $1=$ Not True to $5=$ Very True). The PDS consists of two subscales: (1) the Self-Deceptive Enhancement (SDE) subscale, designed to measure an individual's tendency to give honest but inflated descriptions of himself or herself, and (2) the Impression Management (IM) subscale, which is designed to measure an individual's tendency to provide inflated self-descriptions (i.e., dishonest responses). The IM subscale is of particular interest, as the IM subscale is the one that is usually administered in test batteries as a validity check, to determine whether the respondent is purposefully self-enhancing when completing the test battery measures. The IM subscale was used in this study to measure the degree of social desirability responding on the part of participants, to 
distinguish truthful responses from responses where the participants was likely exaggerating or purposefully trying to impress the interviewer. Paulhus (1991) cites that when responses are obtained from the normal population under no pressure to engage in impression management, it is best to interpret IM scores with a substantive interpretation, viewing the scores as personality traits. In these conditions, IM scores correlated moderately with measures of conscientiousness and agreeableness, suggested that social conventionality may underlie high scores. In contexts where the respondent may feel some pressure to engage in impression management, high scores can be interpreted as "conscious distortion" (Paulhus, 1991). Scores above 12 on the IM subscale indicate that the respondent is "faking good" (i.e., trying to look better), and the interpretation is that the response is "probably invalid" (Paulhus, 1991). Scores under one are also likely invalid and indicate that the respondent is "faking bad" (i.e., trying to look worse).

As indicated, the PDS was included to measure participants' degree of socially desirable responding on the various measures (the SSS and the research interviews). The psychometric properties for this instrument are satisfactory (or better), with convergent validity, divergent validity, and concurrent validity, as well as internal consistency reliability and test-retest reliability all being reported (Paulhus, 1998). Gara, Woolfolk and Allen (2002) also examined the psychometric properties of the PDS and reported adequate levels of internal consistency reliability, and concurrent and discriminant validity. 
Preprogram Interview for offenders. The Preprogram Interview for offenders consisted of two main components: the general interview and the standardized instruments (see Appendix H). Three standardized instruments were included in this interview: a risk assessment instrument, a social support assessment instrument and a set of scales to assess deception. First, either the Level of Service Inventory - Screening Version (LSI-SV; Andrews \& Bonta, 1998) or the Youth Level of Service/Case Management Inventory - Screening Version (YLS/CMI-SV; Hoge \& Andrews, 2004) was used to assess risk level. If the offender was age 18 or over, the LSI-SV was used and if the offender was aged 17 or under, the YLS/CMI-SV was used. Next, the SSS scale (Dolbier \& Steinhardt, 2000) and the PDS (Paulhus, 1998), as previously discussed, were included.

General interview. The general interview for offenders is almost identical to the general interview for victims, except that question terminology was altered slightly to make the questions offender-appropriate and there were additional questions to allow for coding of the risk scale. There were 107 questions in total. Victimization questions were replaced with questions focusing on remorse and guilt. As with the victims, the Physical Health Checklist and the Psychological Health Checklist were scored based on the interview questions.

Level of Service Inventory - Screening Version (LSI-SV). The LSI-SV is a quantitative screening survey of attributes of offenders and their situations relevant to their risk level (Andrews \& Bonta, 1998). The LSI-SV is comprised of eight items, with the first six items being scored as "yes/no" and the last two questions being scored on a scale of " 0 " to " 3 ", where " 0 " is "very unsatisfactory" 
and "3" is "satisfactory". When calculating the total score, the first six questions are summed as zero points for a "no" score and one point for a "yes" score, whereas the last two questions receive zero points for scores of " 2 " and " 3 " and one point for scores of " 0 " and " 1 ". Total scores can range from 0 to 8 , with higher scores indicating higher risk. The LSI-SV categorizes the offender's risk into three levels: total scores ranging from 0 to 2 indicate minimum-risk (i.e., lowrisk), total scores from 3 to 5 indicate medium risk, and total scores from 6 to 8 indicate maximum-risk (i.e., high-risk). The complete scoring key, along with all other standardized instruments, are included in the Preprogram Offender Interview Package (see Appendix H). Although the LSI-SV can be used with offenders as young as 16, it will only be used with adult offenders (e.g., aged 18 and over).

The LSI-SV is based on the comprehensive 54-item Level of Service Inventory - Revised (LSI-R; Andrews \& Bonta, 1995). This well-recognized risk assessment instrument includes 10 dimensions related to risk and need factors: criminal history, education/employment, financial situation, family/marital relationships, accommodation, leisure and recreation activities, companions, alcohol and drug use, emotional/mental health, and attitudes/orientations. Offender's risk level is categorized into five levels: low, low-medium, medium, medium-high and high.

While there is less psychometric research on the properties of the LSI-SV when compared to the LSI-R, the psychometric properties of the LSI-SV appear sound. Although there is no empirical data available on test-retest or inter-rater 
reliability, internal consistency reliability has been demonstrated (Andrews \& Bonta, 1998). ${ }^{11}$ There is supportive evidence for face validity, convergent validity and predictive validity (Andrews \& Bonta, 1998). Overall, the LSI-SV has been found to have good validation, a strong correspondence to the full LSI$\mathrm{R}$, and to be an effective risk assessment instrument.

Youth Level of Service/Case Management Inventory - Screening Version (YLS/CMI:SV). The YLS/CMI-SV (Hoge \& Andrews, 2004) was used to assess risk for all young offenders, ranging from age 12 to 17 . This standardized instrument is a condensed version of the Youth Level of Service/Case Management Inventory (YLS/CMI; Hoge \& Andrews, 1994). The YLS/CMI-SV consists of six questions with a "yes/no" rating, and two questions with a " 0 " to " 3 " Likert rating (as used in the LSI-SV, though the rating scale is reversed; $0=a$ satisfactory situation, with no need for improvement to $3=$ a very unsatisfactory situation with a strong need for improvement). The total score is calculated by assigning one point for each "yes" response and one point for a "2" or "3" score for the last two questions. Total scores range from 0 to 8 , with higher scores indicating a higher risk (and a need for a more thorough assessment).

The original comprehensive YLS/CMI was based on the LSI-R, but was adapted to assess risk and need factors in youths aged 12 to 18 . Consistent with the LSI-R, the YLS/CMI consists of risk and need items, responsivity items, a professional override feature, and a direct link to levels of supervision (Hoge \& Andrews, 2002). Specifically, the comprehensive YLS/CMI consists of 42 items,

${ }^{11}$ Andrews and Bonta (1998) argue that the low alpha values are likely due to, first, the low number of items (8) in the scale, and second, the distinctiveness of the components included. 
based on eight categories: Prior and Current Offences/Dispositions, Family Circumstances/Parenting, Education/Employment, Peer Relations, Substance Abuse, Leisure/Recreation, Personality/Behaviour, and Attitudes/Orientation. An overall risk level (low, medium, high or very high) is produced by a summation of the subscale scores. Overall, the psychometric properties of the YLS/CMI are acceptable, as outlined in the instrument manual (Hoge \& Andrews, 2002) and reported by Jung and Rawana (1999) and Schmidt, Hoge and Gomes (2005).

The YLS/CMI:SV was developed as an initial screening tool (Hoge \& Andrews, 2004) and initial testing, along with data from a recent study (van de Ven, 2004), showed that respondents were easily able to score the majority of items included in this instrument, suggesting that this is an effective screening tool for risk/need assessment. As the YLS/CMI:SV is a relatively new screening tool, there has been less research conducted on its psychometric properties when compared to the YLS/CMI; however, preliminary data to date is promising. van de Ven (2004) conducted a comprehensive examination of the scale's psychometric properties, with a sample of 750 young people who were in conflict with the law, and found the psychometric properties were sound, reporting adequate levels of internal consistency, inter-rater reliability, as well as demonstrating that scale had construct validity (van de Ven, 2004). Postprogram Interview for victims. The Postprogram Interview contained the same questions as the Preprogram Interview; however, additional questions were incorporated pertaining to satisfaction, program outcome, and the type of reparation activities that were completed by the offender. The two standardized questionnaires were 
also repeated, to determine whether change had occurred since the participants began the program. A satisfaction question in the interview was rated on a 4-point scale $(0=n o t$ satisfied, $1=$ somewhat satisfied, $2=$ completed satisfied, 3 = very satisfied). The Victim Postprogram Interview Package can be found in Appendix I.

Postprogram Interview for offenders. As with the victims, the Postprogram Interview contained the same questions as the Preprogram Offender Interview and additional questions were added pertaining to satisfaction, program outcome, and the type of reparation activities that were completed. The risk assessment instrument (either the LSI-SV or YLS/CMI:SV) was not included in the post-interview (as risk was only assessed once, at program intake), though the SSS and the PDS were included. The scoring for program outcome and satisfaction variables were the same for offenders as it was for victims. The Offender Postprogram Interview Package can be found in Appendix $\mathrm{J}$.

Debriefing Form. All research participants received a Debriefing Form at the completion of their participation in the restorative justice process. Program facilitators distributed the form, and researchers followed up with participants at the time of the postprogram interview, which was conducted over the telephone. Once the interview was complete, the interviewer verbally debriefed the participant, reviewing and answering any questions about the form. If problems arose after the research was complete, participants could contact the researchers through their contact information (no problems arose). Special support and safety mechanisms were put in place in the event that an interview with a participant did not go well. For example, a wrap-around process was incorporated, so that program staff knew when researchers were planning to contact a participant for an 
interview, and they were informed after the interview had taken place, so they could follow up with the participant. The Debriefing Form (see Appendix K) thanked the participants and revisited the information outlined in the Information Sheet.

\section{Procedure}

Consultation and development period. The development period of this research began with a thorough review of the literature pertaining to restorative justice, physical health, psychological health and social supports. Brainstorming sessions were also held with a number of academic colleagues and researchers in the area of restorative justice. Interviews were conducted with practitioners and facilitators of restorative justice programs within Canada. Although there were numerous potential areas of study identified, ${ }^{12}$ the tension between research, academic goals and practical reality of program limitations, as well as the restrictions and concerns of practitioners and facilitators were recognized. As a result, although there were several additional areas that could have been explored, this study focused primarily on the effects of restorative justice on participant physical and psychological health. This study aimed to explore an area that had not yet been explored in the context of restorative justice.

In terms of data collection from participants, the goal was to ensure that the entire interview could be administered within 30 minutes. Initial participant interviews with program staff (non-research related) were already quite lengthy, so it was recognized that

\footnotetext{
${ }^{12}$ For example, it would have been interesting to include questions examining perceptions and attitudes about the criminal justice system (the police, the courts, the correctional system, the parole system, etc.) in the preprogram interview, and then examining those same questions postprogram to determine whether a positive restorative justice program would influence opinions. However, since opinions about the criminal justice system, as important as they are, were not directly related to physical health or personal wellbeing, the decision was made not to examine this area in the current study.
} 
the additional time requested would have to be reasonable if clients were going to agree to participate.

A research partnership. Restorative justice programs in the Ottawa area are few. There were two programs that existed, but the funders of the programs were already conducting evaluations. As a result, the funders/researchers were approached to determine whether a partnership could be formed. In January 2004, the researcher approached the Corrections Research Unit of Public Safety and Emergency Preparedness Canada (PSEPC) as well as the two restorative justice programs, in an effort to seek permission for this study to be incorporated into the two PSEPC program evaluations. After negotiation, both PSEPC and the restorative justice programs themselves granted permission for the research to be included in the various PSEPC program evaluation Interview Packages. Therefore, this research study was included under the umbrella of a larger program evaluation being conducted by PSEPC.

Approximately 50 questions in total were added to the PSEPC Interview Packages, but data from approximately 75 questions were used in this study. For example, questions on demographics, victimization, reparation, outcome and satisfaction already existed in the PSEPC program evaluation interviews. After extensive review and negotiation, PSEPC researchers and program staff approved the questions that were posed for the purposes of this study. The most common changes included additional questions being added (more thorough and specific questions) and a change of terminology and wording of certain questions.

Program facilitators from both CJP and the LCCJP agreed to participate in this study, as they felt the focus of the research would be useful to them and to the restorative 
justice research field. There was concern about the length of the interviews, and the format that program participants would prefer. To ensure the procedure was a viable one, a pilot period of data collection took place between April 2004 and October 2004. Information and training sessions were provided to all program staff and facilitators to review the interview questions and address any concerns that were raised. Due to confidentiality and the nature of the serious crimes, program staff introduced the evaluation to participants, and sought their consent for researchers to contact them. Facilitators were provided with a formal script and a list of potential questions and answers to assist facilitators when they introduced the evaluation.

Facilitators introduced the evaluation to all clients, and read the Information Sheet and the Consent Form to the clients during the initial meeting. Researchers were available for questions. Researchers consulted with the facilitators throughout the process, and any new facilitators are contacted and trained in the evaluation procedure.

Pilot period of data collection. In order to test the expanded questionnaires, specifically to record participant reaction to the new questions, as well as determine whether the length of the interviews had become too onerous, the decision was made to have a pilot period for data collection. The pilot data collection phase, which began in April 2004, went slowly, but very well. Clients were asked if they would prefer face-toface interviews and the majority stated that they preferred that interviews be conducted over the telephone, as it was less time consuming and more flexible. Although the length of the interviews was a concern of researchers and program staff, it did not result in participants declining. Participants were told that the interviews were about an hour, and in rare cases, the interview was conducted over two telephone calls. In addition, some 
questions were re-worded based on participant feedback. Participants were also asked if they would grant permission for the victim-offender meeting to be videotaped. It was hoped that all victim-offender meetings, or circles, could be observed via these videotapes; however, there was not one case where all participants granted permission. As a result, the observation of the victim-offender meeting was not possible. Full data collection began in October 2004. Fortunately, the changes made within the data collection period were not major (i.e., mostly small wording changes or added clarification), and therefore the data collected during that time period could be included in this study. The Interview Packages that are presented in the Appendices incorporated all of the changes that were recommended by participants, program staff and other research staff.

\section{Process}

At the commencement of every new case into the restorative justice program, each offender and victim, who agreed to participate in the restorative justice process, was asked by the facilitator for his or her voluntary participation in the research study. Typically, the program facilitator made first contact with a potential program participant over the phone. The program particulars were explained, and if the individual was interested in learning more about the program, a meeting was arranged. Once the client agreed to participate in the restorative justice program, the facilitator introduced the research.

Facilitators explained the purpose of the study, and provided participants with the Information Sheet. If the participant agreed to participate, he or she signed the Consent Form. If the participant had questions about the research, he or she was provided with a 
phone number to contact the researcher, or the researcher was informed that a potential participant had questions, and the researcher contacted the potential participant (if permission for contact was obtained by the facilitator). Clients were assured of confidentiality, specifically regarding their facilitator - none of the information shared with researchers would be shared with any program staff. Also, once the information was received, all identifying information was transformed into descriptive group information. None of the information was linked to participants directly.

Once consent was obtained, the facilitator notified researchers and researchers made contact to schedule an interview. Researchers conducted the interview, asking the questions that were included in the questionnaire package and recorded the responses. The interview took approximately 45 to 60 minutes to complete, depending on the length of the participant's responses. The facilitator was notified as to when the interview would take place and was always advised once it was completed, a procedure developed with facilitators to address safety concerns. Although no information was shared, facilitators followed up with the clients to debrief the interview, as required.

A restorative justice process could take weeks or months, depending on the design of the restorative justice program in question, the seriousness of the crime, the extent of the harm caused to the victim, and potential delays or conflicts with the traditional court system. As a result, there was no expectation that the period of time between interviews would be consistent across participants. However, the study was designed for interviews to be conducted preprogram and postprogram, regardless of the length in between. Facilitators were asked to inform researchers once the case was considered "closed" for the purposes of program, so that researchers could conduct the postprogram interview 
with the clients. A closed case typically meant that sentencing had occurred (or charges were withdrawn) and there was no more expected contact with the clients. The postprogram interview took approximately 30 to 45 minutes to complete. Although the original intention was to conduct postprogram interviews in person, due to feedback received during the pilot period over scheduling and participant preferences, the procedure was changed and all postprogram interviews were completed over the telephone. If a client specifically requested an in-person interview, researchers would have certainly agreed to the request, but this was never the case.

Within the PSEPC research protocol, a file review and a Case Completion Interview with the facilitator took place once the case was closed. Researchers met with the case facilitator to conduct the interview, which took approximately 20 minutes. This documentation was available from PSEPC if additional case information or clarification was required.

\section{Interrater Reliability Process}

In order to assess interrater reliability, once an interview was completed, a second rater reviewed the interview form and completed the checklists based on the information provided in the interview. Given that the checklists were a significant component of this research, ensuring interrater reliability on them was the priority. All checklists (a total of 368 checklists: 4 per participant, 92 participants) were double-checked and included in the interrater analyses.

It was possible that one of four different researchers conducted the interviews, partly due to turn-over in PSEPC staff, and partly because interviews could take place at short notice, any time of the day. All researchers were employed by PSEPC and were 
working on the larger PSEPC evaluation. One researcher was the author of this study, the second was a graduate student, the third had recently completed her M.A., and the third possessed a B. A. in Law, but had experience in psychology. All had extensive interviewing experience with offenders and victims. Because there were four researchers conducting interviews, all checklists were subjected to interrater procedures.

Interrater reliability was examined through the use of percentage agreement on all checklists completed. There were explicit rules on how to code the two checklists; therefore, high interrater reliability was expected. In total, 368 checklists ( 92 participants $\mathrm{x} 4$ checklists), consisting of 4,600 items, were subjected to interrater procedures. As expected, interrater agreement was $99.9 \%$. Of the 4,600 items subjected, only 4 items were scored differently. The four items consisted of: (1) a difference of 1 point on an offender's preprogram PsC item anger, (2) a difference of 1 point on two victim's preprogram PhC item alcohol use, and (3) a difference of 1 point on an offender's postprogram $\mathrm{PhC}$ item alcohol use. Three of the four items under disagreement had to do with alcohol consumption, and what constitutes "some" problem.

\section{Absence of a Control Group}

There is no formal control group included in this study. The typical control group would consist of individuals who experienced the traditional criminal justice system rather than a restorative justice process, allowing for comparisons to be made across the two groups. The current study was designed to examine participant changes that are based within the restorative justice philosophy. The comparisons that are important therefore are those within a restorative justice process (e.g., full restorative justice 
service, some restorative justice service, little restorative justice service), rather than a comparison to a non-restorative justice process.

Drawing the Sample from Two Programs

While there may have been some concern over including two different programs in this study, and combining victims and offenders together for the purposes of this research, experience, as well as discussion with program staff, participants, and fellow researchers, suggests that many of the issues in restorative justice processes are similar. Both programs approached restorative justice in a different way, but the main restorative goals of the two programs were the same. While victims and offenders are inherently different, they share many of the same issues and concerns within the restorative justice context. 


\section{Results}

\section{Assessing Significance}

A number of analyses were used to examine the data from this quasiexperimental, repeated-measures design. Comparisons were conducted between victim and offender groups, the two program groups, as well as between groups of individuals who receive different levels of restorative justice services (e.g., victim-offender meeting versus no meeting).

All statistical analyses were conducted using the statistical software program SPSS (Statistical Package for the Social Sciences, version 13). All missing data was verified or corrected by reviewing research documentation, program case files, or by contacting program staff. The assumptions of each statistical test were reviewed and met, and an alpha level of .05 was used unless otherwise indicated. Two potential covariates were examined, the PDS IM subscale score at the preprogram stage and risk level score of offender. A series of chi-square analyses were used to analyze differences between groups for categorical variables (gamma was used in cases where the cell count was less than 5), whereas t-test analyses were used to compare means between groups for continuous variables. Pearson correlation coefficients were generated to examine relationships between variables. In cases where multiple tests were conducted, a bonferroni correction procedure was employed to reduce the possibility of error (where the alpha level of .05 was divided by the number of tests conducted). An analysis of variance using repeated measures were used to assess differences over time.

Although statistical significance testing is certainly important, this was not the only approach considered when examining the results of this study. It is sometimes 
difficult to obtain large sample sizes in field research, and this is especially the case in restorative justice research. Unfortunately, studies with small samples can lack sufficient statistical power to detect significant differences. In cases of small samples, it has been argued that a nonsignificant result does not necessarily mean that there was no effect and that effect sizes can provide useful information to assess the magnitude of the relationship (Gendreau, 2001).

Effect sizes can inform as to whether nonsignificant findings should be further explored. Reporting effect sizes also allows the results to be placed in the context of current research, assists in guiding researchers formulating future research, and is useful in facilitating future meta-analyses (APA, 2003; Gendreau, 2001). Given the strong case for effect size reporting, effect sizes were examined where appropriate, using Cohen's (1992) conventions. The conventions used for correlations were as follows: small effect = .10 , medium effect $=.30$, and large effect $=.50$. To examine the magnitude of the multivariate tests for ANOVA and MANOVA, the effect size conventions for examining eta squared were as follows: small effect $=.02$, medium effect $=.13$, and large effect $=$ .30 (Cohen, 1992). For univariate tests, the conventions used were: small effect $=.01$, medium effect $=.06$, and large effect $=.30($ Cohen, 1992) .

Next, arguments have also been made regarding the usefulness of reporting confidence intervals (CIs; Gendreau, 2001). If a 95\% CI includes the value of zero, this indicates that the finding is no more likely that chance itself. CIs will not be reported on every variable examined, but where it is appropriate to do so. Although CIs are a useful estimate of uncertainty about the magnitude of an effect, wide or large CIs warn that more research (e.g., a meta-analysis) is needed. 
Lastly, there is the issue of assessing reliable change. Researchers traditionally compare groups by examining the difference in mean scores. There are various statistical methods to examine scores before and after a treatment intervention, to determine whether change is a sampling artifact, a chance finding or a reliable and clinically significant change. Various methods of determining reliable change (RC) and reliable and clinically significant change (RCSC) have been examined in the literature (Atkins, Bedics, McGlinchey, \& Beauchine, 2005; Jacobson \& Truax, 1991; Evans, Margison, \& Barkham, 1998). RC is whether an individual has changed sufficiently that the change is unlikely due to simple measurement unreliability (Evan et al., 1998). RCSC is the change that compares treatment scores of the "problematic" population to scores from the "normal" population. Unfortunately, the measures used in the current study have not been normed in "normal" samples; therefore, RCSC statistics could not be computed. Furthermore, RC statistics cannot be calculated on the two checklists as there are no established reliability statistics, and this study did not set forth to establish reliability estimates for the measures used. This is a useful endeavour for future studies of this nature.

Therefore, in addition to the standard significance testing using $p$ values, where appropriate, these additional means of examining significance (i.e., effect sizes and CIs) are reported.

\section{Sample Descriptives}

Ninety-two participants (50 victims and 42 offenders) were included in the total sample, with 58 participants ( 32 victims and 26 offenders) from the CJP and 34 participants ( 18 victims and 16 offenders) from the LCCJP. Of the 42 offenders, 22 were 
young offenders (YOs), with 14 coming from the LCCJP and eight from the CJP. The total sample consisted of more males $(72.8 \%, n=67)$ than females $(27.2 \%, n=25)$, and this was consistent across the two programs. The age of participants ranged from 13 years to 65 years of age, with the average age being 30.27 years $(S D=15.01)$. There was no significant difference on age between the two programs; however, there was a significant difference in average age between victims and offenders with the majority of victims being in their late thirties and the majority of offenders being under twenty years of age $(M=39.2, S D=6.5$, and $M=19.7, S D=14.4$, respectively; $t(90)=-8.60, p<$ 001). The majority of participants were employed (47.8\%) or in school full-time $(34.8 \%)$. Given that there were a large number of students (YOs) in the sample, it was not surprising that $39.1 \%$ of the sample had less than a grade 12 level of education. Examining victims and offenders separately, there were significant differences between victims and offenders on level of education and employment. Significantly more victims were employed $(70.0 \%)$ when compared to offenders $\left(21 \% ; \chi^{2}(2, N=92)=23.09, p<\right.$ $.001)$ and victims also had a significantly higher level of education $\left(\chi^{2}(2, N=92)\right.$, gamma $=.892, p<.001)$. Almost all $(96.7 \%)$ of the participants were Caucasian. Table 1 outlines the personal-demographic information of the participants in greater detail.

Seventy-one percent (70.7\%) of participants participated in a victim-offender meeting, a circle or a forum ${ }^{13}$. All participants in the LCCJP participated in a meeting, compared to $53.4 \%(n=31)$ of CJP participants. In cases where there was no victimoffender meeting, it was because the victim was not interested in meeting with the

\footnotetext{
${ }^{13}$ As one may recall, all three forms of the "meeting" (i.e., victim-offender meeting, circle or forum) involved the victim(s) and the offender(s), but vary in terms of the number and type of other participants involved (hence it being called either a victim-offender meeting, a circle or a forum). From this point forward, any form of victim-offender meeting will be referred to as the "meeting".
} 
Table 1

Personal-Demographic Characteristics of Victims, Offenders and Total Sample

\begin{tabular}{|c|c|c|c|c|c|c|}
\hline \multirow{2}{*}{ Characteristic } & & \multirow{2}{*}{$\begin{array}{l}\text { Victims } \\
n=50\end{array}$} & \multirow{2}{*}{$\begin{array}{c}\text { Offenders } \\
n=42\end{array}$} & \multirow{2}{*}{$\begin{array}{l}\text { Total } \\
N=92\end{array}$} & \multicolumn{2}{|c|}{$t / \chi^{2}$} \\
\hline & & & & & Group & Program \\
\hline & & & $\%(n)$ & & & \\
\hline \multirow[t]{5}{*}{ Age: } & Under 18 & 8.0 & $45.2(19)$ & $25.0(23)$ & $* * *$ & $* * *$ \\
\hline & $18-29$ & $16.0 \quad(8)$ & $47.6(20)$ & $30.4(28)$ & & \\
\hline & $30-39$ & $20.0(10)$ & $4.8 \quad(2)$ & $13.0(12)$ & & \\
\hline & $40-49$ & $30.0(15)$ & 2.4 & $17.4(16)$ & & \\
\hline & 50 and over & $26.0(13)$ & $0.0 \quad(0)$ & $14.1(13)$ & & \\
\hline \multirow[t]{2}{*}{ Offender Status: } & Adult & - & $47.6(20)$ & $47.6(20)$ & & $* * *$ \\
\hline & Youth & - & $52.4(22)$ & $52.4(22)$ & & \\
\hline \multirow[t]{2}{*}{ Gender: } & Male & $66.0(33)$ & $81.0(34)$ & $72.8(67)$ & & \\
\hline & Female & $34.0(17)$ & $19.0 \quad(8)$ & $27.2(25)$ & & \\
\hline \multirow[t]{4}{*}{ Race: } & Caucasian & $100.0(50)$ & $92.9(39)$ & $96.7(89)$ & & \\
\hline & Aboriginal & $0.0 \quad(0)$ & 2.4 & 1.1 & & \\
\hline & Black & $0.0 \quad(0)$ & $2.4 \quad(1)$ & 1.1 & & \\
\hline & Other & $0.0 \quad(0)$ & 2.4 & $1.1(1)$ & & \\
\hline \multirow[t]{3}{*}{ Education: } & Less than grade 12 & $10.0(5)$ & $73.8(31)$ & $39.1(36)$ & $* * *$ & \\
\hline & High School Diploma & $8.0 \quad(4)$ & 7.1 (3) & $7.6(7)$ & & \\
\hline & College/University & $82.0(41)$ & $19.0(8)$ & $53.3(49)$ & & \\
\hline \multirow[t]{3}{*}{ Employment: } & Student & $16.0 \quad(8)$ & $57.1(24)$ & $34.8(32)$ & $* *$ & \\
\hline & Employed & $70.0(35)$ & $21.4 \quad(9)$ & $47.8(44)$ & & \\
\hline & Homemaker/Ret/Oth & $14.0(7)$ & $21.4 \quad(9)$ & $17.4(16)$ & & \\
\hline \multirow[t]{3}{*}{ Marital Status: } & Single & $26.0(13)$ & $90.5(38)$ & $55.4(51)$ & $* * *$ & \\
\hline & Married/CLaw & $64.0(32)$ & $7.2(3)$ & $38.0(35)$ & & \\
\hline & Separ'd/Div/Widow & 10.0 & $2.4(1)$ & $6.5(6)$ & & \\
\hline
\end{tabular}

$* * * p<.001, * * p<.01,{ }^{*} p<.05$ 
offender, but was interested in pursuing non-meeting restorative options (e.g., receiving a letter of apology, or indirect communication through the caseworker).

Because offenders were included from two different programs, they were compared on gender, age, risk level and offence type. These results can be found in Table 2. Overall, $50.0 \%$ of offenders $(n=21)$ were found to be low-risk, as measured by either the LSI-SV or the YLS/CMI-SV. The CJP had more moderate-risk offenders (10 versus 8 offenders), and was the only program to have any high-risk offenders $(n=3)$. This result is not surprising given that the CJP is a program that deals with more serious crimes. Although the offender risk breakdown varied across programs, the differences were not statistically significant. There was also no difference on whether an offender had previous convictions or on type of index offence $\left(\chi^{2}(3, N=42)\right.$, gamma $=.51, p=$ .07). However, although not a significant difference, the CJP sample consisted of more crimes against the person (80.8\%) than the LCCJP sample (50.0\%). Furthermore, the person-based crimes in the CJP were more serious than the person-based crimes in the LCCJP. In the CJP, crimes against the person included crimes of robbery and serious assaults causing bodily harm, whereas in the LCCJP, crimes against the person category consisted solely of common assaults.

\section{Program Characteristics}

The two programs were similar in that they were both restorative justice programs. Participants in both programs had the opportunity to engage in the restorative justice process, communicate with each other, and be actively involved in developing a 
Table 2

Type of Index Offence, Disposition and Offender Risk Level Characteristics

\begin{tabular}{|c|c|c|c|c|}
\hline Characteristic & & $\begin{array}{r}\mathrm{CJP} \\
n=26\end{array}$ & $\begin{array}{c}\text { LCCJP } \\
n=16\end{array}$ & $\begin{array}{l}\text { Total } \\
N=42\end{array}$ \\
\hline & & & $\%(n)$ & \\
\hline \multirow{4}{*}{$\begin{array}{l}\text { Type of Index } \\
\text { Offence: }\end{array}$} & Person & $80.8(21)$ & $50.0(8)$ & $69.0(29)$ \\
\hline & Property & 11.5 & $43.8(7)$ & $23.8(10)$ \\
\hline & Morals & $0.0 \quad(0)$ & $6.3(1)$ & $2.4(1)$ \\
\hline & Driving & $7.7(2)$ & $0.0(0)$ & $4.8 \quad(2)$ \\
\hline \multirow{8}{*}{$\begin{array}{l}\text { Most Serious Index } \\
\text { Offence: }\end{array}$} & Robbery & $15.4(4)$ & $0.0(0)$ & $9.5(4)$ \\
\hline & Assault CBH/Weapon/Aggravated & $30.8(8)$ & $0.0(0)$ & $19.0(8)$ \\
\hline & Uttering threats & $7.7(2)$ & $0.0(0)$ & $4.8(2)$ \\
\hline & Assault & $15.4(4)$ & $43.8(7)$ & $26.2(11)$ \\
\hline & $\begin{array}{l}\text { Impaired/Dangerous Driving/ } \\
\text { CBH/Death }\end{array}$ & $7.7(2)$ & $0.0 \quad(0)$ & $4.8 \quad(2)$ \\
\hline & Property w Violence (Person) & $11.5(3)$ & $6.3(1)$ & 9.5 (4) \\
\hline & Property & $11.5(3)$ & $43.8 \quad(7)$ & $23.8(10)$ \\
\hline & Other & $0.0(0)$ & $6.3(1)$ & $2.4(1)$ \\
\hline \multirow[t]{8}{*}{ Disposition*: } & Custody & $0.0(0)$ & $0.0 \quad(0)$ & $0.0 \quad(0)$ \\
\hline & Conditional Sentence & $34.6(9)$ & $0.0 \quad(0)$ & 21.4 \\
\hline & Suspended Sentence & $11.5(3)$ & $0.0 \quad(0)$ & 7.1 (3) \\
\hline & Probation & $50.0(13)$ & $0.0 \quad(0)$ & $31.0(13)$ \\
\hline & Fine/Restitution & $19.2 \quad(5)$ & $0.0 \quad(0)$ & 11.9 (5) \\
\hline & Community Service & $30.8 \quad(8)$ & $31.3 \quad(5)$ & $31.0(13)$ \\
\hline & Withdrawn & $38.5(10)$ & $62.5(10)$ & $47.6(20)$ \\
\hline & Pending/Unknown & $3.8(1)$ & 25.0 & 11.9 \\
\hline \multirow[t]{3}{*}{ LSI Risk Level: } & Low $(0-2)$ & $50.0(13)$ & $50.0 \quad(8)$ & $50.0(21)$ \\
\hline & Moderate $(3-5)$ & $38.5(10)$ & $50.0 \quad(8)$ & $42.9(18)$ \\
\hline & $\operatorname{High}(6-8)$ & 11.5 & $0.0(0)$ & 7.1 (3) \\
\hline Previous Convictions & & $7.7(2)$ & $0.0 \quad(0)$ & 4.8 \\
\hline
\end{tabular}

Note. *Categories are not mutually exclusive. 
reparation plan in an attempt to repair harm caused. However, despite the similarities, the programs also differed on some aspects. First, as indicated above, the LCCJP dealt with less serious crimes, whereas the CJP dealt with more serious crimes (as can be seen in Table 2). Second, the average time in the program differed, with the duration of the CJP $(M=114.64$ days, $S D=71.34)$ being longer than the LCCJP $(M=85.29$ days, $S D=$ $57.74)$, though this difference was not statistically significant $(t(84)=1.90, p=.06)$.

Overall (i.e., for both programs combined), the average time from starting the program to last contact was 105 days $(M=105.08, S D=68.32)$, with a range from 13 days to 338 days. It was expected that the time in program would differ across programs, because the CJP, dealing with serious crimes, would likely spend more time working with the victim(s) and the offender(s), preparing them for the victim-offender meeting. On the other hand, the LCCJP attempted to bring all parties together as soon as possible after the referral, something that may be unwise if the cases were more serious, as preparation time may be needed.

There is often a long delay from the offence date to the time when the case comes to court, or is referred to a restorative justice program. While this was the case for the CJP (as the serious cases were usually referred to the program from the courts), this was not the case for the LCCJP. In the small community where the LCCJP operated, program staff worked closely with the police, and often cases were referred pre-charge, shortly after the offence occurred. The number of days from offence date to program start date averaged 40 days $(M=40.13, S D=24.55)$ for the LCCJP and 198 days $(M=197.81, S D$ $=102.90)$ for the CJP, a significant difference $(t(32)=7.18, p<.001 ; 95 \% C I=82.19$ 233.18). 


\section{Data Integrity}

$P D S$. The PDS was included in the interviews to increase the integrity of the data collected. The impression management (IM) subscale of the PDS measures the degree of social desirable responding on the part of participants. Under normal conditions (i.e., low-demand situations), high scores can be interpreted as personality traits of the individual and a need to adhere to social conventionality; however, in cases where the respondent is trying to impress (i.e., high-demand situations), high scores can be interpreted as "conscious distortion" and may cause the researcher to question the validity of other responses provided by the participants (Paulhus, 1991). Scores above 12 or below one on the IM subscale should be interpreted as "probably invalid" (Paulhus, 1991).

Unfortunately, inclusion of the PDS into the interview packages took some time, due to concerns from program staff. As a result, PDS data was only available on 70 participants (40 victims, 30 offenders) at the preprogram stage and 71 participants (40 victims, 31 offenders) at the postprogram stage. The percentage of participants who gave responses that were "probably invalid" is listed in Table 3 below. Note that no participants scored under one on the IM subscale, therefore only scores above 12 are presented in the table.

A chi-square analyses revealed no significant differences between victims $(M=$ 9.24, $S D=3.46)$ and offenders $(M=9.56, S D=3.52)$ at preprogram, postprogram (victims: $M=8.40, S D=3.55$, offenders: $M=8.03, S D=3.36$ ) or between programs (CJP preprogram: $M=10.00, S D=3.36$; CPJ postprogram: $M=8.31, S D=3.23$; LCCJ preprogram: $M=8.72, S D=3.51$; LCCJP postprogram: $M=8.17, S D=3.72$ ) on the 
Table 3

Percentage of Cases "Probably Invalid" by Group and Time

\begin{tabular}{lccc}
\hline & $\begin{array}{c}\text { Victims } \\
(n=40)\end{array}$ & $\begin{array}{c}\text { Offenders } \\
\left(n=30,31^{*}\right)\end{array}$ & $\begin{array}{c}\text { Total } \\
\left(N=70,71^{*}\right)\end{array}$ \\
\hline IM score $>12 @$ Preprogram & $17.5(7)$ & $30.0(9)$ & $22.9(16)$ \\
IM score $>12 @$ Postprogram & $15.0(6)$ & $6.5(2)$ & $11.3(8)$ \\
\hline
\end{tabular}

Note. *In the case of one offender, there was no IM score for Time 1. 
on the IM subscale score. There were, however, significant differences on participant IM subscale scores from preprogram to postprogram, with higher scores being evidenced at the preprogram stage (preprogram: $M=9.37, S D=3.47$; postprogram: $M=8.24, S D=$ $\left.3.45 ; F(1,68)=7.24, p<.01, \eta^{2}=.10\right)$.

IM scores were examined as to their relationship to the physical health checklist (PhC) total score, the psychological health checklist (PsC) total score, Sense of Social Support (SSS) scale total score, and offender risk level score. These results are presented in Table 4. IM scores were significantly correlated with each other (pre and post) but not with any of the other measures, with the exception of the post-IM score being moderately correlated with the $\mathrm{PhC}$ total score at preprogram $(r=.26, p<.05)$.

Because $\mathrm{PhC}$ scores were negatively skewed and did not adhere to a normal distribution, they were collapsed into a categorical variable with three categories [no problems ( $\mathrm{PhC}$ scores of 0 ), some problems ( $\mathrm{PhC}$ scores of 1-3), and several problems (PhC scores of 4 or more)] and the association was tested again. The association between the IM score at postprogram and the PhC total score, with collapsed categories, at preprogram remained significant at the alpha .05 level $(r=.24, p<.05)$.

Given that the IM score was only significantly related to the $\mathrm{PhC}$ score, a decision had to be made as to whether the IM score should be used as covariate in additional analyses. This decision making process took a number of things into consideration. First, there was some debate as to whether the PDS should have been included in the interview. This debate centered on whether the interview process was a high-demand situation (i.e., one where there would be a need to impress) or a low-demand situation 
Table 4

Correlations Between IM Scores, PsH Checklist Scores, and the SSS Scale Scores

\begin{tabular}{lcccccccc}
\hline & Pre-IM & Post-IM & Pre-PhC & Post-PhC & Pre-PsC & Post-PsC & Pre-SSS & Post-SSS \\
\hline Pre-IM & 1.00 & & & & & & \\
Post-IM & $.55^{* * *}$ & 1.00 & & & & & & \\
Pre-PhC & .14 & $.26 *$ & 1.00 & & & & & \\
Post-PhC & .15 & -.01 & $.50^{* * *}$ & 1.00 & & & & \\
Pre-PsC & .09 & .01 & $.49 * * *$ & $.24 *$ & 1.00 & & & \\
Post-PsC & .20 & -.10 & $.43^{* * *}$ & $.33^{* *}$ & $.71 * * *$ & 1.00 & & \\
Pre-SSS & .15 & .21 & -.11 & .01 & -.09 & -.09 & 1.00 & \\
Post-SSS & -.02 & .09 & $-.22^{*}$ & -.10 & -.03 & -.11 & $.66^{* * *}$ & 1.00 \\
\hline Risk Score & -.17 & -.22 & .15 & .03 & $.31^{* *}$ & $.43^{* * *}$ & -.15 & -.12 \\
\hline
\end{tabular}

$* * * p<.001, * * p<.01,{ }^{*} p<.05$

Note. $\mathrm{IM}=$ Impression Management subscale score $\mathrm{PhC}=$ physical health checklist total score PsC = psychological health checklist total score; SSS = Sense of Social Support scale total score.

The $N$ varies across measures. Pre-IM: $N=70$, Post-IM: $N=71$, Pre-PhC: $N=92$, Post-PhC: $N=92$, Pre-PsC: $N=$ 92, Post-PsC: $N=$ 92, Pre-SSS: $N=$ 92, Post-SSS: $N=$ 92, Risk Score: $N=60$. 
(i.e., responses are not given to impress but rather reflect temperament and adherence to social conventions) ${ }^{14}$. Second, the IM score was only significantly correlated (and at only one time interval) with one of the six other measures ( 3 measures, 2 time intervals). The final decision was to run all analyses twice, once with the IM score at preprogram included as a covariate, and again without adding the covariate. However, when it came to running the analyses with the $\mathrm{IM}$ score as a covariate, things got more complicated as one of the assumptions (the assumption of homogeneity of regression slopes) was violated, thereby questioning the appropriateness of using the covariate

Therefore, given the fact that the covariate IM was only significantly correlated with one of the six dependent variables (preprogram physical health), and that the assumption of homogeneity of regression slopes was violated for one of the six dependent variables, any analyses including the covariate should be interpreted with caution. Therefore, the analyses presented below did not include the covariate. ${ }^{15}$

Offender risk level score. Offender risk level was examined to determine whether it should be used as a covariate in the various statistical procedures. Risk score was significantly correlated with only two of the measures (PsC score at pre- and postprogram, $r=.31, p<.01$ and $r=.43, p<.001$, respectively). When testing the assumptions to ensure that risk score would be an appropriate covariate, the univariate analysis testing the assumption of homogeneity of regression slopes revealed this assumption was violated, and therefore risk score was not used as a covariate.

\footnotetext{
14 This debate will be further explored in the discussion section.

${ }^{15}$ The analyses were conducted again using the covariate and the results can be found in Appendix L.
} 
Physical Health, Psychological Health and Sense of Social Support

As Table 4 illustrates, preprogram scores on both checklists, and the SSS scale, were strongly associated with their respective postprogram scores $(\mathrm{PhC}: r=.50, p<.001$; PsC: $r=.71, p<.001 ; \mathrm{SSS}: r=.66, p<.001)$. In addition, physical health $(\mathrm{PhC})$ at preprogram was strongly correlated with psychological health (PsC) at both pre- and postprogram $(r=.49, p<.001 ; r=.43, p<.001$; respectively). Physical health $(\mathrm{PhC})$ at postprogram was also correlated with psychological health (PsC) at pre- and postprogram, but to a lesser degree (see Table 4).

Table 5 outlines the differences between victims and offenders, as well as differences from preprogram to postprogram on the three measures. Figures 3 , 4, and 5 provide a visual depiction of change over time. Lower scores were apparent on both the $\mathrm{PhC}$ and the $\mathrm{PsC}$ at postprogram than at preprogram. A repeated measures analysis was used to examine the differences over time (pre-post) and between groups (victimoffender). A univariate approach was used as it is a more powerful approach when there are only two levels of the within-subjects factor (time), as in this study ${ }^{16}$. There was a significant main effect of time $(F(3,88)=42.67, p<.001)$ and group $(F(3,88)=5.89, p$ $<.001$ ), indicating that further exploration was warranted. There was no interaction effect between time and group. The differences over time were significant for physical health $\left(F(1,90)=7.62, p<.01, \eta_{\mathrm{p}}{ }^{2}=.08\right)$ and psychological health $(F(1,90)=$

\footnotetext{
${ }^{16}$ The univariate approach to repeated measures analysis essentially makes subjects a factor in the design, removing the error due to subjects. If there are more than two levels of the within effect, then there may be problems with the assumption of sphericity. However, since the assumption of sphericity was met in this case (as there are only two levels), the univariate approach is more powerful than the multivariate approach because the former has more degrees of freedom. By using subjects as a factor in the design, the error term becomes smaller because the variability due to subjects has been removed (J. Wood, personal communication (multivariate statistics course notes), November 13, 2002).
} 
Table 5

PhC, PsC, and SSS Scale Scores from Preprogram to Postprogram by Group

\begin{tabular}{|c|c|c|}
\hline Measure & Preprogram & Postprogram \\
\hline $\begin{array}{l}\text { Physical Health Checklist Scores } \\
\text { (collapsed categories) }\end{array}$ & $n(\%)$ & $n(\%)$ \\
\hline \multirow[t]{3}{*}{ Victims } & $0=23(46.0)$ & $0=31(62.0)$ \\
\hline & $1-3=24(48.0)$ & $1-3=16(32.0)$ \\
\hline & $\geq 4=3 \quad(6.0)$ & $\geq 4=3(6.0)$ \\
\hline \multirow[t]{3}{*}{ Offenders } & $0=15(35.7)$ & $0=22(52.4)$ \\
\hline & $1-3=19(45.2)$ & $1-3=14(33.3)$ \\
\hline & $\geq 4=8(19.0)$ & $\geq 4=6(14.3)$ \\
\hline \multirow[t]{3}{*}{ Total } & $0=38(41.3)$ & $0=53(57.6)$ \\
\hline & $1-3=43(46.7)$ & $1-3=30(32.6)$ \\
\hline & $\geq 4=11(12.0)$ & $\geq 4=9(9.8)$ \\
\hline Physical Health Checklist Scores (0-12) & $M(S D)$ & $M(S D)$ \\
\hline Victims & $1.20(1.36)$ & $0.80(1.23)$ \\
\hline Offenders & $1.74(1.86)$ & $1.21(1.77)$ \\
\hline Total & $1.45(1.62)$ & $0.99(1.51)$ \\
\hline \multicolumn{3}{|c|}{ Psychological Health Checklist Scores $(0-26)$} \\
\hline Victims & $5.42(3.42)$ & $1.90(2.73)$ \\
\hline Offenders & $7.50(4.83)$ & $3.86(3.87)$ \\
\hline Total & $6.37(4.23)$ & $2.79(3.42)$ \\
\hline \multicolumn{3}{|l|}{ Sense of Social Support Scale Scores $(0-63)$} \\
\hline Victims & $50.13(6.69)$ & $51.10(6.70)$ \\
\hline Offenders & $46.74(6.22)$ & $46.55(7.08)$ \\
\hline Total & $48.58(6.67)$ & $49.02(7.21)$ \\
\hline
\end{tabular}


Figure 3

\section{PsC Change Over Time By Group}

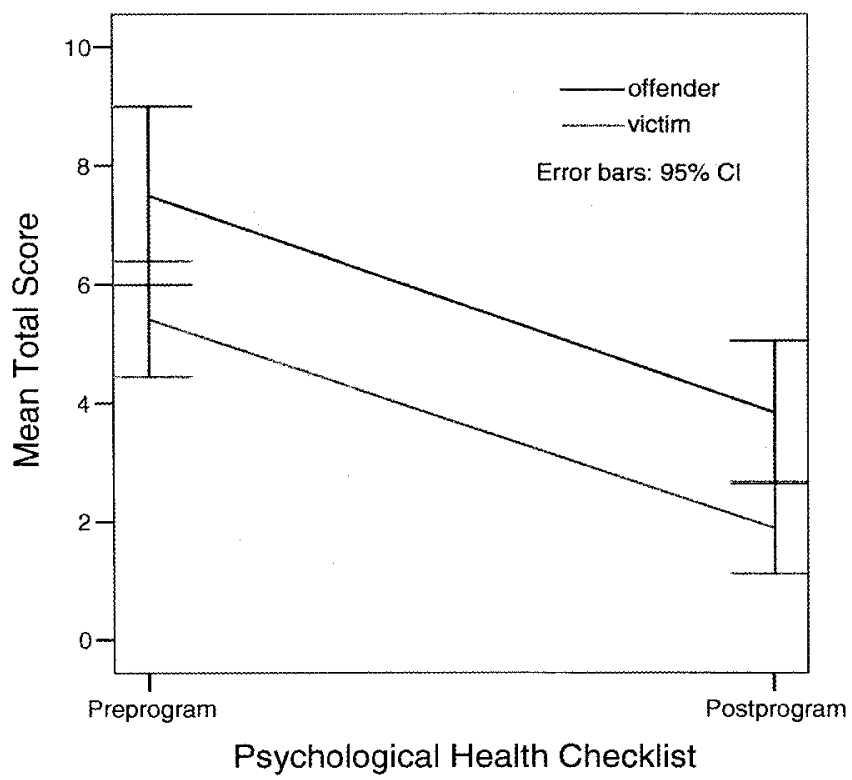

Figure 4

PhC Change Over Time By Group

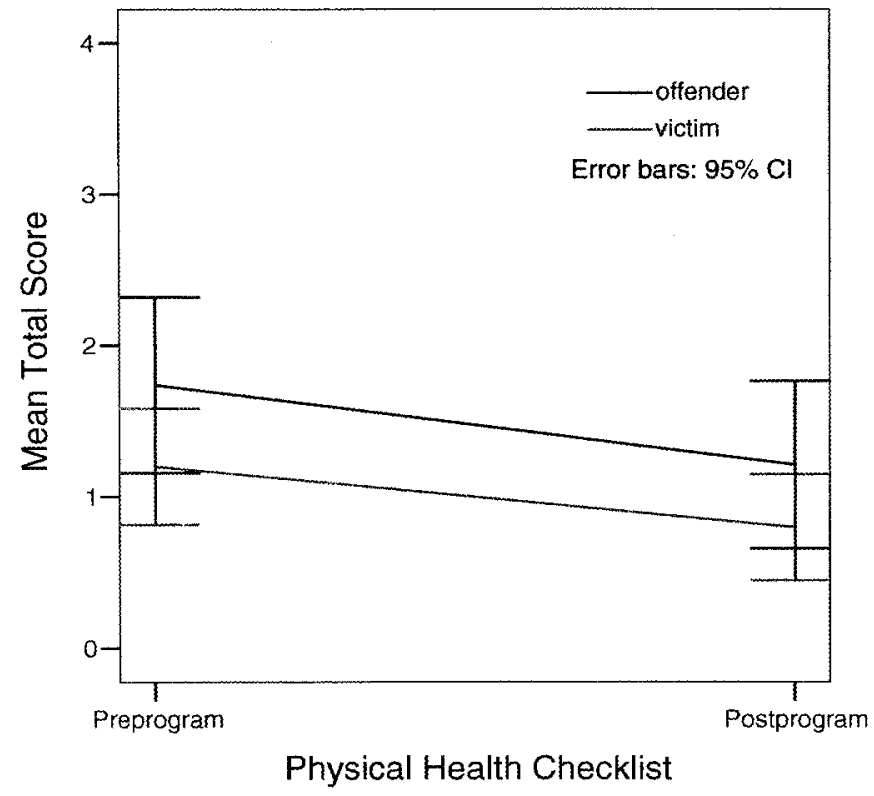

Reproduced with permission of the copyright owner. Further reproduction prohibited without permission. 
Figure 5

SSS Change Over Time By Group

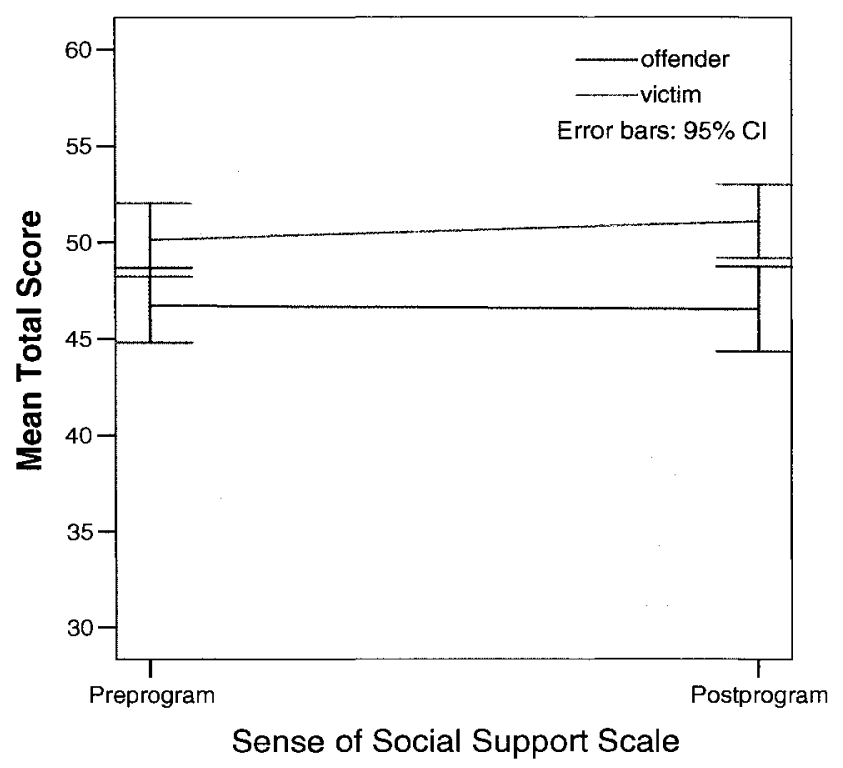

Reproduced with permission of the copyright owner. Further reproduction prohibited without permission. 
$\left.129.79, p<.001, \eta_{\mathrm{p}}{ }^{2}=.59\right)$, but not for sense of social support $(F(1,90)=.41, p=.53$, $\left.\eta_{\mathrm{p}}{ }^{2}=.01\right) . \mathrm{PsC}$ and $\mathrm{PhC}$ scores were higher at the preprogram stage $(M=6.46, S E=.43$, $C I=5.60-7.32$ and $M=1.47, S E=.17, C I=1.18-1.97$, respectively) than they were at the postprogram stage $(M=2.88, S E=.35, C I=2.19-3.56$ and $M=1.01, S E=.16, C I=$ $.50-1.15$, respectively). The estimated marginal mean scores (as well as the $S E$ s and CIs) presented for the $\mathrm{PhC}$ are the non-collapsed variable/score means; however, the collapsed score was used in the analysis. In fact, analyses were run twice, once using the collapsed PhC score, and once without. Both analyses revealed a significant effect over time.

Significant differences between victims and offenders were found for psychological health $\left(F(1,90)=7.97, p<.01, \eta_{\mathrm{p}}{ }^{2}=.08\right)$ and social support $(F(1,90)=$ $\left.9.89, p<.01, \eta_{\mathrm{p}}{ }^{2}=.10\right)$, but not for physical health $\left(F(1,90)=2.86, p=.094, \eta_{\mathrm{p}}{ }^{2}=.03\right)$. The effect size for physical health (.03) is considered small-medium ${ }^{17}$, therefore, it may be that the sample is not large enough to detect the differences between groups. Victims had higher levels of support $(M=50.62, S E=.86, C I=48.92-52.31)$ than offenders $(M$ $=46.64, S E=93, C I=44.79-48.49)$ and offenders had a higher number of psychological health problems (i.e., higher scores on the PsC; $(M=5.68, S E=.53, C I=$ $4.63-6.73)$ than victims $(M=3.66, S E=.48, C I=2.70-4.62)$.

There were a number of variables that may have had an impact on the $\mathrm{PhC}$, the PsC, and the SSS total scores. Therefore, an ANOVA and t-test analyses were used to compare the total scores of the $\mathrm{PhC}, \mathrm{PsC}$, and SSS across age, gender, offence type, offender risk level, as well as satisfaction and whether a victim-offender meeting

\footnotetext{
${ }^{17}$ The conventions for interpreting $\eta_{\mathrm{p}}{ }^{2}$ were: $.01=$ small, $.06=$ medium, $.14=$ large $(\mathrm{J}$. Wood).
} 
occurred. Table 6 illustrated the results in detail. Significant differences were found for age on preprogram SSS $(F(2,91)=5.38, p<.01)$ and postprogram $\operatorname{SSS}(F(2,91)=$ $5.28, p<.01$ ), where participants under the age of 18 were significantly different from the other two groups (18-29 and 30 and over). No differences were found for gender, offence type, offender risk level, or satisfaction. Participants who experienced a victimoffender meeting had significantly higher PsC scores at preprogram $(t(90)=-3.21, p<$ .01 ; no meeting: $M=8.81, S D=5.19$, meeting: $M=5.35, S D=3.31)$ and postprogram $(t$ $(90)=-3.16, p<.01$; no meeting: $M=4.81, S D=4.40$, meeting: $M=1.95, S D=2.50$ ) than participants who did not experience a victim-offender meeting. There was no significant difference on the amount of psychological health change between the meeting and no-meeting groups $(M=3.40, S D=2.44$ and $M=4.00, S D=4.04$, respectively; $t$ $(90)=-.72, p=.48)$

Physical health. As indicated, there was a significant change in physical health from preprogram to postprogram, as measured by the total score on the $\operatorname{PhC}(F(1,90)=$ $7.62, p<.01, \eta_{\mathrm{p}}{ }^{2}=.08$ ); however, there were no significant differences between victims and offenders on total score. Table 7 provides the breakdown of checklist items, by group, over time. Examining each item separately through the use of chi-square analyses, using the bonferroni correction to adjust for alpha $(\alpha=.05 \div 8$ tests $=0.00625)$, a significant difference existed between victims and offenders on only one item, "illegal drug use"; this significant difference was present at the postprogram $\left(\chi^{2}(2, N=92)\right.$, gamma $=-1.00, p<.00625)$ stage, with offenders reporting more illegal drug use than 
Table 6

Examination of Other Variables Potentially Relating to PhC, PsC and SSS

\begin{tabular}{|c|c|c|c|c|c|c|c|c|}
\hline & \multicolumn{4}{|c|}{$\mathrm{PhC}$} & \multicolumn{4}{|c|}{ PsC } \\
\hline & \multicolumn{2}{|c|}{ Preprogram } & \multicolumn{2}{|c|}{ Postprogram } & \multicolumn{2}{|c|}{ Preprogram } & \multicolumn{2}{|c|}{ Postprogram } \\
\hline & $M(S D)$ & $F / t$ & $M(S D)$ & $F / t$ & $M(S D)$ & $F / t$ & $M(S D)$ & $F / t$ \\
\hline Age & & .36 & & .65 & & 1.95 & & 1.05 \\
\hline Under $18(n=23)$ & $1.23(1.32)$ & & $.70(1.52)$ & & $5.52(3.40)$ & & $2.39(2.57)$ & \\
\hline $18-29(n=28)$ & $1.64(1.93)$ & & $1.00(1.44)$ & & $7.64(4.27)$ & & $3.57(3.58)$ & \\
\hline 30 and over $(n=41)$ & $1.41(1.57)$ & & $1.15(1.56)$ & & $5.98(4.51)$ & & $2.49(3.70)$ & \\
\hline Gender & & -1.14 & & -.97 & & -1.21 & & -1.25 \\
\hline Male $(n=67)$ & $1.33(1.68)$ & & $.90(1.48)$ & & $6.04(4.35)$ & & $2.52(3.25)$ & \\
\hline Female $(n=25)$ & $1.76(1.42)$ & & $1.24(1.59)$ & & $7.24(3.83)$ & & $3.52(3.81)$ & \\
\hline Offence Type & & -.82 & & -.52 & & -1.84 & & -.31 \\
\hline Person $(n=58)$ & $1.55(1.66)$ & & $1.05(1.69)$ & & $6.98(4.24)$ & & $2.65(3.36)$ & \\
\hline Non-Person $(n=34)$ & $1.26(1.56)$ & & $.88(1.15)$ & & $5.32(4.06)$ & & $2.88(3.15)$ & \\
\hline Risk Level & & -1.79 & & -1.14 & & -1.26 & & -2.26 \\
\hline Low $(n=21)$ & $1.24(1.51)$ & & $.90(1.51)$ & & $6.57(4.18)$ & & $2.57(2.64)$ & \\
\hline $\operatorname{Med} / \operatorname{High}(n=21)$ & $2.24(2.07)$ & & $1.52(1.99)$ & & $8.43(5.34)$ & & $5.14(4.50)$ & \\
\hline Satisfaction & & -1.40 & & -.97 & & -1.59 & & .90 \\
\hline Less $(n=20)$ & $1.00(1.41)$ & & $.70(1.53)$ & & $5.05(2.87)$ & & $3.40(3.62)$ & \\
\hline More $(n=72)$ & $1.57(1.66)$ & & $1.07(1.50)$ & & $6.74(4.48)$ & & $2.63(3.37)$ & \\
\hline V-O Meeting & & .15 & & -.65 & & $-3.21^{* *}$ & & $-3.16 * *$ \\
\hline Yes $(n=62)$ & $1.46(1.57)$ & & $.92(1.36)$ & & $5.35(3.30)$ & & $1.95(2.50)$ & \\
\hline No $(n=27)$ & $1.41(176)$ & & $1.15(1.83)$ & & $8.81(5.19)$ & & $4.81(4.43)$ & \\
\hline
\end{tabular}




\begin{tabular}{|c|c|c|c|c|}
\hline & \multicolumn{4}{|c|}{ SSS } \\
\hline & \multicolumn{2}{|l|}{ Preprogram } & \multicolumn{2}{|l|}{ Postprogram } \\
\hline & $M(S D)$ & $F / t$ & $M(S D)$ & $F / t$ \\
\hline $\operatorname{Age}^{18}$ & & $5.38 * *$ & & $5.28 * *$ \\
\hline Under 18 & $44.91(7.44)$ & & $45.21(7.06)$ & \\
\hline $18-29$ & $49.13(5.79)$ & & $49.18(6.45)$ & \\
\hline 30 and over & $50.27(6.10)$ & & $51.04(7.08)$ & \\
\hline Gender & & -.22 & & -1.44 \\
\hline Male & $48.49(6.82)$ & & $48.36(7.25)$ & \\
\hline Female & $48.84(6.35)$ & & $50.78(6.94)$ & \\
\hline Offence Type & & .25 & & .37 \\
\hline Person & $48.45(6.60)$ & & $48.80(6.69)$ & \\
\hline Non-Person & $48.82(6.87)$ & & $49.39(8.12)$ & \\
\hline Risk Level & & 1.98 & & 1.93 \\
\hline Med/High & $44.90(5.97)$ & & $44.50(7.08)$ & \\
\hline Satisfaction & & -.63 & & -1.08 \\
\hline Less & $47.76(6.37)$ & & $47.48(6.43)$ & \\
\hline More & $48.81(6.77)$ & & $49.45(7.40)$ & \\
\hline V-O Meeting & & -.66 & & .12 \\
\hline Yes & $48.29(6.62)$ & & $49.08(7.09)$ & \\
\hline No & $49.29(6.85)$ & & $48.87(7.62)$ & \\
\hline
\end{tabular}

${ }^{18}$ Post hoc comparisons of the ANOVA examining age and SSS indicated that was a significant difference at preprogram between the Under 18 group and the $18-29$ group (mean difference $=-4.22, p<.05, C I=-7.79--.66$ ) as well as the $30 \&$ over group (mean difference $=-5.37, p<.05, C I=-8.66--2.07$ ). The same results were found at the postprogram stage (Under 18 group compared to the $18-29$ group: mean difference $=-3.97, p<.05, C I=-7.82--.11$ and Under 18 group compared to $30 \&$ over group: mean difference $=-5.83, p<.05, C I=-9.40--2.26$ ). 
Table 7

Presence of Physical Health Items by Group

\begin{tabular}{|c|c|c|c|c|c|c|c|}
\hline \multirow{2}{*}{$\begin{array}{l}\text { Physical Health } \\
\text { Checklist Item }\end{array}$} & \multicolumn{3}{|c|}{ Preprogram } & \multicolumn{4}{|c|}{ Postprogram } \\
\hline & No Problem & Some Problem & Major Problem & No Problem & Some Problem & \multicolumn{2}{|c|}{ Major Problem } \\
\hline Sleeping & & $\%(n)$ & & & $\%(n)$ & & \\
\hline Victims & $66.0(33)$ & $4.0 \quad(2)$ & $30.0(15)$ & $80.0(40)$ & 2.0 & 18.0 & (9) \\
\hline Offenders & $61.9(26)$ & $11.9 \quad(5)$ & $26.2(11)$ & $81.0(34)$ & $2.4 \quad(1)$ & 16.7 & (7) \\
\hline Total & $64.1(59)$ & $7.6(7)$ & $28.3(26)$ & $80.4(74)$ & 2.2 & $17.4(1$ & \\
\hline \multicolumn{8}{|l|}{ Eating Habits } \\
\hline Victims & $94.0(47)$ & $6.0(3)$ & - & $96.0(48)$ & $4.0 \quad(2)$ & & - \\
\hline Offenders & $81.0(34)$ & $19.0 \quad(8)$ & - & $92.9(39)$ & 7.1 (3) & & - \\
\hline Total & $88.0(81)$ & $12.0(11)$ & - & $94.6(87)$ & $5.4 \quad(5)$ & & - \\
\hline \multicolumn{8}{|l|}{ Alcohol Use } \\
\hline Victims & $94.0(47)$ & $6.0(3)$ & $0.0 \quad(0)$ & $94.0(47)$ & $6.0 \quad(3)$ & 0.0( & (0) \\
\hline Offenders & $90.5(38)$ & $9.5(4)$ & $0.0 \quad(0)$ & $85.7(36)$ & $9.5(4)$ & 4.8( & (2) \\
\hline Total & $92.4(85)$ & $7.6(7)$ & $0.0 \quad(0)$ & $90.2(83)$ & $7.6(7)$ & 2.2( & (2) \\
\hline \multicolumn{8}{|c|}{ Prescribed Drug Use } \\
\hline Victims & $82.0(41)$ & $18.0 \quad(9)$ & $0.0 \quad(0)$ & $86.0(43)$ & $14.0 \quad(7)$ & 0.0( & (0) \\
\hline Offenders & $73.8(31)$ & $21.4 \quad(9)$ & 4.8 (2) & $85.7(36)$ & $14.3(6)$ & 0.0( & (0) \\
\hline Total & $78.3(72)$ & $19.6(18)$ & $2.2(2)$ & $85.9(79)$ & $14.1(13)$ & 0.0 & $(0)$ \\
\hline \multicolumn{8}{|l|}{ Illegal Drug Use } \\
\hline Victims & $94.0(47)$ & $6.0 \quad(3)$ & $0.0 \quad(0)$ & $100.0(50)$ & $0.0 \quad(0)$ & 0.0 & $(0)$ \\
\hline Offenders & $76.2(32)$ & $21.4 \quad(9)$ & $2.4(1)$ & $81.0(34)$ & $14.3 \quad(6)$ & 4.8( & (2) \\
\hline Total & $85.9(79)$ & $13.0(12)$ & 1.1 & $91.3(84)$ & $6.5(6)$ & 2.2( & (2) \\
\hline \multicolumn{8}{|l|}{ Exercise } \\
\hline Victims & $86.0(43)$ & $14.0 \quad(7)$ & - & $86.0(43)$ & $14.0 \quad(7)$ & & - \\
\hline Offenders & $85.7(36)$ & $14.3 \quad(6)$ & - & $85.7(36)$ & $14.3 \quad(6)$ & & - \\
\hline Total & $85.9(79)$ & $14.1(13)$ & - & $85.9(79)$ & $14.1(13)$ & & - \\
\hline \multicolumn{8}{|l|}{ Other } \\
\hline Victims & $92.0(46)$ & $8.0 \quad(4)$ & $0.0 \quad(0)$ & $98.0(49)$ & $2.0 \quad(1)$ & 0.0 & (0) \\
\hline Offenders & $95.2(40)$ & $2.4(1)$ & $2.4(1)$ & $95.2(40)$ & $4.8 \quad(2)$ & $0.0 \quad($ & $(0)$ \\
\hline Total & $93.5(86)$ & $5.4 \quad(5)$ & $1.1(1)$ & $96.7(89)$ & 3.3 (3) & 0.0 & $(0)$ \\
\hline \multicolumn{8}{|c|}{ Participant's Own Health Rating } \\
\hline Victims & $98.0(49)$ & $2.0(1)$ & $0.0 \quad(0)$ & $98.0(49)$ & $2.0 \quad(1)$ & 0.0 & $(0)$ \\
\hline Offenders & $100.0(42)$ & $0.0 \quad(0)$ & $0.0 \quad(0)$ & $97.6(41)$ & $2.4(1)$ & 0.0( & (0) \\
\hline Total & $98.9(91)$ & $1.1(1)$ & $0.0 \quad(0)$ & $97.8(90)$ & $2.2(2)$ & 0.0( & $(0)$ \\
\hline
\end{tabular}


victims. Although program groups were combined, based on the rationale that all participants experienced a restorative justice process, further chi-square analyses were conducted to determine whether there were significant differences on the individual items across program groups. No statistically significant differences across programs were found.

Four hypotheses were put forth regarding physical health. The first was that a significant positive change was expected from preprogram to postprogram, as evidenced by lower scores on the $\mathrm{PhC}$ at the end of the restorative justice process. As the repeated measures analyses indicated, there was a significant change in the $\mathrm{PhC}$ scores $(F(1,90)=$ $7.62, p<.01, \eta_{\mathrm{p}}{ }^{2}=.08$ ), with lower scores at program completion (preprogram: $M=1.47$, $S E=.17, C I=1.18-1.97$; postprogram: $M=1.01, S E=.16, C I=.50-1.15)$.

Physical health and satisfaction. The second hypothesis examined that relationship between satisfaction and physical health change. It was expected that participants who had a higher level of satisfaction, would evidence a greater degree of positive physical health change from pre- to postprogram. Given that the distribution of scores were negatively skewed, a median-split on total scores (to create a low-change and high-change group) was no longer feasible. The correlation between the $\mathrm{PhC}$ change score and the level of satisfaction was not significant $(r=.08, p=.45)$.

The satisfaction variable was collapsed into a categorical variable "less satisfied" (consisting of "not satisfied" and "somewhat satisfied" responses) and "more satisfied" (consisting of "satisfied" and "very satisfied" responses) and the $\mathrm{PhC}$ change variable was collapsed into "negative change", "no change", "positive change" and "positive change 4+" (scores of 4 or greater). A chi-square analysis (using gamma as there were 
cells with a count less than 5) was not significant $\left(\chi^{2}(3, N=92)=.18, p=.36\right)$, indicating that the hypothesis was not supported. To examine effect size, an ANOVA was run to obtain an effect size $\left(F(1,91)=.62, p=.43, \eta_{\mathrm{p}}{ }^{2}=.01\right)$, but it indicated that power was not an issue.

Physical health and type of crime. The third hypothesis was related to physical health change and type of crime, specifically hypothesizing that participants who experienced a "more-serious" crime (defined as crime against the person) would have higher scores on the PhC at preprogram, and that these participants would also exhibit a greater degree of change from pre- to postprogram. A t-test analysis was conducted using the PhC total score and the more/less-serious crime variable, and the result was nonsignificant $(t(90)=-.82, p=.42, C I=-.98-.41)$. The analysis was rerun using the collapsed $\mathrm{PhC}$ score, and the result remained nonsignificant. Furthermore, participants who experienced a crime against the person did not exhibit a significantly greater degree of change when compared to participants who experienced a non-person-based crime ( $t$ $(90)=-.35, p=.73, C I=-.79-.56)$. Once again, the analysis was run using the collapsed change variable (no change, positive change etc.) and it remained nonsignificant.

Physical health and social support. The fourth hypothesis posited that participants with higher levels of perceived social support would exhibit fewer physical health problems at the preprogram stage. Therefore, a Pearson correlation coefficient was generated, with the expectation of a significant negative correlation. The correlation between preprogram SSS total score and program PhC score was nonsignificant $(r=-.11$, $p=.29$ ), although the relationship was in the expected direction. The majority of 
participants were grouped about the mean score; therefore in order to create two distinct groups (low-SSS and high-SSS) the top 14 scores (which reflected scores of 56 and above) and bottom 13 scores (reflecting scores of 40 or lower) were used. A t-test analyses comparing the two groups on total $\mathrm{PhC}$ score at preprogram revealed no significant differences $(t(25)=.60, p=.55$.

Psychological health. Results presented earlier indicated that there was a significant change in psychological health from preprogram to postprogram, as measured by the total score on the $\operatorname{PsC}\left(F(1,90)=129.79, p<.001, \eta_{\mathrm{p}}{ }^{2}=.59\right)$. PsC scores were higher at the preprogram stage $(M=6.46, S E=.43, C I=5.60-7.32)$ than they were at the postprogram stage $(M=2.88, S E=.35, C I=2.19-3.56)$. Significant differences between victims and offenders were also found $\left(F(1,90)=7.97, p<.016, \eta_{\mathrm{p}}{ }^{2}=.08\right)$. Table 8 provides the breakdown of checklist items, by group, over time.

Using chi-square analyses to examine each item separately, adjusting for alpha ( $\alpha$ $=.05 \div 17$ tests $=0.00294$ ), significant differences existed between victims and offenders at preprogram on the four following items: shame/guilt $\left(\chi^{2}(2, N=92)\right.$, gamma $=-.98, p<.001)$, depression $\left(\chi^{2}(2, N=92)\right.$, gamma $\left.=-.67, p<.0029\right)$, self-reliance $\left(\chi^{2}\right.$ $(1, N=92)=12.08, p<.001)$, and self-esteem $\left(\chi^{2}(1, N=92)=10.70, p<.0029\right)$.

Offenders evidenced more problems with shame/guilt, depression, self-reliance, and self-esteem when compared to victims. At postprogram, offenders continued to exhibit more problems with shame/guilt than victims $\left(\chi^{2}(1, N=92)=66.53, \mathrm{p}<.001\right)$. There were no other significant differences between victims and offenders at postprogram on the various $\mathrm{PsC}$ items. The two programs were also compared, and no 
Table 8

Presence of Psychological Health Items by Group

\begin{tabular}{|c|c|c|c|c|c|c|c|c|}
\hline \multirow{2}{*}{$\begin{array}{l}\text { Psychological Health } \\
\text { Checklist Item }\end{array}$} & \multicolumn{4}{|c|}{ Preprogram } & \multicolumn{4}{|c|}{ Postprogram } \\
\hline & $\begin{array}{c}\text { No } \\
\text { Problem }\end{array}$ & $\begin{array}{l}\text { Some } \\
\text { Problem }\end{array}$ & \multicolumn{2}{|c|}{$\begin{array}{l}\text { Major } \\
\text { Problem }\end{array}$} & $\begin{array}{l}\text { No } \\
\text { Problem }\end{array}$ & $\begin{array}{c}\text { Some } \\
\text { Problem }\end{array}$ & \multicolumn{2}{|c|}{$\begin{array}{c}\text { Major } \\
\text { Problem }\end{array}$} \\
\hline Safety & & $\%(n)$ & & & & $\%(n)$ & & \\
\hline Victims & $46.0(23)$ & $50.0(25)$ & 4.0 & (2) & 78.0 & $22.0(11)$ & 0.0 & (0) \\
\hline Offenders & $73.8(31)$ & $26.2(11)$ & 0.0 & $(0)$ & $90.5(38)$ & 9.5 (4) & 0.0 & (0) \\
\hline Total & $58.7(54)$ & $39.1(36)$ & 2.2 & (2) & $83.7(77)$ & $16.3(15)$ & 0.0 & (0) \\
\hline \multicolumn{9}{|l|}{ Fear } \\
\hline Victims & $44.0(22)$ & $48.0(24)$ & 8.0 & (4) & $74.0(37)$ & $24.0(12)$ & 2.0 & (1) \\
\hline Offenders & $59.5(25)$ & $38.1(16)$ & 2.4 & (1) & $81.0(34)$ & 19.0 & 0.0 & (0) \\
\hline Total & $51.1(47)$ & $43.5(40)$ & 5.4 & (5) & $77.2(71)$ & $21.7(20)$ & 1.1 & (1) \\
\hline \multicolumn{9}{|l|}{ Vulnerability } \\
\hline Victims & $54.0(27)$ & $46.0(23)$ & & - & $96.0(48)$ & $4.0 \quad(2)$ & & - \\
\hline Offenders & $52.4(22)$ & $47.6(20)$ & & - & $95.2(40)$ & $4.8(2)$ & & - \\
\hline Total & $53.3(49)$ & $46.7(43)$ & & - & $95.7(88)$ & $4.3 \quad(4)$ & & - \\
\hline \multicolumn{9}{|l|}{ Anger } \\
\hline Victims & $36.0(18)$ & $64.0(32)$ & 0.0 & $(0)$ & $84.0(42)$ & 14.0 & 2.0 & (1) \\
\hline Offenders & $38.1(16)$ & $61.9(26)$ & 0.0 & $(0)$ & $78.6(33)$ & $19.0 \quad(8)$ & 2.4 & (1) \\
\hline Total & $37.0(34)$ & $63.0(58)$ & 0.0 & $(0)$ & $81.5(75)$ & $16.3(15)$ & 2.2 & (2) \\
\hline \multicolumn{9}{|l|}{ Shame/Guilt } \\
\hline Victims & $86.0(43)$ & 14.0 & 0.0 & $(0)$ & $98.0(49)$ & $2.0 \quad(1)$ & 0.0 & $(0)$ \\
\hline Offenders & 7.1 (3) & $90.5(38)$ & 2.4 & (1) & $14.3(6)$ & $85.7(36)$ & 0.0 & (0) \\
\hline Total & $50.0(46)$ & $48.9(45)$ & 1.1 & (1) & $59.8(55)$ & $40.2(37)$ & 0.0 & (0) \\
\hline \multicolumn{9}{|l|}{ Depression } \\
\hline Victims & $86.0(43)$ & $14.0 \quad(7)$ & 0.0 & $(0)$ & $92.0(46)$ & $8.0 \quad(4)$ & 0.0 & (0) \\
\hline Offenders & $52.4(22)$ & $33.3(14)$ & 14.3 & (6) & $81.0(34)$ & 11.9 & 7.1 & (3) \\
\hline Total & $70.7(65)$ & $22.8(21)$ & 6.5 & $(6)$ & $87.0(80)$ & $9.8(9)$ & 3.3 & (3) \\
\hline \multicolumn{9}{|l|}{ Thoughts of Suicide } \\
\hline Victims & $98.0(49)$ & 2.0 & & - & $100.0(50)$ & $0.0 \quad(0)$ & & - \\
\hline Offenders & $92.9(39)$ & $7.1 \quad(3)$ & & - & $97.6(41)$ & $2.4(1)$ & & - \\
\hline Total & $95.7(88)$ & $4.3 \quad(4)$ & & - & $98.9(91)$ & $1.1(1)$ & & - \\
\hline \multicolumn{9}{|l|}{ Anxiousness/Stressed } \\
\hline Victims & $38.0(19)$ & $50.0(25)$ & 12.0 & (6) & $76.0(38)$ & $24.0(12)$ & 0.0 & (0) \\
\hline Offenders & $31.0(13)$ & $52.4(22)$ & 16.7 & (7) & $59.5(25)$ & $33.3(14)$ & 7.1 & (3) \\
\hline Total & $34.8(32)$ & $51.1(47)$ & 14.1( & (13) & $68.5(63)$ & $28.3(26)$ & 3.3 & (3) \\
\hline
\end{tabular}




\begin{tabular}{|c|c|c|c|c|c|c|c|c|}
\hline \multirow{2}{*}{$\begin{array}{l}\text { Psychological Health } \\
\text { Checklist Item }\end{array}$} & \multicolumn{4}{|c|}{ Preprogram } & \multicolumn{4}{|c|}{ Postprogram } \\
\hline & $\begin{array}{c}\text { No } \\
\text { Problem }\end{array}$ & $\begin{array}{l}\text { Some } \\
\text { Problem }\end{array}$ & \multicolumn{2}{|c|}{$\begin{array}{l}\text { Major } \\
\text { Problem }\end{array}$} & $\begin{array}{c}\text { No } \\
\text { Problem }\end{array}$ & $\begin{array}{c}\text { Some } \\
\text { Problem }\end{array}$ & \multicolumn{2}{|c|}{$\begin{array}{l}\text { Major } \\
\text { Problem }\end{array}$} \\
\hline Hurt/Disappointment & & $\%(n)$ & & & & $\%(n)$ & & \\
\hline Victims & $50.0(25)$ & $50.0(25)$ & & - & $68.0(34)$ & $32.0(16)$ & & - \\
\hline Offenders & $73.8(31)$ & $26.2(11)$ & & - & $85.7(36)$ & $14.3 \quad(6)$ & & - \\
\hline Total & $60.9(56)$ & $39.1(36)$ & & - & $76.1(70)$ & $23.9(22)$ & & - \\
\hline \multicolumn{9}{|c|}{ Upset/Confusion/Frustration } \\
\hline Victims & $38.0(19)$ & $62.0(31)$ & 0.0 & $(0)$ & $88.0(44)$ & $12.0 \quad(6)$ & 0.0 & $(0)$ \\
\hline Offenders & $45.2(19)$ & $54.8(23)$ & 0.0 & $(0)$ & $76.2(32)$ & $23.8(10)$ & 0.0 & $(0)$ \\
\hline Total & $41.3(38)$ & $58.7(54)$ & 0.0 & $(0)$ & $82.6(76)$ & $17.4(16)$ & 0.0 & $(0)$ \\
\hline \multicolumn{9}{|l|}{ Self-reliance } \\
\hline Victims & $82.0(41)$ & $18.0 \quad(9)$ & & - & $86.0(43)$ & $14.0 \quad(7)$ & & - \\
\hline Offenders & $47.6(20)$ & $52.4(22)$ & & - & $71.4(30)$ & $28.6(12)$ & & - \\
\hline Total & $66.3(61)$ & $33.7(31)$ & & - & $79.3(73)$ & $20.7(19)$ & & - \\
\hline \multicolumn{9}{|l|}{ Self-esteem } \\
\hline Victims & $92.0(46)$ & 8.0 & & - & $96.0(48)$ & $4.0 \quad(2)$ & & - \\
\hline Offenders & $64.3(27)$ & $35.7(15)$ & & - & $81.0(34)$ & $19.0 \quad(8)$ & & - \\
\hline Total & $79.3(73)$ & $20.7(19)$ & & - & $89.1(82)$ & $10.9(10)$ & & - \\
\hline \multicolumn{9}{|l|}{ Interfering Thoughts } \\
\hline Victims & $94.0(47)$ & $6.0 \quad(3)$ & 0.0 & $(0)$ & $100.0(50)$ & $0.0 \quad(0)$ & 0.0 & $(0)$ \\
\hline Offenders & $61.9(26)$ & $38.1(16)$ & 0.0 & (0) & $90.5(38)$ & $9.5(4)$ & 0.0 & $(0)$ \\
\hline Total & $79.3(73)$ & $20.7(19)$ & 0.0 & $(0)$ & $95.7(88)$ & $4.3(4)$ & 0.0 & $(0)$ \\
\hline \multicolumn{9}{|l|}{ Counsellor } \\
\hline Victims & $92.0(46)$ & $8.0 \quad(4)$ & & - & $96.0(48)$ & $4.0 \quad(2)$ & & - \\
\hline Offenders & $73.8(31)$ & $26.2(11)$ & & - & $76.2(32)$ & $23.8(10)$ & & - \\
\hline Total & $83.7(77)$ & $16.3(15)$ & & - & $87.0(80)$ & $13.0(12)$ & & - \\
\hline \multicolumn{9}{|l|}{ Outlook } \\
\hline Victims & $90.0(45)$ & 10.0 & 0.0 & $(0)$ & $90.0(45)$ & 10.0 & 0.0 & $(0)$ \\
\hline Offenders & $66.7(28)$ & $33.3(14)$ & 0.0 & $(0)$ & $83.3(35)$ & $14.3 \quad(6)$ & 2.4 & (1) \\
\hline Total & $79.3(73)$ & $20.7(19)$ & 0.0 & $(0)$ & $87.0(80)$ & $12.0(11)$ & 1.1 & $(1)$ \\
\hline \multicolumn{9}{|l|}{ Other } \\
\hline Victims & $56.0(28)$ & $44.0(22)$ & 0.0 & $(0)$ & $92.0(46)$ & $8.0 \quad(4)$ & 0.0 & $(0)$ \\
\hline Offenders & $54.8(23)$ & $38.1(16)$ & 7.1 & (3) & $73.8(31)$ & $23.8(10)$ & 2.4 & (1) \\
\hline Total & $55.4(51)$ & $41.3(38)$ & 3.3 & (3) & $83.7(77)$ & $15.2(14)$ & 1.1 & (1) \\
\hline \multicolumn{9}{|c|}{ Participant's Own Psychological Health Rating } \\
\hline Victims & $100.0(50)$ & $0.0 \quad(0)$ & 0.0 & $(0)$ & $100.0(50)$ & $0.0 \quad(0)$ & 0.0 & $(0)$ \\
\hline Offenders & $97.6(41)$ & $2.4 \quad(1)$ & 0.0 & $(0)$ & $97.6(41)$ & $2.4 \quad(1)$ & 0.0 & $(0)$ \\
\hline Total & $98.9(91)$ & 1.1 & 0.0 & $(0)$ & $98.9(91)$ & $1.1 \quad(1)$ & 0.0 & $(0)$ \\
\hline
\end{tabular}


significant differences were found. Four hypotheses were posited regarding psychological health. First, a significant positive change was expected from preprogram to postprogram, as evidenced by lower scores on the $\mathrm{PsC}$ at the end of the restorative justice process. As the repeated measures analyses indicated, there was a significant change in the PsC scores, with higher scores exhibited at preprogram $(M=6.46, S E=.43, C I=5.60$ - 7.32) than postprogram $(M=2.88, S E=.35, C I=2.19-3.56)$.

Psychological health and satisfaction. The second hypothesis predicted a relationship between satisfaction and psychological health change. It was expected that participants who had a higher level of satisfaction would exhibit a greater degree of positive $\mathrm{PsC}$ change from pre- to postprogram. Using the same procedure as when testing the related physical health hypothesis, a correlation was first run on the full satisfaction variable and the total PsC change score. The correlation between the two variables was significant $(r=.31, p<.01)$, indicating there was a positive relationship. A chi-square analysis was used on the collapsed categorical variables (less/more satisfied and negative/no/positive/positive4+ change), and these results were also significant $\left(\chi^{2}(3, N\right.$ $=92)$, gamma $=.59, p<.01)$. As hypothesized, participants who were more satisfied exhibited more positive psychological health change. Table 9 outlines these results in detail.

Psychological health and type of crime. The third hypothesis predicted that participants who experienced a crime against the person (i.e., a "more serious" crime) would exhibit higher PsC scores at the commencement of the restorative justice process than participants who experienced a less serious crime. Linked closely was a subhypothesis that participants who experienced a person-based crime would also exhibit a 
greater degree of positive change over the course of the program. Neither hypothesis was supported. The result of the t-test analysis using the preprogram PsC total score and the more/less-serious crime variable was nonsignificant $(t(90)=-1.84, p=.07, C I=-3.45-$ .13). Furthermore, participants who experienced a crime against the person did not exhibit a significantly greater degree of psychological change when compared to participants who experienced a non-person-based crime $(t(90)=-.35, p=.73, C I=-.79-$ $.56)$.

Psychological health and social support. The final hypothesis regarding psychological health predicted that, when entering the program, participants with higher levels of perceived social support would exhibit fewer psychological health problems. Although it was expected that the Pearson correlation coefficient would indicate a significant negative relationship between the preprogram SSS score and the preprogram PsC score, this was not the case $(r=-.09, p=.393)$, proving this hypothesis was not supported. Again, the high-SSS group was compared to the low-SSS group on preprogram PsC score, but no significant difference was found $(t(21)=-.21, p=.83)$.

Sense of social support. Results indicated that there was no significant differences in SSS scores from preprogram to postprogram $\left(F(1,90)=.41, p=.53, \eta_{\mathrm{p}}{ }^{2}=\right.$ $.01)$; however, there was a significant difference between victims and offenders $(F(1,90)$ $=9.89, p<.01, \eta_{\mathrm{p}}{ }^{2}=.10$ ), with victims indicating higher social support levels than offenders at both measurement points (preprogram: victims $M=50.13, S D=6.69$, offenders $M=46.74, S D=6.67$; postprogram: victims $M=51.10, S D=6.70$, offenders $M=46.55, S D=7.08)$. 
Table 9

Satisfaction Categories by Categories of Psychological Change

\begin{tabular}{lccc}
\hline \multirow{2}{*}{ Psychological Checklist Change } & \multicolumn{3}{c}{ Satisfaction } \\
\cline { 2 - 4 } & Less Satisfied & More Satisfied & Total \\
\hline \multirow{3}{*}{ Positive Change (4+) } & $20.0(4)$ & $45)$ \\
Positive Change (1-3) & $40.0(8)$ & $45.8(33)$ & $40.2(37)$ \\
No Change & $25.0(5)$ & $6.9(5)$ & $44.6(41)$ \\
Negative Change & $15.0(3)$ & $1.4(1)$ & $10.9(10)$ \\
\hline
\end{tabular}


Two hypotheses related to sense of social support. First, it was hypothesized that there would be an increase in participants' sense of social support from program commencement to program completion. As the results above indicate, this was not the case. Although there was a slight increase in SSS score for the total group, it was not significant. Interestingly, it was only the victims who exhibited a positive increase over time, as the offenders scores decreased slightly. Second, it was hypothesized that sense of social support would be linked to overall health change. In order to examine this hypothesis, one overall health change score was created (the PhC change score and the PsC change scores were added together) and a correlation was obtained to determine the association between the overall health change variable and preprogram SSS total score. Although the correlation was in the appropriate direction (negative relationship), it was not significant $(r=-.08, p=.48)$. Correlations were run separately for victims $(r=-.07$, $p=.65)$ and offenders $(r=-.07, p=.64)$, but neither relationship became significant. The high-SSS was compared to the low-SSS group to determine whether there was a significant difference in the total change scores. A t-test indicated that there was no significant difference between the two groups on the amount of total health change $(t(12)$ $=-.41, p=.69$ ).

\section{Offender Risk Level}

It was expected that higher offender risk levels would be associated with lower satisfaction levels. To test this relationship, a correlation was run between offender risk level scores and satisfaction scores. A negative relationship was expected, suggesting that higher offender risk levels are associated with lower satisfaction levels. The Pearson correlation coefficient was not significant $(r=-.10, p=.38)$. In cases where a victim 
participated in the study, but their offender did not, no risk score was available to correspond to the victim $(n=13)$. A chi-square analysis was conducted using the 2-level satisfaction variable (less and more) and risk level (low, medium, high) and the result was nonsignificant $\left(\chi^{2}(2, N=79)\right.$, gamma $\left.=-.10, p=.68\right)$. To further examine this, two risk groups were created: a low-risk offender group and a second group that combined the medium-risk and the high-risk offenders. These two groups were compared on satisfaction (less/more) to determine whether there were differences between the two groups. No significant differences were found using this technique either $\left(\chi^{2}(1, N=79)\right.$ $=.31, p=.39$ ).

\section{Victim-Offender Meeting}

It was hypothesized that participants who experienced a victim-offender meeting would experience a higher degree of overall health change than participants who did not experience a meeting. To test this hypothesis, a t-test analysis was used to compare the mean overall health change scores between the two groups (no meeting and meeting). There was no significant difference between the two groups $(t(90)=-.38, p=.71, C I=-$ $2.01-1.37)$. In fact, although not significant, there was more change in the group that did not experience a meeting $(M=4.26, S D=4.63$ versus $M=3.94, S D=3.27)$.

A second hypothesis predicted that there would be no statistically significant differences on satisfaction between participants who experienced a victim-offender meeting and those who did not. To test this hypothesis, a chi-square analysis was used to compare the two groups on satisfaction (less/more). As predicted, no statistically significant differences were found $\left(\chi^{2}(1, N=92)=1.08, p=.23\right)$. The analysis was run separately for victims and offenders. While there remained no statistically significant 
relationship between satisfaction and meeting for victims, the relationship became significant for offenders $\left(\chi^{2}(1, N=42)=1.00, p<.01\right)$. Table 10 shows the results in greater detail. As the results demonstrate, offenders who did not experience a meeting were more satisfied than those that did experience a meeting, whereas the opposite was true for victims. 
Table 10

Satisfaction Categories by Victim-Offender Meeting by Group

\begin{tabular}{lccc}
\hline \multirow{2}{*}{ Victim-Offender Meeting } & \multicolumn{3}{c}{ Satisfaction } \\
\cline { 2 - 4 } & Less Satisfied & More Satisfied & Total \\
\hline Victims & $\%(n)$ & $100.0(12)$ \\
$\quad$ No V-O meeting & $18.3(4)$ & $66.7(8)$ & $100.0(38)$ \\
V-O meeting & & $81.6(31)$ & $100.0(15)$ \\
Offenders & $0.0(0)$ & $100.0(15)$ & $100.0(27)$ \\
No V-O meeting & $33.3(9)$ & $66.7(18)$ & \\
V-O meeting & & & $100.0(27)$ \\
Total & $14.8(4)$ & $85.2(23)$ & $100.0(65)$ \\
No V-O meeting & $24.6(16)$ & $75.4(49)$ & \\
V-O meeting & &
\end{tabular}




\section{Discussion}

The main goal of this study was to examine the effects of restorative justice processes on participants' physical health, psychological health, and sense of social support. Research literature to date has suggested that restorative justice processes may have positive impacts on a participant's health (Beven et al., 2005; Bonta et al., 2002; Latimer et al., 2001; Rugge et al., 2005; Strang, 2002; Umbreit, 1994; Wemmers \& Cyr, 2005). Studies in this area have referred to positive effects on wellbeing, psychological health, and victim fear levels (Wemmers \& Cyr, 2005), but no studies have examined specific areas within psychological or physical health (with the exception of victim fear). Although this study is somewhat exploratory in nature, with several limitations, its goal to contribute to and advance this area of restorative justice research has been accomplished.

\section{Psychological Health}

First, results found that there were positive changes in participants' psychological health from program commencement to program completion. In this regard, these findings are consistent with past research (Rugge et al., 2005; Strang, 2002; Umbreit, 1994; Wemmers \& Cyr, 2005). This study extended this research by examining over a dozen specific psychological health items (e.g., anger, fear, shame/guilt, depression, etc.) - all indicators where restorative justice facilitators felt they had seen change in past clientele $^{19}$. Decreases were noted on all these variables, indicating perhaps that the indicators chosen were appropriate. The various items were summed through the

\footnotetext{
${ }^{19}$ Prior to the development of the $\mathrm{PhC}$ and the $\mathrm{PsC}$, program staff and various restorative justice facilitators were consulted as to what indicators they felt should be examined, based on their experience with victims and offenders.
} 
Psychological Health Checklist ( $\mathrm{PhC}$ ), and decreases in score from preprogram to postprogram were noted for $84.8 \%(n=78)$ of participants. Eleven percent $(10.9 \% ; n=$ 10) of participants exhibited no change from preprogram to postprogram; however, it should be noted that these participants all had low scores at commencement. Specifically, $90 \%(n=9)$ of the no-change group had scores of five or less and $50 \%(n=$ 5) had scores of one or less. Results indicated that there were no significant differences between victims and offenders - they both exhibited positive change over the course of the program.

Interestingly, there was a significant difference found between participants who experienced a victim-offender meeting and those who did not, with meeting participants scoring lower on the PsC at both preprogram and postprogram. It could be that participants who experienced a higher degree of psychological health symptoms (e.g., upset) did not want to add the potential stress or anxiousness associated with a meeting. Restorative justice proponents would argue that it is precisely these participants who would benefit the most from an encounter. Participants who experienced a victimoffender meeting were compared to those who did not, and there were no significant differences in psychological health change.

One of the indicators in the psychological health checklist was "anger". This item revealed some interesting results. Although there was a general decrease in "anger" over time, there were some participants who increased from preprogram to postprogram. The numbers were few $(n=2)$, but it is possible that if a participant does not achieve a satisfying result from the program, they may evidence more anger at the postprogram stage. Although not the case in this study, it is possible that sentencing (e.g., a harsher 
sentence than expected) could increase an offender's anger level, and it is possible that if the process does not meet the victims' expectations (e.g., meet the victim's needs), they may feel anger at program completion. Lastly, there are cases that are referred to restorative justice programs that do not fit nicely into the victim/offender mold. In cases of bar fights, or other assaults, police charging practices do not necessarily reflect the degree of responsibility of both parties. For example, the "victim" may be the victim because s/he called the police first or, despite starting the fight, may have received more injuries. The restorative justice process attempts to uncover the truth, encouraging all parties to take responsibly for their actions. These cases are particularly challenging for restorative justice facilitators.

Interestingly, participants were also asked specifically to provide a rating on their own overall psychological health, and in almost all cases $(98.9 \%)$, they indicated there was "no problem", a rating that was consistent at preprogram and postprogram. In essence, participants never felt that they had any problems with their psychological health. However, when asked questions pertaining to the specific indicators, participants rated them accordingly (which indicated that there were "problems" in some areas). ${ }^{20}$ Although there are certainly other potential indicators of psychological health, the results of this study suggest that the indicators examined are appropriate and potentially being affected by the restorative justice process. The question still remains as to how large a role the restorative justice process is playing in this change.

\footnotetext{
${ }^{20}$ This finding also reaffirms the methodology used in the structuring of interview questions, specifically that additional information can be obtained using precise follow-up questions in conjunction with a more general question.
} 
Physical Health

Although the issue of physical health has come up less often in restorative justice research, it would follow that physical health may also be impacted by the crime, as research has demonstrated that both psychological and physical effects may result from negative or stressful incidents (such as a criminal incident; Birmes et al., 2001; Koss et al., 1991; Leahy et al., 2003; Markesteyn, 1992; Mezy, 1988; Norris et al., 1997). Studies have referred to lack of sleep and substance use of restorative justice participants but have not formally used the term "physical health". As a result, this study aimed to examine some indicators of physical health that may also be impacted by the restorative justice process (e.g., sleeping, eating, alcohol use, drug use, etc.).

Results indicated that there were changes in participants' physical health, as measured by the indicators, from preprogram to postprogram. The presence of physical health indicators was much less in this sample than were psychological health indicators. Although there were less indicators pertaining to physical health (6 items compared to 15 items), the mean scores on the physical health checklist (PhC) were much lower than the $\operatorname{PsC}(M=1.45, S D=1.62$ and $M=6.37, S D=4.23$ at preprogram, respectively). Over forty percent $(41.3 \%, n=38)$ of participants exhibited no physical health indicators at preprogram, and this increased to $56.5 \%(n=52)$ at postprogram. It was therefore not surprising that $45.7 \%(n=42)$ of participants did not exhibit any change in the physical health indicators from preprogram to postprogram, though $36.9 \%(n=34)$ did exhibit positive change (i.e., a decrease in number of indicators as reflected by a decrease in PsC total score). 
Victims and offenders were compared on the various physical health indicators. Results found that there was significant difference between victims and offenders on only one item, "illegal drug use". This was not a surprising result. Interestingly, one offender increased the level of alcohol and drug use from preprogram to postprogram. While this result pertained to only one offender, and it may be a spontaneous, unrelated change, it would not be unexpected to see this type of result again. Past research has found that offenders describe the restorative justice process as very difficult, with the meeting being the most difficult part (Rugge et al., 2005). It is possible that the increase is reflective of a coping mechanism for these offenders. Overall, for the $58.7 \%(n=54)$ of participants who exhibited at least one physical health problem at preprogram, $63.0 \%(n=34)$ exhibited a positive change and $20.4 \%(n=11)$ exhibited no change in the number of physical health symptoms from preprogram to postprogram.

\section{Social Support}

Past research has suggested that some victims and offenders enter the restorative justice process with a higher number of needs (Rugge et al., 2005). There has been discussion over the years amongst various restorative justice programs as to why this is the case. At first reflection, it could be assumed that the higher need victims have experienced a more traumatizing, serious person-based crime, and that higher need offenders are high-risk offenders that have a high number of criminogenic needs. However, a recent study found that this is not always the case (Rugge et al., 2005). One of the secondary goals of restorative justice is to reintegrate the victim and offender back into their community, drawing on their respective social networks. Another premise of restorative justice is to assist in building social networks for those participants who are 
lacking social support. Given this, along with the research that has found that social support plays a positive role in an individual's ability to successfully deal with traumatizing or stressful events (Gal, 2003; Greenberg \& Ruback, 1992; NolenHoesksema \& Davis, 1999; Norris et al., 1997; Park et al., 1996; Park, 1998), this study incorporated a social support component.

Specifically, the presence of social support has been linked to positive psychological health outcomes (e.g, increased psychological well-being; Lambert et al., 1990) as well as positive physical health outcomes (e.g., decreased susceptibility to disease, lower mortality rates, lower cardiovascular reactivity, and enhanced immune functioning (Blazer, 1982; Jemmot \& Magliore, 1988; Kamarck et al., 1990). Furthermore, social support research has found that the perception of social support is as important as the presence of actual support (Dolbier \& Steinhardt, 2000; Gal, 2003; Hill, 2004; Norris et al., 1997). Given the nature of the restorative justice process, it was more feasible to collect information on perceived social support; therefore, this study incorporated an examination of perceived social support and its relationship to changes in psychological and physical health.

Somewhat surprisingly, there was not a significant relationship between sense of social support and physical and psychological health. The majority of participants evidenced high levels of perceived social support, both at preprogram and postprogram. Although victims scored slightly higher, indicating that they felt that had a higher level of support than offenders, this difference was not significant. Younger participants (i.e., under 18 years of age) felt they had less support than adults, though this perhaps can be explained by the turmoil of the teenaged years. 
Nevertheless, a sense of social support was not correlated with the number of psychological and physical health indicators (as measured by the $\mathrm{PsC}$ and the $\mathrm{PhC}$ ), as expected. There are a number of other possibilities that may explain this finding. This hypothesis was based on previous findings of a restorative justice program that dealt with participants who experienced a serious crime. In that case, facilitators identified only some participants who were high-need (Rugge et al., 2005). One of the programs included in this current study was the program that was examined in the Rugge et al. report (2005). Therefore, discussions with program staff were possible, to determine, non-empirically, whether the samples differed in terms of need. High-need cases are usually memorable cases. Discussions with program staff, and a review of the files, indicated that there were fewer high-need participants in this sample than in the previous evaluation. One possible explanation was that high-need participants lacked social support. Therefore, although there may have been differences in social support for the participants in the previous evaluation, there were fewer high-need participants in this sample, which may have explained why no differences were detected. In essence, none of the participants were particularly high-need, and it is with these participants that differences in social support were expected. Another possibility is that the explanation posited is simply not the case.

It is also possible that only individuals with a high sense of social support entered the restorative process, as it could be perceived as a "risky" endeavour, one that may only be entered if an individual felt that they had the presence of social support, should it be needed. Another possibility is that perhaps individuals with a high level of perceived social support are more outgoing and more likely to engage in conversation with others, 
perhaps making the process, and potentially a meeting, less intimidating. There are many possibilities. However, generally speaking, the majority of participants in this study exhibited high levels of perceived social support, and this was consistent over the course of the program.

Impacts of Participant Satisfaction, Victim-Offender Meetings, Offence Type and Offender Risk Level

Previous research has found that there is a positive association of consumer satisfaction with services and outcomes (Carlson \& Gabriel, 2001; Lebow, 1982; Pandiani et al., 2001). Therefore, it was hypothesized that in order to derive optimal benefits from the restorative justice process, participants need to be satisfied. Results indicated that participant satisfaction was associated with changes in physical health and psychological health, in that participants who were more satisfied evidenced a greater degree of positive change. These results support previous research that suggests that participant satisfaction is needed in order for optimal outcomes to occur.

As reviewed earlier, research has also suggested that a victim-offender meeting may result in a "richer" experience (Braithwaite, 2002), and that satisfaction levels may vary depending on the type of restorative justice process that participants experience. This study examined this issue in two ways. First, satisfaction levels were compared for participants who experienced a victim-offender meeting with those who did not. No significant differences were found for victims; however, a significant difference was found for offenders. Specifically, offenders were more satisfied if they did not experience a meeting and, although not significant, victim responses suggested that the opposite was true. These results are intriguing but may be explained by the following. 
Past research has found that both offenders and victims cite the meeting as one of the most difficult, but also one of the most rewarding, aspects of the restorative justice process (Rugge et al., 2005). While the meeting may be difficult for both parties, offenders may find it particularly difficult to meet face-to-face with their victim(s) and admit guilt, apologize, take responsibility, and attempt to repair the harm they caused. Offenders may feel obligated to agree to meet the victims, in order to be accepted into a restorative justice process, whereas victims are provided with a choice (in the CJP a meeting is optional, and in the LCCJP victims could choose not to participate in the program if they do not want to meet). Therefore, an offender may feel relieved, and thereby satisfied, if they do not have to go through with the meeting, but can respond to victim requests in an alternative manner. For victims, while the meeting may be very emotionally draining, they get to "see" the remorse, hear the apology in person, and communicate directly to the offender the impact the crime had on them, and the reparative actions they would like to receive from the offender. This process can be very satisfying. For victims who chose not to meet, again, that was their choice, and they may be satisfied in that they had a choice, but also because they did not have to do something that they were reluctant or anxious about doing.

Second, the importance of the victim-offender meeting was examined in relation to changes in participant health. If it holds that the restorative justice process is more beneficial and richer if there is a meeting (and this is still debated), it may be that the presence of a meeting may result in higher levels of health change for participants who experienced a meeting when compared to those who did not. This was not the case in this study, and research needs to continue to examine the impacts of a victim-offender 
meeting. The results of this study suggest that a meeting does not need to occur in order for participants to be satisfied, or for them to receive positive benefits from the restorative justice process.

It was expected that offence type might play a role, in terms of satisfaction levels as well as the number of degree of symptoms exhibited by participants. While it was expected that participants who experienced a crime against the person might be different from those who experienced a less-serious crime (e.g., property crime), this was not the case in this study. There were no differences between participants who experienced a crime against the person and those who did not in regards to physical health or psychological health change.

Linking closely with offence type, offender risk level was also taken into consideration, in terms of health change and satisfaction. Results indicated that neither offence type, nor offender risk level was related. Consistent with past restorative justice research (Bonta et al., 2006), the majority of the offenders in this sample were found to be low-risk. This suggests that low-risk offenders may be more interested in participating in restorative justice processes. In the case of the program that deals with serious crime, it suggests that an offender who commits a serious crime is not necessarily a high-risk offender.

Reflections

Research in the restorative justice field can be challenging. Sometimes there are many learnings that do not come from the data itself. This study results in some additional "findings" that may inform future research. First, program staff are very proud of their programs and very protective of the clients they serve; this is certainly a positive 
position. However, this translated into a number of practical considerations for researchers. Program staff need to be involved in the research, from a questionnaire development perspective, but also in terms of implementing and carrying out the research within the program (as they are usually the ones who initially introduce the research).

Second, restorative justice processes are flexible and do not always fit nicely into a structured research methodology. Formalized assessment or procedures are recognized as important, but not always adhered to. Facilitators recognize participants' needs and adapt accordingly. Structure is not always useful in this regard.

Third, communication in the restorative justice process takes place informally and at the participant's pace. Administration of standardized questionnaires, rather than open-ended, informal communication, can be challenging. There is also the time factor. After a participant has spent several hours speaking with his or her caseworker, they then needed to spend almost an hour talking to researchers in an interview. While there were many items that were worthy of exploration from a research perspective, interviews had to remain reasonable in length. Even in this study, there was some concern as to whether the participants' responses were less reliable towards the end of the interview.

The last learning that will be presented has to do with the use of the impression management subscale (of the Paulhus Deception Scales; Paulhus, 1991). First, there was reluctance among program staff to include a measure that could potentially assess "deception"; even the word itself caused concern. Next, even if they agreed that offenders had potential motivation to deceive (or impression manage), considering this for victims was uncomfortable territory. Fellow researchers, as well as program staff needed to be convinced as to its merits. However, concerns about including the measure 
did not end here. There was discussion among those who were more familiar with the instrument as to whether the interview process with the researcher was considered a highdemand situation (i.e., one where there would be a need to impress). It is possible that offenders who are trying to enter a restorative justice program (i.e., appearing remorseful to the caseworker at intake, etc.) may exercise impression management. However, it is also possible that victims may do the same (e.g., if a victim's real motive is revenge, he or she may have to appear open to the restorative process in order to be accepted into the program). In both instances, any distortion would be more likely to occur with program staff as opposed to research staff as the interviews were completely confidential. If this is the case, high impression management scores may very well indicate a participant's personality traits and desire to adhere to social convention (Paulhus, 1991).

Based on this experience, it is recommended that researchers step back and revisit the larger issue. While the scale was originally included to increase the integrity of the data collected, it certainly raised concerns about its other potential uses. The issue of deception, and impression management are closely linked to the ongoing debate about the need for offender assessment, as offenders become involved in restorative justice processes. While offenders are currently "assessed" by program staff, the assessment is more concerned about the offender's willingness to admit responsibility, be truthful and open to repairing the harm caused.

The inclusion of standardized risk assessment instruments, administered by trained administrators, may prove beneficial. This debate is ongoing - restorative justice programs attempt to meet the needs of offenders, but have no means of assessing criminogenic needs, those needs that are associated with criminal behaviour. While most 
restorative justice programs specifically indicate that they do not want recidivism to be a measure of success, there is little doubt that it is certainly an outcome measure that program funders dictate must be examined. The issues of offender assessment, as well as the usefulness of using recidivism as an outcome measure, were not addressed in this study, but they should be considered.

\section{Limitations}

While there are many interesting and important findings in this study, there were limitations. First and foremost was the absence of a formal control group. While consideration was given to obtaining a comparison group from the traditional court system, past research exists indicating that there are differences between the two groups (Rugge et al., 2005). The purpose of this study was to examine changes in psychological and physical health within the restorative justice population, comparing across groups of participants who received different types of restorative justice services (i.e., meeting versus no meeting). Therefore, the comparisons that were important for this study were those across different levels of a restorative justice process (e.g., meeting versus no meeting), rather than to a comparison group who did not receive any restorative justice process

Second, and perhaps just as important as the first limitation, is that although the results indicated that change occurred, there is no way of knowing whether this change was due primarily to the restorative justice process. In order to address this limitation, statistical options were explored. While there are statistical means of assessing reliable and clinically reliable change, these means were not feasible given the instruments used in this study. 
Third, this study used an informal and unstandardized method to determine the number of health problems participants exhibited. While it would have been preferential to include standardized measures, this research was limited in the number of questions that could be added to an ongoing research evaluation. Standardized assessment instruments assessing physical and psychological health would also have resulted in a larger number of indicators being examined. Overall, however, this study did examine a number of items, and provided a preliminary indication that this area is worthy of additional examination.

Fourth, the issue of sample size must be considered. In order to partially address this concern, additional methods of assessing significance were utilized where appropriate when interpreting statistical results. While results did not appear to be affected by the size of the sample, a larger sample would have allowed for additional statistical analyses, in addition to increased credibility and generalizablitity of the results.

\section{Future Research}

As indicated in the introduction, restorative justice research is still in its infancy. While there are things that researchers are fairly certain of (e.g., the restorative justice process is generally more satisfying when compared to the traditional justice system), there are many, many areas left to be explored. Hence, the future research possibilities are endless. In the context of this study, the findings support previous preliminary research that suggests that restorative justice processes may have a positive impact on participants' psychological and physical health. This study added to the restorative justice field by specifically examining many specific indicators of physical and psychological health of program participants, and the change of these indicators over the 
course of the restorative justice process. Furthermore, social support was included to examine its role in restorative justice processes. Future research should more closely examine the various indicators, and incorporate standardized instruments that measure these areas. Lastly, there is also a need for restorative justice researchers to continue to explore theoretical models of restorative justice. In addition to validating current restorative justice theories, research should also examine various psychological theories (e.g., social learning theory) as these may contribute to the development of solid theoretical models of restorative justice processes. 


\section{References}

American Psychological Association (n.d.). Press Release. Available online at: http://www.apa.org/release/stress_immune.html. Accessed on July 30, 2005.

Andrews, D. A., \& Bonta, J. (2003). The psychology of criminal conduct $\left(3^{\text {rd }}\right.$ ed.). Cincinnati, $\mathrm{OH}$ : Anderson Publishing.

Andrews, D. A., \& Bonta, J. (1995). Level of Service Inventory-Revised. Multi-Health Systems Inc. Toronto, Canada.

Andrews, D. A., \& Bonta, J. (1998). Level of Service Inventory - Screening Version. Multi-Health Systems Inc. Toronto, Canada.

Andrews, D. A., \& Bonta, J. (1998). Level of Service Inventory - Screening Version: User's Manual. Multi-Health Systems Inc. Toronto, Canada.

Atkins, D. C., Bedics, J. D., McGlinchey, J. B., \& Beauchaine, T. P. (2005). Assessing clinical significance: Does it matter which method we use? Journal of Consulting and Clinical Psychology, 73(5), 982-989.

Barret, T. W., \& Mizes, J. S. (1988). Combat level and social support in the development of post-traumatic stress disorder in Vietnam Veterans. Behavior Modification, 12, $100-115$.

Baumeister, R., \& Leary, M. R. (1995). The need to belong: desire for interpersonal attachments as a fundamental human motivation. Psychological Bulletin, 117, 497529.

Bazemore, G., \& Griffiths, C. T. (1997). Conferences, circles, boards, and mediations: The "New Wave" of community justice decision-making. Federal Probation, 61(2), $25-37$. 
Bazemore, G., \& Umbreit, M. (1994). Rethinking the sanctioning function in juvenile court: Retributive or restorative responses to youth crime. Unpublished manuscript.

Bazemore, G., \& Umbreit, M. (1994). Balanced and Restorative Justice: Program Summary: Balanced and Restorative Justice Project. Washington, D.C.: U.S. Department of Justice, Office of Juvenile Justice and Delinquency Prevention.

Beven, J. P., Hall, G., Froyland, I., Steels, B., \& Goulding, D. (2005). Psychiatry, Psychology and Law, 12(1), 194-206.

Birmes, P., Carreras, D., Ducassé, J. L., Charlet, J. P., Warner, B. A., Lauque, D., \& Schmitt, L. (2001). Peritraumatic dissociation, acute stress, and early posttraumatic stress disorder in victims of general crime. Canadian Journal of Psychiatry, 46, $649-651$.

Blazer, D. G. (1982). Social support and mortality in an elderly community population. American Journal of Epidemiology, 115, 684-694.

Boney-McCoy, S., \& Finkelhor, D. (1996). Is youth victimization related to trauma symptoms and depression after controlling for prior symptoms and family relationships? A longitudinal, prospective study. Journal of Consulting and Clinical Psychology, 64(6), 1406-1416.

Bonta, J., Jesseman, R., Rugge, T., \& Cormier, R. (2006). Restorative justice and recidivism: Promises made, promises kept? In D. Sullivan \& L. Tift (Eds.), Handbook of Restorative Justice: A Global Perspective (pp. 108-120). New York, NY: Routledge. 
Bonta, J., Wallace-Capretta, S., Rooney, J., \& McAnoy, K. (2002). An outcome evaluation of a restorative justice alternative to incarceration. Contemporary Justice Review, 5(4), 319-338.

Braithwaite, J., \& Mugford, S. (1994). Conditions of successful reintegration ceremonies. British Journal of Criminology, 34, 139-171.

Braithwaite, J. (1989). Crime, Shame and Reintegration. United Kingdom: Cambridge University Press.

Braithwaite, J. (1996). Restorative justice and a better future. Dorothy J. Killam Memorial Lecture. Dalhousie University, October.

Braithwaite, J. (1999). Restorative justice: Assessing optimistic and pessimistic accounts. In M. Tonry (Ed.), Crime and justice: A review of research (pp. 1-127). Chicago: University of Chicago Press.

Braithwaite, J. (2002). Restorative Justice and Responsive Regulation. New York: Oxford University Press.

Broidy, L., Cauffman, E., Espelage, D. L., Mazerolle, P., \& Piquero, A. (2003). Sex differences in empathy and its relation to juvenile offending. Violence and Victims, 18(5), 503-516.

Brown, G. W., \& Harris, T. O. (1978). Social Origins of Depression: A Study of Psychiatric Disorder in Women. New York: Free Press.

Campbell, R., \& Raja, S. (1999). The secondary victimisation of rape victims: Insights from mental health professionals who treat survivors of violence. Violence and Victims, 14, $261-275$. 
Campbell, R., Sefl, T., Barnes, H. E., Ahren, C. E., Wasco, S. M., \& Zaragoza-Diesfeld, Y. (1999). Community services for rape survivors: Enhancing psychological well-being or increasing trauma? Journal of Consulting and Clinical Psychology, 67(6), 847-858.

Canada, House of Commons. (1988). Taking Responsibility: Report of the Standing Committee on Justice and Solicitor General on its Review of Sentencing, Conditional Release and Related Aspects of Corrections. Ottawa: Supply and Services Canada.

Carlson, M. J. \& Gabriel, R. M. (2001). Patient satisfaction, use of services, and one-year outcomes in publicly funded substance abuse treatment. Psychiatric Services, 52, $1230-1236$.

Casarez-Levision, R. (1992). An empirical investigation of coping strategies used by victims of crime: Victimization redefined. In E. Viano(Ed.), Critical issues in victimology: International perspectives (pp. 46-57). New York: Springer Publishing Co.

Chatterjee, J. (1999). A report on the evaluation of $R C M P$ restorative justice initiative: Community justice forum as seen by participants. Ottawa: Royal Canadian Mounted Police.

Church Council on Justice and Corrections (n.d.). Church Council on Justice and Corrections website. Available Online at: http://www.ccjc.ca/main.cfm. Accessed on May 12, 2005.

Clairmont, D. (2005). The Nova Scotia Restorative Justice Initiative: Final Evaluation Report. Ottawa: National Crime Prevention Centre. Government Report. 
Cohen, F. (1980). Coping with surgery: Information, psychological preparation, and recovery. In L. W. Poon (Ed.), Aging in the 1980's (pp.375-382). Washington: APA.

Cohen, J. (1992). A power primer. Psychological Bulletin, 112, 155-159.

Cohen, R. L. (2001). Provocations of restorative justice. Social Justice Research, 14(2), 209-232

Cohen, R. L. (2001). Regret, reconciliation, and restorative justice: Introduction to a special issue of social justice research. Social Justice Research, 14(2), 121-124.

Cohen, S., \& Syme, S.L. (1985). Social Support and Health. Orlando, Fl: Academic Press.

Cohen, S., \& Wills, T. A. (1985). Stress, social support, and the buffering hypothesis. Psychological Bulletin, 98, 310-357.

Cormier, R. B. (2002). Restorative justice: Directions and principles-developments in Canada. Solicitor General Canada, User Report 2002-02.

Criminal Code of Canada (2005). Martin's Annual Criminal Code 2005. Aurora, Ontario: Canada Law Book Inc.

Cullen, F. T. (1994). Social support as an organizing concept for criminology: Presidential address to the Academy of Criminal Justice Sciences. Justice Quarterly, 11, 527-559.

Daly, K. (2005). A tale of two studies: Restorative justice from a victim's perspective. In E. Elliott \& R. M. Gordon (Eds.), New Directions in Restorative Justice: Issues, Practice, Evaluation (pp. 153-174). United Kingdom: Willan Publishing. 
Deci, E. L., \& Ryan, R. M. (1991). A motivational approach to self: Integration in personality. In Nebraska Symposium on Motivation: perspectives on Motivation, No. 38 (pp. 237-288). Lincoln: University Nebraska Press.

Department of Justice, Canada. (2000). Restorative Justice in Canada: A Consultation Paper. Ottawa, Ontario.

Department of Justice, Nova Scotia. (1998). A Program for Nova Scotia: Restorative Justice. Halifax, Nova Scotia.

Dohrenwend, B. S., \& Dohrenwend, B. P. (1974). Stressful Life Events: Their Nature and Effects. New York: Wiley Publishing.

Dolbier, C. L., \& Steinhardt, M. A. (2000). The development and validation of the sense of support scale. Behavioral Medicine, 25(4), 169-179.

Dunlap, W. P., Cortina, J. M., Vaslow, J. B., \& Burke, M. J. (1996). Meta-analysis of experiments with matched groups or repeated measures designs. Psychological Methods, 1, 170-177.

Evans, C., Margison, F., \& Barkham, M. (1998). The contribution of reliable and clinically significant change methods to evidence-based mental health. Evidence Based Mental Health, 1, 70-72.

Fattah, E. A. (2001). Victims' rights: Past, present and future. A global view. In R. Cario and D. Salas (Eds.), Euvre de Justice et Victimes, 1. Paris: L'Harmattan Sciences Criminelles.

Fava, G. A., \& Sonino, N. (2000). Psychosomatic medicine: Emerging trends and perspectives. Psychotherapy and Psychosomatics, 69, 184-197. 
Folkman, S., \& Moskowitz, J. T. (2004). Coping: Pitfalls and promise. Annual Review of Psychology, 55, 745-574.

Gal, M. (2003). An investigation of the impact of chronic work stress and critical incidents on correctional staff and the factors that moderate it. Unpublished doctoral dissertation, Carleton University, Ottawa.

Gara, M. A., Woolfolk, R. L., \& Allen, L. A. (2002). Social cognitive complexity and depression: Cognitive complexity moderates the correlation between depression self-ratings and global self-evaluation. Journal of Nervous and Mental Disease, $190(10), 670-676$.

Gendreau, P. (2001). We must do a better job of cumulating knowledge. Canadian Psychology, 43(3), 205-210.

Greenberg, M. S., \& Ruback, R. B. (1992). After the Crime: Victim Decision Making. New York: Plenum Press.

Greer, M. (2005). Mental stress wreaks physical havoc on workers. Monitor on Psychology, 36(5), 28-29.

Hahn, P. (1998). Emerging Criminal Justice: Three Pillars for a Proactive Justice System. Thousand Oaks, CA: Sage Publications.

Hartwig, H. J., \& Myers, J. E. (2003). A different approach: Applying a wellness paradigm to adolescent female delinquents and offenders. Journal of Mental Health Counseling, 25(1), 57-75.

Hill, J. K. (2004). Working with victims of crime: A manual applying research to clinical practice. Ottawa: Department of Justice Canada. 
Hoge, R., \& Andrews, D. A. (2002). Youth Level of Service Case Management Inventory. Multi-Health Systems Inc. Toronto, Canada.

Hoge, R., \& Andrews, D. A. (2004). Youth Level of Service Case Management Inventory - Screening Version. Unpublished document. Department of Psychology, Carleton University.

Holmes, T. H., \& Rahe, R. (1967). The social readjustment rating scale. Journal of Psychosomatic Research, 11, 213-218.

House, J. S., \& Khan, R. L. (1985). Measures and concepts of social support. In S. Cohen and S. L. Syme (Eds.), Social Support and Health (pp.83-108). Orlando, Florida: Academic Press.

Hudson, J., \& Gallaway, B. (1996). Introduction. In B. Gallaway \& J. Hudson (Eds.), Restorative justice: International perspectives (pp. 1-14). Monsey, NY: Criminal Justice Press.

Hughes, P., \& Mossman, M. J., (2001). Re-thinking Access to Criminal Justice in Canada: A Critical Review of Needs, Responses and Restorative Justice Initiatives. Research \& Statistics Division, Department of Justice Canada. Available online at: http://canada.justice.gc.ca/en/ps/rs/rep/2003/rr03-2.pdf.

Jacobson, N. S., \& Truax, P. (1991). Clinical significance: A statistical approach to defining meaningful change in psychotherapy research. Journal of Consulting and Clinical Psychology, 59(1), 12-19.

Jung, S., \& Rawana, E. P. (1999). Risk and need assessment of juvenile offenders. Criminal Justice and Behavior, 26, 69-89. 
Kong, R. (2004). Victim services in Canada, 2002/03. Juristat, 24(11). Statistics Canada. Catalogue no. 85-002-XPE.

Koss, M. P., Koss, P. G., \& Woodruff, W. J. (1991). Deleterious effects of criminal victimization on women's health and medical utilization. Archives of Internal Medicine, 151(2), 342-347.

Krug, A. (n.d). Benton County Oregon Juvenile Department Services. Available online: http://www.co.benton.or.us/juvenile/services/mediation.html. Accessed July 30, 2005

Lambert, V. A., Lambert, C. E., Klipple, G. L., \& Mewshaw, E. A. (1990). Relationships among hardiness, social support, severity of illness and psychological well being in women with rheumatoid arthritis. Health Care for Women International, 11, 159173.

Landman, J. (2001). The limits of reconciliation: The story of a perpetrator, Katherine Ann Power. Social Justice Research, 14(2), 171-188.

LaPrairie, C. (1992). Aboriginal crime and justice: Explaining the present, exploring the future. Canadian Journal of Criminology, 34, 281-297.

Latimer, J., Dowden, C., \& Muise, D. (2001). The effectiveness of restorative justice practices: A meta-analysis. Ottawa: Department of Justice Canada.

Lazarus, R. S., \& Folkman, S. (1984). Stress, Appraisal and Coping. New York: Springer.

Leahy, T., Pretty, G., \& Tenenbaum, G. (2003). Childhood sexual abuse narratives in clinically and nonclinically distressed adult survivors. Professional Psychology: Research and Practice, 34(6), 657-665. 
Lebow, J. (1982). Consumer satisfaction with mental health treatment. Psychological Bulletin, 91, 244-259.

Lepore, S. J., Silver, R. C., Wortman, C. B., \& Wayment, H. A. (1996). Social constraints, intrusive thoughts and depressive symptoms among bereaved mothers. Journal of Personality and Social Psychology, 70, 271-282.

Levine, M. (2000). The family group conferencing model in the New Zealand Children, Young Persons, and Their Families Act of 1989: Review and evaluation. Behavioral Sciences and the Law, 18, 517-556.

Llewellyn, J., \& Howse, R. (1998). Restorative justice: A conceptual framework. Ottawa, ON: Law Commission of Canada.

Lyons, J. A. (1989). Strategies for adjusting the potential positive adjustment following trauma. Journal of Traumatic Stress, 40, 93-111.

Makkai, T., \& Braithwaite, J. (1994). Reintegrative shaming and regulatory compliance. Criminology, 32, 361-385.

Markesteyn, T. (1992). The psychological impact of nonsexual criminal offenses on victims. Ottawa: Public Safety \& Emergency Preparedness Canada, No. 1992-21.

McCold, P. (1999). Restorative justice practice: The state of the field. Community Service Foundation. Pipersville, Pennsylvania.

McCold, P., \& Wachtel, T. (2002). Restorative justice theory validation. In E. G. M. Weitekamp \& H. J. Kerner (Eds.), Restorative Justice Theoretical Foundations (pp. 110-142). United Kingdom: Willan Publishing.

McFarlane, A. C., Atchison, M., Rafalowica, E., \& Papay, P. (1994). Physical symptoms in post-traumatic stress disorder. Journal of Psychosomatic Research, 38, 715-726. 
McFarlane, A.C. \& Yehuda, R. (1996). Resilience, vulnerability, and the course of posttraumatic reactions. In B. van der Kolk, A. C. McFarlane, \& L. Weisaeth. (Eds.), Traumatic stress: The effects of overwhelming experience on mind, body, and society (pp 155-181). New York: Guilford Press.

Mezy, G. (1988). Reactions to rape: Effect, counseling and the role of health professionals. In M. Maguire \& J. Pointing (Eds.), Victims of Crime: A new deal (pp. 66-73). Milton Keyes: Open University Press.

Mikulincer, M., \& Florian, V. (1998). The relationship between adult attachment styles and emotional and cognitive reactions to stressful events. In J. A. Simpson \& W. S. Rholes (Eds.), Attachment Theory and Close Relationships (pp. 143-165). New York: Guilford Press.

Nolen-Hoesksema, S., \& Davis, C. G. (1999). Thanks for sharing that: Ruminators and their social support networks. Journal of Personality and Social Psychology, 77(4), 801-814.

Norris, F. H., \& Kaniasty, K. (1996). Received and perceived social support in times of stress: A test of the social support deterrence model. Journal of Personality and Social Psychology, 71, 498-511.

Norris, F. H., Kaniasty, K., \& Thompson, M. P. (1997). The psychological consequences of crime: Findings from longitudinal population-based studies. In R. C. Davis, A. J. Lurigo \& W. G. Skogan (Eds.), Victims of Crime (pp. 146-166). Thousand Oaks, CA: Sage Publications. 
Pandiani, J. A., Banks, S. M., \& Schacht, L. M. (2001). Consumer satisfaction and incarceration after treatment. Administration and Policy in Mental Health, 29(2), $145-155$

Park, C. L. (1998). Stress-related growth and thriving through coping: The roles of personality and cognitive processes. Journal of Social Issues, 54, 337-355.

Park, C. L., Cohen, L. H., Murch, R. (1996). Assessment and prediction of stress-related growth. Journal of Personality, 64, 71-105.

Paulhus, D. (1998). Paulhus Deception Scales. Multi-Health Systems Inc. Toronto, Canada.

Paulhus, D. (1998). Paulhus Deception Scales: User's Mamual. Multi-Health Systems Inc. Toronto, Canada.

Peachey, D. E. (1989). The Kitchener experiment. In Wright, M., \& Galaway, B. (Eds.), Mediation and criminal justice: Victims, offenders and community (pp. 14-26). Newbury Park, CA: Sage.

Roach, K. (2000). Changing punishment at the turn of the century: Restorative justice on the rise. Canadian Journal of Criminology, 42, 249-280.

Roberts, T. (1995). Evaluation of the Victim-Offender Mediation Project, Langley, B.C. Ottawa: Solicitor General Canada.

Rozanski, A., Blumenthal, J.A., \& Kaplan, J. (1999). Impact of psychological factors on the pathogenesis of cardiovascular disease and the implications for therapy. Circulation, 99, 2192-2217. 
Rugge, T., Bonta, J., \& Wallace-Capretta, S. (2005). Evaluation of the Collaborative Justice Project: A Restorative Justice Program for Serious Crime. Ottawa: Public Safety and Emergency Preparedness Canada, User Report 2005-02.

Rugge, T. \& Cormier, R. B. (2005). Restorative justice in cases of serious crime: an evaluation. In E. Elliott \& R. M. Gordon (Eds.), New Directions in Restorative Justice: Issues, Practice, Evaluation (pp. 266-277). United Kingdom: Willan Publishing.

Ryff, C. D. (1989). Happiness is everything or is it? Explorations on the meaning of psychological well being. Journal of Personality and Social Psychology, 57, 10691081.

Ryff, C. D., Singer, B., Wing, E., \& Love, G. D. (2001). Elective affinities and invited agonies: mapping emotion with significant others onto health. In C. D. Ryff \& B. Singer (Eds.), Emotion, Social Relationships and Health: Third Annual Wisconsin Symposium on Emotion (pp. 133-175). New York: Oxford University Press.

Scheff, T. (1998). Community conferences: Shame and anger and therapeutic jurisprudence. Revista Juridica Universidad de "Puerto Rico, 67, 97-119.

Schmidt, F., Hoge, R. D., \& Gomes, L. (2005). Reliability and validity analyses of the youth level of service/case management inventory. Criminal Justice and Behavior, 32(3), 329-344.

Segerstrom, S. C., \& Miller, G. E. (2005). Psychological stress and the human immune system: A meta-analytic study of 30 years of inquiry. Psychological Bulletin, $130(4), 601-630$ 
Sherman, L. (2003). Reason for emotion: Reinventing justice with theories, innovations and research - the American Society of Criminology 2002 Presidential Address. Criminology, 41, 1-38.

Sherman, L. W., \& Strang, H. (1997). The Right Kind of Shame for Crime Prevention. RISE Working Paper 1. Canberra: Law Program, RSSS, Australian National University.

Sherman, L. W., Strang, H., \& Woods, D. J. (2000) [Internet] Recidivism patterns in the Canberra reintegrative shaming experiments (RISE). Canberra, Centre for Restorative Justice, Research School of Social Sciences, Australian National University. Available online at: http://www.aic.gov.au/rjustice/rise/recidivism/ Accessed 1st February, 2005.

Solomon, Z., Mikulincer, M., \& Avitzur, E. (1988). Coping, locus of control, social support and combat related post-traumatic stress disorder: A prospective study. Journal of Personality and Social Psychology, 55(2), 279-285.

Sonino, N., \& Fava, G. A. (1998). Psychological aspects of endocrine disease. Clinical Endocrinology, 49, 1-7.

Sonino, N, Fava, G. A., \& Boscaro, M. (1993). A role for life events in the pathogenesis of Cushing's disease. Clinical Endocrinology, 38, 261-264.

Statistics Canada. (1999). General social survey, 1999, Cycle 13 Victimization, Questionnaire package. Ottawa.

Strang, H. (2002). Repair or Revenge: Victims and Restorative Justice. Oxford: Clarendon Press.

Sullivan, S. (2005). Victims and the criminal justice system. Justice Report, 20(3), 9-11 
Thoits, P. A. (1995). Stress, coping, and social support processes: where are we? What next? Journal of Health and Social Behavior, 35, 53-79.

Uchino, B. N., Cacioppo, J. T., \& Kiecolt-Glaser, J. K. (1996). The relationship between social support and physiological processes: A review with emphasis on underlying mechanisms and implications for health. Psychological Bulletin, 199, 488-511.

Uchino, B. N., Uno, D., \& Holt-Lunstad, J. (1999). Social support, physiological processes and health. Current Directions in Psychological Science, 8, 145-148.

Umbreit, M. S. (1994). Victim Meets Offender: The Impact of Restorative Justice and Mediation. Monsey, New York: Criminal Justice Press.

Umbreit, M. S. (1995). Mediation of Criminal Conflict: An Assessment of Programs in Four Canadian Provinces. Minnesota, U.S.A.: The Center for Restorative Justice and Mediation, University of Minnesota.

United Nations (2002). Basic Principles on the Use of Restorative Justice Programmes in Criminal Matters. The United Nations document containing this resolution is titled: Resolutions and decisions adopted by the Economic and Social Council at its substantive session of 2002, E/2002/INF/2/Add.2. Available online:

http://www.un.org/esa/coordination/ecosoc/doc2002.htm

van de Ven, J. T. C. (2004). Assessment of risk and need factors and service use in diverted youth. Unpublished doctoral dissertation, Carleton University, Ottawa.

Van Ness, D. W. (2002). United Nations Economic and Social Council Endorses Basic Principles of Restorative Justice. Available online:

http://www.restorativejustice.org/rj3/Feature/August02/ECOSOC\%20Acts.htm. 
Van Ness, D. W. (2002a). The shape of things to come: a framework for thinking about a restorative justice system. In E. G. M. Weitekamp \& H. J. Kerner (Eds.), Restorative Justice Theoretical Foundations (pp. 1-20). United Kingdom: Willan Publishing.

Van Stokkom, B. (2002b). Moral emotions in restorative justice conferences: Managing shame, designing empathy. Theoretical Criminology, 6(3), 339-360.

Viano, E. (1978). Victims, offenders and the criminal justice system: Is restitution an answer? In B. Galaway and J. Hudson (Eds.), Offender Restitution in Theory and Action (pp. 91-99). Lexington, MA: Lexington Books.

Webster, C., Harris, G., Rice, M., Cormier, C., \& Quinsey, V. (1994). The Violent Prediction Scheme: Assessing Dangerousness in High Risk Men. Toronto: University of Toronto.

Weitekamp, E. G. M., \& Kerner, H. J. (2002). Restorative Justice Theoretical Foundations. United Kingdom: Willan Publishing.

Wemmers, J., \& Cyr, K. (2005). Can mediation be therapeutic for crime victims? An evaluation of victims' experiences in mediation with young offenders. Canadian Journal of Criminology and Criminal Justice, 47(3), 527-544.

Werthington, E., \& Kessler, R. C. (1986). Perceived support, received support and adjustment to stressful life events. Journal of Health and Social Behavior, 27. 7889.

Wexler, D., \& Winick, B. (1996). Law in a Therapeutic Key: Developments in Therapeutic Jurisprudence. Durham, NC: Carolina Academic Press. 
Winick, B. (1996). The jurisprudence of therapeutic jurisprudence. In D. Wexler and B. Winick, Law in a Therapeutic Key: Developments in Therapeutic Jurisprudence. Durham, NC: Carolina Academic Press.

Wright, R.J., Rodriguez, M, \& C Cohen, S. (1998). Review of psychological stress and asthma. Thorax, 53, 1066-1074.

Zehr, H. (1990). Changing Lenses. Waterloo, ON: Herald Press.

Zehr, H. (1995). Changing Lenses: A New Focus for Crime and Justice. Waterloo, ON: Herald Press.

Zehr, H. (2002). The Little Book of Restorative Justice. Intercourse, PA: Good Books. 
Appendix A

PSEPC Information Sheet For Victims \& Offenders 


\title{
Research Evaluation of the Lanark County Community Justice Program
}

\author{
The Impact of Restorative Justice Practices
}

\section{Information Sheet for Participants}

Purpose: Public Safety and Emergency Preparedness Canada (PSEPC) is conducting an evaluation of the Lanark County Community Justice Program (LCCJP) to examine the impacts of restorative processes on participants. In order to examine the impacts and effectiveness of programs such as these, it is necessary to obtain feedback from those who have had direct experiences with the program. It is hoped that by talking with program participants, we can get an understanding of what may need to be done to improve this program to ensure goals and objectives are being met.

Task requirements: Participation in this research evaluation involves two confidential interviews - one to be conducted at the start of the program and one upon completion of the program. In addition, you will be asked to complete a short, self-report research questionnaire just prior to the LCCJP conference.

Duration and locale: The two confidential interviews will be conducted either over the phone or in person - whichever is most convenient for you. Each interview will take approximately 30-45 minutes to complete (time may vary across participants).

Potential risk/discomfort: The questions contained in the confidential interviews and the research questionnaire may be of a sensitive nature. This evaluation is designed to ask questions about your perceptions of safety and risk, your physical and psychological well-being, your relationships, your specific experiences with this program and restorative justice in general. We also ask some demographic questions to obtain a profile of the participants involved with this program. If you do not wish to answer specific questions or you wish to withdraw your participation, you may do so at any time and your participation in LCC.JP will not be affected.

Anonymity/confidentiality: All information collected during the interviews and the research questionnaire will remain strictly confidential and will be used by PSEPC staff for research purposes only. The data collected throughout this evaluation will be coded to ensure no individual will be identifiable. We would like to videotape the conferences however will do so only in the event all conference participants provide consent. These tapes will be used and viewed by PSEPC staff only for research purposes. Videotaping is not a compulsory component of your participation and should you decline consent to be videotaped during the conference, you can still take part in the evaluation.

Right to withdraw: Your participation in this study is completely voluntary and you may withdraw your participation at any time.

Research Personnel: Should you have any questions or concerns, or if require any additional information, please contact us any time at the numbers provided below.

Tanya Rugge, M.A.

Principal Researcher

Corrections Research

(613) $991-2826$
Terri-Lynne Scott, B.A. Evaluation Coordinator Corrections Research (613) $991-5837$

Public Safety and Emergency Preparedness Canada 340 Laurier Avenue West, 10E Ottawa, Ontario K1AOP8 


\section{Appendix B}

PSEPC Consent Form For Victims and Offenders 
Public Saltety and Erinergestey

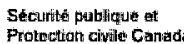

Pieparoudintss Canada

Research Evaluation of the Lanark County Community Justice Program

The Impact of Restorative Justice Practices

Public Safety and Emergency Preparedness Canada

Ottawa, Ontario

\section{Consent Form}

I understand that Public Safety and Emergency Preparedness Canada (PSEPC) is conducting an evaluation of the Lanark County Community Justice Program (LCCJP) to examine the impacts of restorative justice processes on participants. It has been explained to me that I will be contacted by PSEPC researchers to answer questions in two confidential interviews, one at the start and one at the completion of the program. In addition, I understand that I will be asked to complete a confidential research questionnaire prior to the LCCJP conference.

I have been assured that all information gathered will be used by PSEPC for research purposes only and will remain strictly confidential. It has been explained to me that nonidentifying information, including quotations, without attributing them to any specific individual, may be released to LCCJP staff if they are deemed to be particularly useful and descriptive regarding the impact of the Project. I also recognize that participating in this research is voluntary, I may withdraw at anytime without penalty and this is not a condition of participating in the Lanark County Community Justice Project.

\section{Consent to participate in the evaluation}

I have read and understand the above conditions for participation in the evaluation of the Lanark County Community Justice Program.

Signature of Program Participant

Name of Program Participant (Please print)
Date

Best Time to Call

Witness Signature (can be LCCJP facilitator)

Date

Name of Witness (Please print) 
Appendix C

PSEPC Preprogram Interview Package For Victims 


\section{Preprogram Interview Package for Victims}

Please contact the author for a copy of this interview.

Inquires can be made to: tanya.rugge@psepc.gc.ca.

Thank you. 
Appendix D

Physical Health Questions 


\section{Physical Health Questions}

1. How has this incident affected you?

2. (o)At the time of the incident(s), or within the $\mathbf{3 0}$ days following the incident, did you experience any of the following? (Read list Mark all that appiy) (Do not include physical imjury, financial loss, or medical treatment in this question)
$\square$ (12) Sleeping problems
$\square$ (14) Change in eating habits

3. Do you now use alcohol, medication or illegal drugs to stop "thoughts" of the incident? $\square$ (1) Yes $\square$ (3) No

4. Have your drinking habits (or your use of alcohol) changed since the incident? Do you now....
$\square$ (1) Drink more than before the incident
(4) Don't drink ( $g \circ$ to Q 41)
$\square$ (2) Drink about the same as before the incident
(r) Refused
$\square$ (3) Drink less than before the incident

5. In the past month, how often did you drink alcoholic beverages? Was it....
$\square$ (1) Every day?
(Use of alcohol is a measure of a person's healthi)
(2) 4-6 times a week?
(3) 2-3 times a week?
(4) Once a week?
$\square$ (7) Never drinks?
(5) Once or twice in the past month?
$\square$ (x) Don't know
(6) Never in the past month?
$\square$ (r) Refused

6. On how many occasions in the past month, have you had five or more drinks? (Consider a drink to be one beer, one small glass of wine or $1 \% / 2$ oz. of liquor.)

7. Have you ever used drugs? $\square$ (1) Yes $\square$ (3) No

a. If yes, what have you used?

8. Do you currently use drugs? $\square$ (1) Yes $\square$ (3) No

a. If yes, how often and what do you use?

9. Has an alcohol problem or drug problem caused you problems at school or work in the past year? (i.e, been suspended, fired etc) $\square$ (1) Yes $\square$ (3) No

10. Do you regularly have trouble going to sleep or staying asleep? $\square$ (1) Yes $\square$ (3) No

11. During the past month, have you used medication or drugs (prescription or over the counter) to .....
a) Help you sleep?
$\square$ Yes
$\square$ No
Refused 
12. Compared to other people your age, how would you describe your usual state of health? Would you say it is ...

(Refers to long term health, i.e. a condition lasting or expected to last more than 6 months.)

(If the respondent suffers from a temporary injury, ask about his/her usual condition.)
$\square$ (1) Excellent?
$\square$ (3) Good?
$\square$ (5) Poor?
$\square$ (2) Very good?
$\square$ (4) Fair?

13. How would you describe your eating habits? Are they...

(Eat regularly, eat healthy etc.)
$\square$ (1) Excellent?
$\square$ (3) Good?
(5) Poor?
(2) Very good?
(4) Fair?

14. How would you describe your level of exercise, or the amount of exercise you incorporate into your life? Is it...
$\square$ (1) Excellent?
$\square$ (3) Good?
(5) Poor?
(2) Very good?
(4) Fair?

15. In terms of physical health, have there been any changes as a result of the incident that have not been mentioned above? $\square$ (1) Yes

a. If yes, what are those changes?

\section{Other Physical Health-Related Questions to keep in mind when scoring the}

\section{Physical Health Checklist:}

16. Were you physically injured as a result of this incident?

(1) Yes

(3) No

a. If yes, what degree of physical pain do you currently experience?
$\square$ (1) No pain
$\square$ (3) Constant pain
$\square$ (5) Disfiguration
$\square$ (2) Mild discomfort
$\square$ (4) Extreme pain

17. ADULT: Have you missed work, missed any of your responsibilities, or have not been able to meet your obligations due to poor health? $\square$ (1) Yes $\square$ (3) No Y/O: Have you missed school, missed any of your responsibilities, or have not been able to meet your obligations due to poor health? $\square$ (1) Yes $\square$ (3) No

18. ADULT: Has a change in your health, as a result of this incident, interfered with your regular activities, such as playing with your children, exercising with your friends, going for a walk, engaging in leisure activities, cleaning your house, etc.)? $\square(1)$ Yes $\square$ (3) No

Y/O: Has a change in your health, as a result of this incident, interfered with your regular activities, such as exercising with your friends, going for a walk, engaging in leisure activities, etc.)?

$\square$ (1) Yes

(3) No 
Appendix E

Physical Health Checklist 


\section{Physical Health Checklist}

(To be completed based on responses from the Preprogram Interview)

Participant Name:

$\square$ Victim @ Preprogram $\square$ Offender @ Preprogram

$\square$ Victim @ Postprogram $\square$ Offender @ Postprogram

\begin{tabular}{|l|l|l|l|}
\hline Indicators: & $\mathbf{0}=$ no problem & $\mathbf{1}=$ some problem & $\mathbf{2 =}$ major problem \\
\hline Sleeping & & & \\
\hline Eating Habits & & & \\
\hline Alcohol Use & & & \\
\hline Prescribed Drug Use & & & \\
\hline Illegal Drug Use & & & \\
\hline Exercise & & & \\
\hline Other: & & & \\
\hline Participant's Own Health Rating & & & \\
\hline Sub-Totals & & & \\
\hline
\end{tabular}

TOTAL SCORE:

\section{Coding Instructions:}

\begin{tabular}{|l|l|l|}
\hline Item & $\begin{array}{l}\text { Based on } \\
\text { Responses } \\
\text { from Qs: }\end{array}$ & Specific Coding Rules \\
\hline Sleeping: & $1,2,10,11$ & $\begin{array}{l}\text { If \#2 \&\#11 are yes, but \#10 is no, score as 1. If \#10 is yes, score } \\
\text { as } 2 .\end{array}$ \\
\hline Eating: & $1,2,13$ & Score as 0 or 1 only. Excellent, very good, good, fair $=0$, poor $=1$. \\
\hline Alcohol Use: & $1,3,4,5,6,9$ & Consistent judgment call (based on combination of responses) \\
\hline Prescribed Drugs: & $1,3,7,8,9,11$ & Consistent judgment call (based on combination of responses) \\
\hline Illegal Drugs: & $1,3,7,8,9,11$ & Consistent judgment call (based on combination of responses) \\
\hline Exercise: & 1,14 & Score as 0 or 1 only. Excellent, very good, good, fair $=0$, poor $=1$. \\
\hline Other: & 1,15 & To be determined based on participant's comments. \\
\hline $\begin{array}{l}\text { Participant's Own } \\
\text { Health Rating }\end{array}$ & 12 & Score as 0 or 1 only. Excellent, very good, good, fair $=0$, poor $=1$. \\
\hline
\end{tabular}

* Note: Question numbers are based on questions listed in Appendix D: Physical Health Questions. 
Appendix F

Psychological Health Questions 


\title{
Psychological Health Questions
}

(For example purposes, physical health questions taken from the Preprogram Interview Package For Victims)

\section{B. Perceptions, Safety and Risk}

1. Would you describe the world as a safe place? $\square$ (1) Yes $\square$ (2) Somewhat $\square$ (3) No

2. Would you say that you feel safe in your home? $\quad \square$ (1) Yes $\square$ (2) Somewhat $\quad \square$ (3) No

3. Do you feel safe in your neighbourhood? $\quad \square(1)$ Yes $\quad \square(2)$ Somewhat $\quad \square$ (3) No

4. How safe do you feel from crime walking ALONE in your neighbourhood after dark? Do you feel .... (If respondent cannot walk, ask if they would go out in a wheelchair)
(1) Very safe?
(4) Very unsafe?
(2) Reasonably safe?
(5) Does not walk alone
(3) Somewhat unsafe?

\begin{abstract}
in your neighbourhood after dark?
\end{abstract}
(1) Daily? [go to Q...]
$\square$
(4) Less than once a month?
(2) At least once a week?
5) Never?
(3) At least once a month?

6. If you felt safer from crime, would you walk alone after dark more often?
(1) Yes
(3) No

7. When ALONE in your home in the evening or at night, do you feel...
(1) Very worried?
(3) Not at all worried about your safety from crime?
(2) Somewhat worried?
(4) Never alone

8. (v)Have you stopped doing any of these activities because of fear or anxiety?
(1) Yes
(3) No

9. Have you ever done any of the following things to PROTECT yourself or your property from crime? Have you ever .....

(Probe to be sure action was taken as a protection from crime)
a) changed your routine, activities, or avoided certain places?
Yes $\square$ No $\square$ Refused
b) installed new locks or security bars?
Yes $\square$ No $\square$ Refused
c) installed burglar alarms or motion detector lights on your house or vehicle? Yes $\square$ No $\square$ Refused $\square$
d) taken a self defense course?
Yes $\square$ No $\square$ Refused $\square$
e) changed your phone number?
f) obtained a dog?
g) obtained a gun?
h) changed residence or moved?
Yes $\square$ No $\square$ Refused
Yes $\square$ No $\square$ Refused
Yes $\square$ No $\square$ Refused
Yes $\square$ No $\square$ Refused

10. Have you done any of these in the last 12 months? (a to $h$ )
(1) Yes
(3) No $\square$
(r) Refused $\square$ 
11. Do you do any of the following things to make yourself safer from crime? Do you routinely....

(Routinely means "most of the time" even if you occasionally forget.)
a) carry something to defend yourself or to alert other people?
Yes
No
Refused
b) lock the car doors for your personal safety when alone in a car? Yes
No
Refused
c) when alone and returning to
before getting into the car?
Yes $\square$ No $\square$ Refused
d) plan your route with safety in mind?
Yes $\square$ No $\square$ Refused
e) stay at home at night because you are afraid to go out alone?
Yes
№
Refused

12. Is there anything else you do to increase your personal safety that I have not already mentioned?
(n) Nothing else
(r) Refused

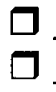

13. In general, are you satisfied or dissatisfied with your personal safety from crime? (Is that somewhat or very?)
(1) Satisfied
(2) Dissatisfied
$\Rightarrow \quad$ Somewhat
(3) No opinion
$\Rightarrow$
Somewhat
Very
(r) Refused

14. On a scale of 1 to 10 , where 1 is not afraid at all and 10 is extremely afraid, where would you place your current fear of crime?

$\begin{array}{cccccccccc}\begin{array}{c}1 \\ \begin{array}{c}\text { Not afraid } \\ \text { at all }\end{array}\end{array} & 2 & 3 & 4 & 5 & 6 & 7 & 8 & 9 & \begin{array}{c}10 \\ \text { Extremely } \\ \text { afraid }\end{array} \\ \end{array}$

a. Are you afraid that the offender will commit another crime against you?
(1) Yes
(3) No

b. On a scale of 1 to 5 , where 1 is very unlikely and 5 is very likely, how likely do you think it is that the offender will commit another crime against somebody else?
1
2
3
4
5
Very Unlikely
Unlikely
Not sure
Likely
Very Likely

15. Where do you think you would have placed your fear of crime before the incident? (where 1 is not afraid at all and 10 is extremely afraid)?

$\begin{array}{ccccccccc}1 & 2 & 3 & 4 & 5 & 6 & 7 & 8 & 9 \begin{array}{r}10 \\ \begin{array}{c}\text { Extremely } \\ \text { afraid } \\ \text { at all }\end{array}\end{array}\end{array}$

\section{The Incident \& Related Health}

16. How has this incident affected you? 
17. As a result of this incident, do you now do any of the following:
a. avoid walking alone at night
b. prefer to stay home rather than go out
Yes $\square$ No $\square$ Refused
c. installed a burglar alarm on my house and/or vehicle
Yes $\square$ No $\square$ Refused
d. turn on all of the lights upon arriving home
Yes $\square$ No $\square$ Refused
Yes $\square$ No $\square$ Refused
e. am more suspicious of strangers
f. am uneasy when in a vehicle
g. take extra precautions before going out
Yes $\square$ No $\square$ Refused
Yes $\square$ No $\square$ Refused
Yes $\square$ No $\square$ Refused

18. (v)Have you felt more vulnerable since the incident?
$\square$ (1) Yes
Nulneable: able to be physically or emotionaly hut)
$\square$ (2) Somewhat
$\square$ (3) No

19. (v)At the time of the incident(s) or within the 30 days following the incident, did you experience any of the following?

(Read list. Mark all that apply) (Do not include physical injury, financial loss or medical treatment in this question.)
$\square$ (1) Afraid for children
$\square$ (2) Anger
$\square$ (3) Ashamed/guilty
$\square$ (4) Depression
$\square$ (15) Thoughts of suicide
(21) Anxiousness/stressed
(19) Anxiety attacks
$\square$ (5) Fear
$\square$ (6) Hurt/disappointment
$\square$ (13) Upset/confusion/frustration
口 (11) Shock/disbelief
$\square$ (7) Increased self-reliance
$\square$ (20) Decreased self-reliance
$\square$ (8) Lowered self esteem
$\square$ (9) More cautious/aware
$\square$ (10) Problems relating to men/women

20. Have you sought or received help from a counselor since the incident? $\square(1)$ Yes $\square(3)$ No

21. Do you now use alcohol, medication or illegal drugs to stop "thoughts" of the incident?

$$
\square \text { (1) Yes } \square(3) \text { No }
$$

22. How often do you think about the incident?
$\square$ (1) Rarely
(4) Daily
$\square$ (2) Sometimes (couple times a month)
(5) All the time
(3) Often (weekly)

23. Would you say that thoughts of the incident are interfering with your daily life?
$\square$ (1) Yes
$\square$ (2) Somewhat
$\square$ (3) No 
24. Thinking back to the incident, and how you had dealt with the aftermath, what advice, if any, would you give another person in a similar situation?

\section{Lifestyle Questions (Physical Health \& Psychological Health)}

25. Overall, how would you describe your psychological health (or mental well-being)?
$\square$ (1) Excellent?
(3) Good?
(5) Poor?
$\square$ (2) Very good?
$\square$ (4) Fair?

26. You may have experienced many changes as a result of this incident. Would you say that there has been a change in your outlook on life since this incident?
$\square(1)$ Yes
$\square$ (2) Somewhat
$\square(3)$ No

27. Here is a list of how people feel at different times. During the past few weeks, how often have you felt....
(a) Euphoric/on top of the world
(b) Very lonely or remote from other people

$\square$
(c) Particularly excited or interested in something
(d) Depressed or very unhappy
(e) Pleased about having accomplished something
(f) Bored
(g) Proud because someone complimented you on something you had done
(h) So restless you couldn't sit long in a chair
(i) That things were going your way
(j) Upset because someone criticized you
(k) Stressed

Often

Sometimes

Once/twice Never

28. Based on how you feel right now, on a scale of 1 to 10 , where 1 is very conflicted and 10 is completely at peace, where would you place yourself?

$\begin{array}{cccccccccc}1 & 2 & 3 & 4 & 5 & 6 & 7 & 8 & 9 & \begin{array}{c}10 \\ \text { Completely } \\ \text { at peace }\end{array} \\ \text { conflicted } & & & & & & & & & \end{array}$

29. On a scale of 1 to 10 , where 1 is very sad and 10 is very happy, where would you currently place yourself?

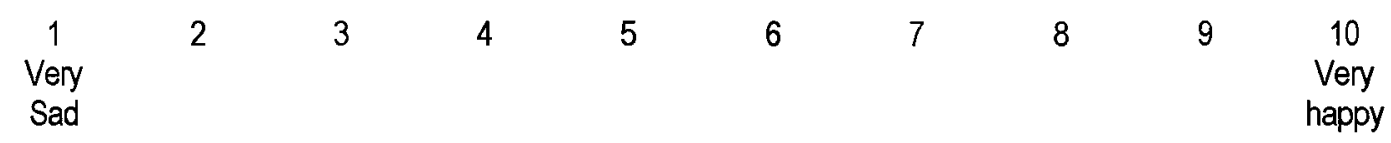


30. Has there been a change in your overall happiness since the incident? $\square(1)$ Yes $\square(3)$ No

31. (v) One of the common results of being victimized is feeling violated - feeling that there was a failure to respect you, that you were treated wrongly, and that there was an intrusion on your life, your privacy and your space. On a scale of 1 to 5 , how violated do you feel right now?

$$
1
$$

Very violated
2

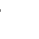

3

Somewhat
4 5

Not at all violated 
Appendix G

Psychological Health Checklist 


\section{Psychological Health Checklist}

(To be completed based on responses from the Preprogram Interview)

Participant Name:
$\square$ Victim @ Preprogram
$\square$ Offender @ Preprogram
$\square$ Victim @ Postprogram
$\square$ Offender @ Postprogram

\begin{tabular}{|l|l|l|l|}
\hline Indicators: & $\mathbf{0 = n 0}$ problem & $\mathbf{1}=$ some problem & $\mathbf{2}=$ major problem \\
\hline Safety & & & \\
\hline Fear & & & \\
\hline Vulnerability & & & \\
\hline Anger & & & \\
\hline Shame/Guilt & & & \\
\hline Depression & & & \\
\hline Thoughts of suicide & & & \\
\hline Anxiousness/Stressed & & & \\
\hline Hurt/Disappointment & & & \\
\hline Upset/Confusion/Frustration & & & \\
\hline Self-reliance & & & \\
\hline Self-esteem & & & \\
\hline Interfering thoughts & & & \\
\hline Counsellor & & & \\
\hline Outlook & & & \\
\hline Other: & & & \\
\hline Participant's Own Psych. H. Rating & & & \\
\hline & Sub-Totals & & \\
\hline
\end{tabular}

TOTAL SCORE:

\section{Coding Instructions:}

\begin{tabular}{|l|l|l|}
\hline Item & $\begin{array}{l}\text { Based on Responses } \\
\text { from Qs: }\end{array}$ & Specific Coding Rules \\
\hline Safety & $\begin{array}{l}1,2,3,4,5,6,7,9,10, \\
11,12,13,16\end{array}$ & $\begin{array}{l}\text { Consistent judgment call (based on } \\
\text { combination of responses) }\end{array}$ \\
\hline Fear & $\begin{array}{l}8,9,10,14,15,16,17, \\
19\end{array}$ & $\begin{array}{l}\text { Consistent judgment call (based on } \\
\text { combination of responses) }\end{array}$ \\
\hline
\end{tabular}




\begin{tabular}{|c|c|c|}
\hline Vulnerability & 16,18 & $\begin{array}{l}\text { Score as } 0 \text { or } 1 \text { only. No }=0 \text {, Somewhat } \& \\
\text { Yes }=1 .\end{array}$ \\
\hline Anger & 16,19 & $\begin{array}{l}\text { Consistent judgment call (based on } \\
\text { combination of responses) }\end{array}$ \\
\hline Shame/Guilt & 16,19 & Score as 0 or 1 only. No $=0$, Yes $=1$. \\
\hline Depression & $16,19,27$ & $\begin{array}{l}\text { Consistent judgment call (based on } \\
\text { combination of responses) }\end{array}$ \\
\hline Thoughts of suicide & 16,19 & Score as 0 or 1 only. No $=0$, Yes $=1$. \\
\hline Anxiousness/Stressed & $16,19,27,28,29$ & $\begin{array}{l}\text { Consistent judgment call (based on } \\
\text { combination of responses) }\end{array}$ \\
\hline Hurt/Disappointment & 16,19 & Score as 0 or 1 only. No $=0$, Yes $=1$ \\
\hline Upset/Confusion/Frustration & $16,19,27,28,29$ & $\begin{array}{l}\text { Consistent judgment call (based on } \\
\text { combination of responses) }\end{array}$ \\
\hline Self-reliance & 16,19 & Score as 0 or 1 only. No $=0$, Yes $=1$. \\
\hline Self-esteem & 16,19 & Score as 0 or 1 only. No $=0$, Yes $=1$ \\
\hline Interfering Thoughts & $16,19,21,22,23$ & $\begin{array}{l}\text { Consistent judgment call (based on } \\
\text { combination of responses) }\end{array}$ \\
\hline Counsellor & 16,20 & Score as 0 or 1 only. No $=0$, Yes $=1$ \\
\hline Outlook & $16,26,28,29$ & $\begin{array}{l}\text { Consistent judgment call (based on } \\
\text { combination of responses) }\end{array}$ \\
\hline Other: & 16,24 & $\begin{array}{l}\text { Consistent judgment call (based on } \\
\text { combination of responses) }\end{array}$ \\
\hline $\begin{array}{l}\text { Participant's Own } \\
\text { Psychological Health Rating }\end{array}$ & 25 & $\begin{array}{l}\text { Score as } 0 \text { or } 1 \text { only. Excellent, very good, } \\
\text { good, fair }=0, \text { poor }=1 \text {. }\end{array}$ \\
\hline
\end{tabular}

* Note: Question numbers are based on questions listed in Appendix D: Physical Health Questions. 
Appendix $\mathrm{H}$

PSEPC Preprogram Interview Package For Offenders 


\section{Preprogram Interview Package for Offenders}

Please contact the author for a copy of this interview.

Inquires can be made to: tanya.rugge@psepc.gc.ca.

Thank you. 
Appendix I

PSEPC Postprogram Interview Package For Victims 


\section{Postprogram Interview Package for Victims}

Please contact the author for a copy of this interview.

Inquires can be made to: tanya.rugge@psepc.gc.ca.

Thank you. 


\section{Appendix J}

PSEPC Postprogram Interview Package For Offenders 


\section{Postprogram Interview Package for Offenders}

Please contact the author for a copy of this interview.

Inquires can be made to: tanya.rugge@psepc.gc.ca.

Thank you. 
Appendix K

PSEPC Debriefing Form For Victims and Offenders 


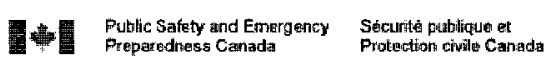

Research Evaluation of the Lanark County Community Justice Program

The Impact of Restorative Justice Practices

\section{Debriefing Form for Participants}

We would like to thank you for your participation in this important evaluation of the Lanark County Community Justice Program (LCCJP). Evaluations such as these are necessary in order to determine if the program is achieving its goals and objectives. It is only by speaking directly with program participants that we can gain a sense of how the program is performing and the impact it has on its participants. By hearing your experiences and insight into the program, areas for improvement can be identified and targeted for change.

It is hoped that the results of this study will contribute to an understanding of the effectiveness of restorative processes on participants. The comments, criticisms and suggestions of those who experience these processes directly are necessary not only to improve these programs, but to improve upon the criminal justice system overall.

We realize it may have been difficult to share your experiences with us, but are grateful for the time you took to participate and for sharing this information. Should you have any questions or concerns, or if you are experiencing hardships as a result of this restorative justice process, we encourage you to contact your LCCJP program caseworker.

If you would like a copy of the final research report, please feel free to contact us. Thank you again for your participation - your time and participation are a valuable resource for us and we are very appreciative.

Tanya Rugge, M.A.

Principal Researcher

Corrections Research

(613) $991-2826$
Terri-Lynne Scott, B.A.

Evaluation Coordinator Corrections Research (613) $991-5837$

Public Safety and Emergency Preparedness Canada 340 Laurier Avenue West, 10E

Ottawa, Ontario K1AOP 
Appendix L

Repeated Measures Analyses Results

Using the Covariate (Impression Management Subscale Score) 


\section{Repeated Measures Analyses Results}

Using the Covariate (Impression Management Subscale Score)

The repeated measures analysis was re-run using the IM score at preprogram as a covariate. The omnibus test revealed a significant effect of time $(F(3,65)=7.83, p<$ $.001)$ and group $(F(3,65)=3.13, p<.05)$, but not for the covariate IM subscale score $(F$ $(3,65)=.61, p=.61)$. The effect of time was no longer significant for physical health $(F$ $\left.(1,67)=2.03, p=.16, \eta_{\mathrm{p}}{ }^{2}=.03\right)$, it was now almost significant for sense of social support $\left(F(1,67)=3.41, p=.07, \eta_{\mathrm{p}}{ }^{2}=.05\right)$, and it remained significant for psychological health $\left(F(1,67)=21.40, p<.001, \eta_{\mathrm{p}}{ }^{2}=.24\right)$. There were still no significant interactions. Also, the effect of group indicated that there was no longer a significant difference between victims and offenders for psychological health $\left(F(1,67)=2.16, p=.15, \eta_{\mathrm{p}}{ }^{2}=\right.$ $.03)$, but results remained the same for social support (still significant: $F(1,67)=7.32, p$ $\left.=.010, \eta_{\mathrm{p}}{ }^{2}=.10\right)$ and physical health (still nonsignificant: $F(1,67)=1.84, p=.18, \eta_{\mathrm{p}}{ }^{2}=$ $.03)$. 